\author{
UNIVERSIDADE DE SÃO PAULO \\ ESCOLA DE ENFERMAGEM
}

MIRIAN CRISTINA DOS SANTOS ALMEIDA

\title{
CORRELAÇÃO ENTRE CLIMA ORGANIZACIONAL, SATISFAÇÃO NO TRABALHO E BURNOUT EM TRABALHADORES DE ENFERMAGEM
}




\section{MIRIAN CRISTINA DOS SANTOS ALMEIDA}

\section{CORRELAÇÃO ENTRE CLIMA ORGANIZACIONAL, SATISFAÇÃO NO TRABALHO E BURNOUT EM TRABALHADORES DE ENFERMAGEM}

Tese apresentada ao Programa de PósGraduação em Gerenciamento em Enfermagem (PPGEn) da Escola de Enfermagem da Universidade de São Paulo para obtenção do título de Doutora em Ciências.

Área de concentração: Fundamentos e Práticas de Gerenciamento em Enfermagem e em Saúde.

Orientadora: Prof ${ }^{\mathrm{a}}$. Dr $\stackrel{\text { a }}{ }$. Patricia Campos Pavan Baptista

São Paulo 
AUTORIZO A REPRODUÇÃO E DIVULGAÇÃO TOTAL OU PARCIAL DESTE TRABALHO, POR QUALQUER MEIO CONVENCIONAL OU ELETRÔNICO, PARA FINS DE ESTUDO E PESQUISA, DESDE QUE CITADA A FONTE.

Assinatura:

Data:

\section{Catalogação na Publicação (CIP) \\ Biblioteca "Wanda de Aguiar Horta" \\ Escola de Enfermagem da Universidade de São Paulo}

Almeida, Mirian Cristina dos Santos

Correlação entre clima organizacional, satisfação no trabalho e burnout em trabalhadores de enfermagem / Mirian Cristina dos Santos Almeida. São Paulo, 2017.

$129 \mathrm{p}$.

Tese (Doutorado) - Escola de Enfermagem da Universidade de São Paulo.

Orientadora: Prof.. Dr. ㄹ. Patricia Campos Pavan Baptista

Área de concentração: Fundamentos e Práticas de Gerenciamento em Enfermagem e em Saúde

1. Enfermagem. 2. Saúde ocupacional. 3. Satisfação no trabalho. 4. Esgotamento profissional. I. Título. 
Nome: Mirian Cristina dos Santos Almeida

Título: Correlação entre clima organizacional, satisfação no trabalho e burnout em trabalhadores de enfermagem

Tese apresentada ao Programa de Pós-Graduação em Gerenciamento em Enfermagem da Escola de Enfermagem da Universidade de São Paulo para obtenção do título de Doutora em Ciências.

Aprovada em:

\section{Banca Examinadora}

Orientador: Prof. Dr.

Instituição:

Assinatura:

Prof. Dr. Instituição:

Julgamento: Assinatura:

Prof. Dr. Instituição:

Julgamento: Assinatura:

Prof. Dr. Instituição:

Julgamento: Assinatura:

Prof. Dr. Instituição:

Julgamento: Assinatura:

Prof. Dr. Instituição:

Julgamento: Assinatura: 


\section{DEDICATÓRIA}

Aos meus pais Maria José e Manoel pelas incessantes orações, pelo exemplo de superação, integridade e amor.

Ao André, meu amor, esposo, amigo e companheiro, por sonhar meus sonhos e me impulsionar a alcançá-los.

Nosso amor foi gerado por Deus! Te amo demais!!

Ás minhas filhas por me proporcionarem a alegria de ser mãe e renovar minhas esperanças e forças para lutar por um mundo melhor.

Rebeca, tão pequena e tão responsável, o seu sorriso e apoio me fortifica! Linda!!

Raquelzinha, minha pequena doutoranda, mesmo nas longas horas de dedicação à tese, lembrava-me que não estava sozinha, com seus toques no meu ventre. Amo infinitamente vocês, minhas joias!

A todos os trabalhadores de enfermagem do Litoral Norte de São Paulo que fazem a diferença na vida de tantos caiçaras.

Com carinho,

Mirian Cristina dos Santas Almeida 


\section{AGRADECIMENTOS}

Primeiramente ao meu Grande Deus, e quão Grande Ele é! Sem Ele eu não chegaria aqui...Por Ele e Para Ele são todas as coisas. Obrigada por me amar tanto!

À querida e competente orientadora professora Dra Patrícia Campos Pavan Baptista pelo incentivo, disponibilidade, paciência, dedicação e carinho durante 0 desenvolvimento desta tese. Fez-me sentir acolhida nos momentos que mais precisei! Um exemplo de ser humano e profissional a ser seguido!

À professora Dr. ${ }^{a}$ Arlete Silva, minha gratidão eterna pelo incentivo constante e por me fazer acreditar que seria capaz de cursar o doutorado na Escola de Enfermagem da USP. Mostrou-me novos horizontes e mudou meu futuro!!

À querida Professora Dr. a Vanda Elisa Andres Felli pelos ensinamentos, carinho e incentivo.

Às professoras Dra Elisabete Borges e Dra Cristina Queirós pelas valiosas sugestões no Exame de Qualificação. Gratidão à Prof. Dra Elizabete Borges pela calorosa recepção e ensinamentos, durante visita técnica realizada à Escola Superior de Enfermagem do Porto (ESEP), Portugal.

Ao MSc Bernardo dos Santos pelo apoio, profissionalismo e comprometimento nas análises estatísticas.

Aos meus amigos e companheiros de estudo Silmar Silva e Vinicius Gomes Barros. Obrigada pela troca de conhecimentos, por partilhar dos meus anseios, dificuldades e vitórias.

A todos os colegas do grupo de pesquisa "Estudos sobre a Saúde do Trabalhador de Enfermagem e Saúde (GESTES) pela parceria no dia-a-dia e contribuição nesta pesquisa, especialmente Maria Fernanda M. Jukemura e Priscila Oliveira Rocha que me auxiliaram com o banco de dados.

Aos funcionários e docentes da Escola de Enfermagem da USP, que de forma direta ou indireta, contribuíram para a elaboração desta tese.

Aos meus irmãos Debora, Marcelo e Denise e demais membros da família pelas orações e incentivo. Especialmente à Denise e Anderson que me acolheram em seu lar, durante boa parte do doutorado, me apoiando nos momentos de fragilidade.

Aos meus alunos e ex-alunos do curso de Graduação em Enfermagem que me impulsionaram e apoiaram, principalmente durante o árduo processo de coleta de dados, em especial a querida Carla Sena Costa, que além de ex-aluna, tornou-se amiga e minha motorista particular durante a peregrinação pelas instituições de saúde do Litoral norte de São Paulo.

Aos trabalhadores de enfermagem do Litoral Norte de São Paulo que me acolheram nas diversas instituições de saúde e dedicaram parte do seu precioso tempo respondendo os questionários desta pesquisa. 
"Bem-auenturada aquele que teme aa Senhor e anda nos seus caminhos. Pais comerás do trabalho das tuas mãas: feliz será e te irá bem". Salmas 128:1-2

"O Senhar Deus é a minha farca. e fará as meus pés cama os de uma corsa. e me fará andar em lugares altas. Habacuque 3.19. 
Almeida MCS. Correlação entre clima organizacional, satisfação no trabalho e burnout em trabalhadores de enfermagem [tese]. São Paulo: Escola de Enfermagem, Universidade de São Paulo; 2017.

\section{RESUMO}

Introdução: A síndrome de burnout, caracterizada por níveis elevados de exaustão emocional e despersonalização e reduzida realização profissional, tem sido grande causa de adoecimento psíquico nos trabalhadores de enfermagem, com sério impacto na qualidade dos serviços e segurança do paciente. Objetivos: Analisar a correlação entre clima organizacional, satisfação no trabalho e burnout nos trabalhadores de enfermagem do litoral norte de São Paulo e propor estratégias para promoção de clima organizacional favorável e da satisfação no trabalho. Método: Estudo transversal, correlacional, com abordagem quantitativa, realizado em 2015/2016, com trabalhadores de enfermagem de estabelecimentos de saúde públicos/filantrópicos do Litoral Norte de São Paulo. Seguiramse todos os princípios éticos da legislação vigente. Para coleta de dados, foram utilizados o Questionário de Caracterização Sociodemográfica e Profissional, a Escala de Clima Organizacional para Organizações de Saúde, o Questionário de Satisfação no Trabalho S20/23 e o Maslach Burnout Inventory. Foi realizada análise descritiva e analítica dos dados, por meio de frequências relativas, absoluta, média, desvio padrão, mínimo e máximo, bem como testes de associação e correlação entre as variáveis, adotando-se intervalo de confiança de 95\%. Resultados: Dos 534 trabalhadores de enfermagem participantes do estudo, $90,45 \%$ são mulheres, $62,92 \%$ declarou estado conjugal estável e a maioria $(92,5 \%)$ contribui financeiramente com sustento da família. Possuem idade média de 37,69 anos, renda pessoal mensal média de $R \$ 2.136,72(\mathrm{dp}=1.283,00)$ e tempo médio de formação profissional de 10,29 anos. Quanto ao cargo, identificou-se $72,28 \%$ de auxiliares/técnicos de enfermagem, seguido de enfermeiros assistenciais (21,35\%); $52,24 \%$ atuam na atenção hospitalar e $42,51 \%$ na atenção básica à saúde. Considerando a média dos escores, o Clima Organizacional foi avaliado como regular $(\bar{x}=3,32)$, tendo o fator Remuneração apresentado menor média $(\bar{x}=2,16)$. Verificou-se que os trabalhadores apresentam níveis médios de Satisfação no Trabalho $(\bar{x}=3,4)$, sendo o menor índice de satisfação atribuído à Satisfação com Ambiente Físico de Trabalho $(\bar{x}=3,27)$. Quanto à Síndrome de Burnout, observaram-se níveis moderados de Exaustão Emocional $(\bar{x}=1,67)$, baixos de Despersonalização $(\bar{x}=0,86)$ e elevados de Realização Profissional $(\bar{x}=2,94)$. Ao correlacionar os construtos foram identificados correlação positiva forte entre Satisfação no Trabalho e Clima Organizacional $(r=0,673)$; correlação negativa moderada entre Exaustão Emocional e Clima Organizacional $(r=-0,408)$; correlação negativa moderada entre Exaustão Emocional e Satisfação no Trabalho $(r=-0,457)$; e correlação negativa moderada entre Despersonalização e Satisfação no Trabalho $(r=-0,319)$. Apresentaram resultados estatisticamente significativos na associação com pelo menos um dos fatores dos construtos as variáveis sociodemográficas e ocupacionais sexo, estado conjugal, possuir filhos, nível de escolaridade, realização de atividade física/ lazer, possuir dependentes que presta cuidados, local de trabalho, cargo e regime de trabalho. As sugestões para promoção do clima organizacional e da satisfação no trabalho estão relacionadas ao fortalecimento da gestão por meio de investimento em Políticas de Recursos Humanos, Políticas de Saúde do Trabalhador, Instrumentalização para Gestão Participativa e Planejamento. Conclusão: Ao correlacionar os construtos foram identificados correlação positiva forte entre Satisfação no Trabalho e Clima Organizacional; correlação negativa moderada entre Exaustão Emocional e Clima Organizacional; correlação negativa moderada entre Exaustão Emocional e Satisfação no Trabalho; e correlação negativa moderada entre Despersonalização e Satisfação no Trabalho. O fortalecimento da gestão, por meio da utilização de ferramentas gerenciais, foi proposto como estratégia para promoção do clima organizacional favorável e da satisfação no trabalho.

PALAVRAS-CHAVE: Enfermagem. Saúde do trabalhador. Satisfação no trabalho. Esgotamento Profissional. Clima Organizacional. 
Almeida MCS. Correlation among organizational climate, job satisfaction and Burnout among nursing workers [thesis]. São Paulo: School of Nursing, University of São Paulo; 2017.

\section{ABSTRACT}

Introduction: Characterized by high levels of emotional exhaustion, depersonalization and decreased professional achievement, Burnout syndrome has been a great cause of psychic illness in nursing workers, with a serious impact on the quality of services and on the patient safety. Objectives: To analyze the correlation among organizational climate, job satisfaction and Burnout among nursing workers from the northern shore of São Paulo and to propose strategies to promote a favorable organizational climate as well as job satisfaction. Method: This is a cross- sectional and correlational study, with a quantitative approach, which was performed in 2015/2016, with nursing workers from public/philanthropic health facilities in the Northern Shore of São Paulo. We have followed all the ethical principles of the current legislation. In order to collect data, we used the Sociodemographic and Professional Characterization Questionnaire, the Organizational Climate Scale for Health Organizations, the Job Satisfaction Questionnaire - S20/23 and the Maslach Burnout Inventory. We performed an analytical and descriptive analysis of the data by means of relative and absolute frequencies, average, standard deviation, minimum and maximum, in addition to tests of association and correlation among variables, adopting a 95\% confidence interval. Results: Of the 534 nursing workers who took part in this study, 90.45\% are women, $62.92 \%$ declared a stable marital status, and most of them (92.5\%) have financially contributed to the family livelihood. They have an average age of 37.69 years, an average monthly personal income of $\mathrm{R} \$ 2.136,72$ ( $\mathrm{sd}=1.283,00$ ) and an average professional training time of 10.29 years. Regarding the position held, we identified $72.28 \%$ of nursing assistants/technicians, followed by health care nurses (21.35\%); $52.24 \%$ work in hospital care and $42.51 \%$ in primary health care. Taking into account the average scores, the Organizational Climate was rated as regular $(\bar{x}=3.32)$, where the factor of Remuneration showed the lowest average $(\bar{x}=2.16)$. We found that workers unveil average levels of Job Satisfaction $(\bar{x}=3.4)$, where the lowest index of satisfaction was attributed to the Satisfaction with Physical Work Environment $(\bar{x}=3.27)$. With regard to Burnout syndrome, we noted moderate levels of Emotional Exhaustion $(\bar{x}=1.67)$, low levels of Depersonalization $(\bar{x}=0.86)$ and high levels of Professional Achievement $(\bar{x}=2.94)$. When correlating the constructs, we identified strong positive correlation between Job Satisfaction and Organizational Climate ( $r=0.673)$; moderate negative correlation between Emotional Exhaustion and Organizational Climate $(r=-0.408)$; moderate negative correlation between Emotional Exhaustion and Job Satisfaction $(\mathrm{r}=-0.457)$; and moderate negative correlation between Depersonalization and Job Satisfaction $(r=-0.319)$. The sociodemographic and occupational variables of gender, marital status, having children, schooling level, physical or leisure activity, having dependent people for providing care, work place, position, and work regime showed statistically significant results in the association with at least one of the factors of the constructs. The suggestions for promoting organizational climate and job satisfaction are related to the strengthening of management through investment in Human Resources Policies, Worker's Health Policies, Instrumentation for Participatory Management and Planning. Conclusion: When correlating the constructs, we identified strong positive correlation between Job Satisfaction and Organizational Climate; moderate negative correlation between Emotional Exhaustion and Organizational Climate; moderate negative correlation between Emotional Exhaustion and Job Satisfaction; and moderate negative correlation between Depersonalization and Job Satisfaction. The strengthening of management by means of the use of management tools was proposed as a strategy to promote a favorable organizational climate and job satisfaction.

KEYWORDS: Nursing. Occupational health. Job satisfaction. Burnout, professional. Organizational climate. 


\section{LISTA DE ILUSTRAÇÕES}

Figura 1- Elementos causais da satisfação no trabalho - Teoria de Locke.

Figura 2- Diferença entre clima organizacional e cultura 27 organizacional.

Figura 3- $\quad$ Características da Síndrome de Burnout.

Figura 4- $\quad$ Mapa do Litoral Norte de São Paulo.

Figura 5- $\quad$ Estratégias para promoção do Clima Organizacional favorável e da Satisfação no Trabalho.

Gráfico 1 -

Média do escore dos itens da Escala de Clima 56 Organizacional para Organizações de Saúde (ECOOS) em trabalhadores de enfermagem. São Paulo, 2015/2016.

Gráfico 2 - Média do escore dos itens do Questionário de Satisfação no Trabalho - S20/23 em trabalhadores de enfermagem. São Paulo, 2015/2016.

Gráfico 3 - Média do escore dos itens das dimensões do Maslach Burnout Inventory - Human Services Survey (MBI-HSS) em trabalhadores de enfermagem. São Paulo, 2015/2016.

Gráfico 4- Distribuição das estratégias sugeridas pelos trabalhadores de enfermagem para promoção do Clima Organizacional favorável e da Satisfação no Trabalho, segundo as categorias. São Paulo, 2015/2016.

Quadro 1- Estratégias sugeridas pelo trabalhadores de enfermagem para promoção do Clima Organizacional favorável e da Satisfação no Trabalho. São Paulo, 2015/2016. 


\section{LISTA DE TABELAS}

Tabela 1 - Caracterização dos trabalhadores de enfermagem segundo variáveis categóricas sociodemográficas. São Paulo, 2015/2016.

Tabela 2 - Caracterização dos trabalhadores de enfermagem 53 segundo variáveis categóricas relacionadas ao trabalho. São Paulo, 2015/2016.

Tabela 3 - Estatística descritiva da Escala de Clima Organizacional para Organizações de Saúde (ECOOS) em trabalhadores de enfermagem. São Paulo, 2015/2016.

Tabela 4 - Estatística descritiva do Questionário de Satisfação no Trabalho - S20/23 em trabalhadores de enfermagem. São Paulo, 2015/2016.

Tabela 5 - Estatística descritiva do Maslach Burnout Inventory 60 Human Services Survey (MBI-HSS) em trabalhadores de enfermagem. São Paulo, 2015/2016.

Tabela 6 - $\quad$ Análise das correlações entre o escore total da Escala de 62 Clima Organizacional para Organizações de Saúde (ECOOS) e Questionário de Satisfação no Trabalho (S20/23) e as dimensões do Maslach Burnout Inventory Human Services Survey (MBI-HSS) em trabalhadores de enfermagem. São Paulo, 2015/2016.

Tabela 7 - $\quad$ Análise das correlações entre as dimensões da Escala de Clima Organizacional para Organizações de Saúde (ECOOS) e Questionário de Satisfação no Trabalho (S20/S23) e Maslach Burnout Inventory - Human Services Survey (MBI-HSS) em trabalhadores de enfermagem. São Paulo, 2015/2016. 
Tabela 8 - $\quad$ Análise das correlações entre a variável categórica Local de Trabalho e as dimensões da Escala de Clima Organizacional para Organizações de Saúde (ECOOS), Questionário de Satisfação no Trabalho (S20/S23) e Maslach Burnout Inventory - Human Services Survey (MBI-HSS). São Paulo, 2015/2016.

Tabela 9 - $\quad$ Análise das correlações entre a variável categórica Cargo e as dimensões da Escala de Clima Organizacional para Organizações de Saúde (ECOOS), Questionário de Satisfação no Trabalho (S20/S23) e Maslach Burnout Inventory - Human Services Survey (MBI-HSS). São Paulo, 2015/2016.

Tabela 10 - Análise das correlações entre a variável categórica Regime de Trabalho e as dimensões da Escala de Clima Organizacional para Organizações de Saúde (ECOOS), Questionário de Satisfação no Trabalho (S20/S23) e Maslach Burnout Inventory - Human Services Survey (MBI-HSS). São Paulo, 2015/2016. 


\section{LISTA DE SIGLAS}

CAPS Centro de Apoio Psicossocial

CLT Consolidação das Leis Trabalhistas

COFEN Conselho Federal de Enfermagem

DE Despersonalização

DP Desenvolvimento Profissional

ECOOS Escala de Clima Organizacional para Organizações de Saúde

EE Exaustão Emocional

ESF Estratégia Saúde da Família

EST Estratégia

GESTES Grupo de Pesquisa "Estudos sobre a Saúde do Trabalhador de

IBGE Instituto Brasileiro de Geografia e Estatística

LD Liderança

$\mathrm{MBI} \quad$ Maslach Burnout Inventory

MBI-HSS Maslach Burnout Inventory - Human Services Survey

RC Relação com a Comunidade

ReEE Relacionamento e Espírito de Equipe

REM Remuneração

RP Realização Profissional

S20/S23 Questionário de Satisfação no Trabalho

SAFT Satisfação com Ambiente Físico no Trabalho

SAMU Serviço de Atendimento Móvel de Urgência

SIT Satisfação Intrínseca no Trabalho

SM Salário Mínimo

SPSS Statistical Package for the Social Sciences for Windows

SRH Satisfação com Relações Hierárquicas

ST Segurança no Trabalho

TCLE Termo de Consentimento Livre e Esclarecido

UBS Unidades Básicas de Saúde

UPA Unidade de Pronto Atendimento

USF Unidades de Saúde da Família 


\section{SUMÁRIO}

1 INTRODUÇÃO

.15

2 CONTEXTUALIZANDO A SATISFAÇÃO NO TRABALHO, O CLIMA

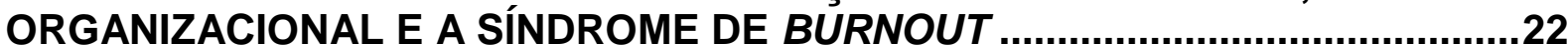

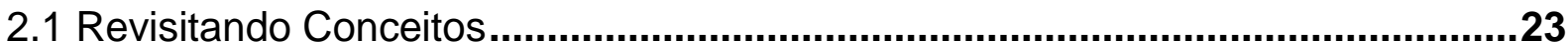

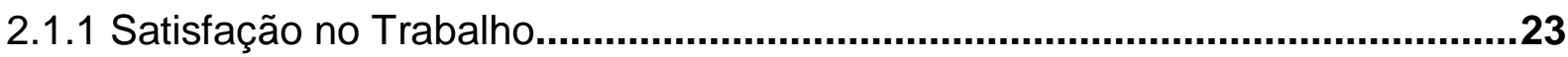

2.1.2 Clima Organizacional ...............................................................................25

2.1.3 Síndrome de Burnout ..................................................................................28

2.2 Influência da Satisfação no trabalho e percepção do Clima organizacional na

Síndrome de Burnout em trabalhadores de enfermagem ..........................................31

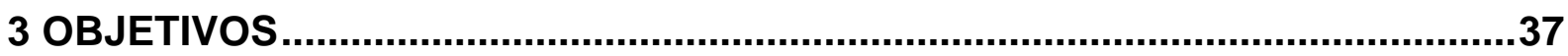

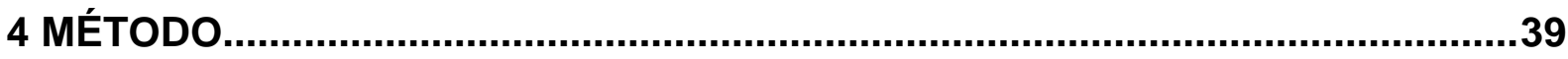

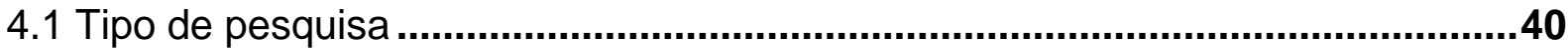

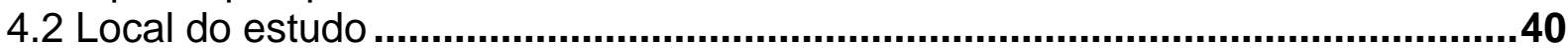

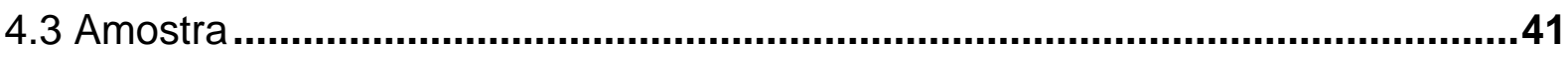

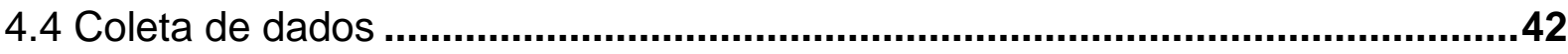

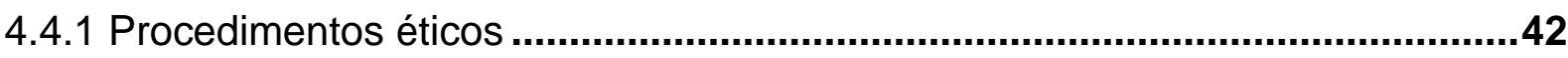

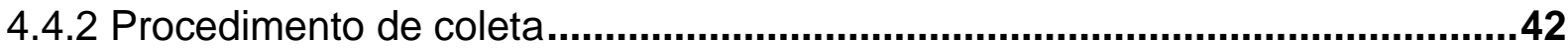



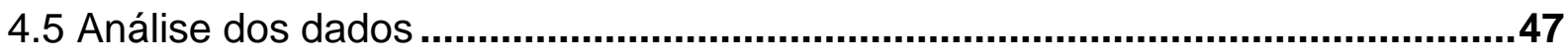

5 RESULTADOS

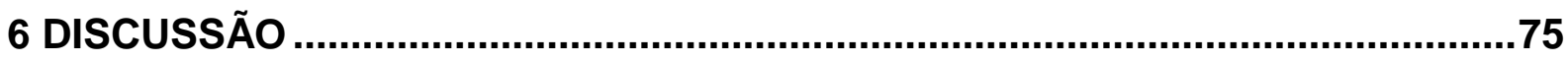

7 CONCLUSÃO

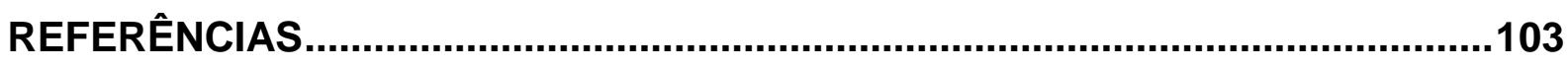

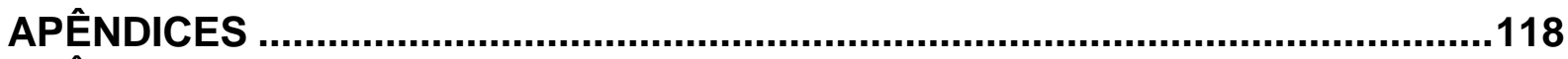

APÊNDICE A- Caracterização dos Sujeitos da Pesquisa ......................................119

APÊNDICE B- Escala de Clima Organizacional para Organizações de Saúde

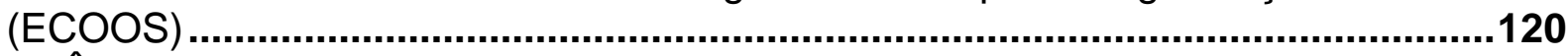

APÊNDICE C - Questionário de Satisfação no Trabalho- S20/S23 .........................123

APÊNDICE D- Maslach Burnout Inventory (MBI) …............................................124

APÊNDICE E- Estratégias para Promoção de Clima Organizacional Favorável e da Satisfação no Trabalho …………..................................................................125

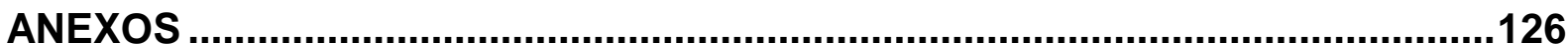

ANEXO 1- Parecer do Comitê de Ética e Pesquisa ..............................................127 


\section{Apresentaçãa}

O interesse pela saúde do trabalhador surgiu no decorrer de minha trajetória profissional após sofrer um acidente de trabalho com pérfurocortante, durante realização de glicemia capilar em uma paciente portadora da Síndrome da Imunodeficiência Adquirida. Na época, trabalhava como enfermeira da Estratégia Saúde da Família em uma Unidade Básica de Saúde onde atuei por 9 anos, mas anteriormente já havia atuado por 2 anos e meio em uma Unidade de Terapia Intensiva. O seguimento pós-acidente foi um processo doloroso e de muitos questionamentos. Como a paciente apresentava resistência a algumas drogas antirretrovirais, fiz uso de medicamentos mais potentes, e fiquei em acompanhamento por tempo maior do que preconizado rotineiramente; apresentei muitas reações adversas e fiquei afastada do trabalho nos primeiros 15 dias de tratamento. Nesse período, além de pensar muito sobre os meus sonhos e projetos pessoais, refleti sobre o trabalho em saúde, a correria do dia a dia, a sobrecarga de trabalho que os trabalhadores da saúde enfrentam, seja na atenção básica ou hospitalar, além de diversos outros aspectos como insuficiência de recursos humanos e materiais e o sofrimento por muitas vezes não conseguir oferecer a assistência de qualidade que os pacientes têm por direito, devido à falta de governabilidade e o processo moroso para resolução de alguns entraves.

Assim, motivada em estudar sobre a saúde do trabalhador ingressei no curso de especialização. Após, já no mestrado me mantive nesta área, quando pesquisei sobre acidentes de trabalho ocorridos com agentes comunitários de saúde. Em 2013, tive o prazer de iniciar minha participação no Grupo de Pesquisa "Estudos sobre a Saúde do Trabalhador de Enfermagem e Saúde (GESTES)" na Escola de Enfermagem da Universidade de São Paulo, onde passei a investigar mais especificamente sobre a saúde do trabalhador de enfermagem, foco principal desta tese de doutorado.

Este estudo é parte do Projeto Multicêntrico "Dos contextos de trabalho à saúde ocupacional dos profissionais de enfermagem, um estudo comparativo entre Portugal, Brasil e Espanha", desenvolvido entre a Escola de Enfermagem da 
Universidade de São Paulo, Brasil, a Universidade de Oviedo, Espanha, a Escola Superior de Enfermagem do Porto e a Universidade do Porto, Portugal, que investiga dados referentes ao burnout, satisfação no trabalho, presenteísmo e resiliência entre os trabalhadores de enfermagem dos referidos países.

Sabendo que 0 adoecimento por transtornos mentais nos trabalhadores de enfermagem se constitui uma realidade preocupante nos diferentes contextos, de modo que, associar o impacto do clima organizacional e da satisfação no trabalho para melhoria desses agravos pode representar uma das estratégias essenciais para a mudança no panorama na força de trabalho em enfermagem, o presente estudo com abordagem quantitativa, transversal, correlacional teve por objetivos avaliar o clima organizacional, a satisfação no trabalho e a ocorrência de burnout nos trabalhadores de enfermagem do litoral norte de São Paulo, verificar a associação entre estes e elaborar estratégias para promoção de clima organizacional favorável e da satisfação no trabalho.

O trabalho apresentado nas próximas páginas está disposto em 7 capítulos:

* No capítulo 1 encontra-se a introdução;

* No capítulo 2 está a contextualização sobre satisfação no trabalho, clima organizacional e síndrome de burnout, explicitando os achados na literatura sobre a influência da satisfação no trabalho e percepção do clima organizacional favorável na síndrome de burnout em trabalhadores de enfermagem;

* No capítulo 3 estão descritos os objetivos deste estudo;

* No capítulo 4 está exposto o método utilizado para realização da pesquisa, bem como a forma de condução da análise dos dados;

* No capítulo 5 estão apresentados os resultados encontrados;

* No capítulo 6 está exposta a discussão;

* No Capítulo 7 estão as conclusões do estudo. 
1 Tutraduçãa 


\section{INTRODUÇÃO}

Nas últimas décadas, a sociedade tem vivenciado transformações no mundo do trabalho, associadas à globalização, às relações de consumo, à competitividade do mercado, ao acelerado avanço tecnológico e científico, à pressão por aumento produtividade com redução de custos e à exigência de produtos de qualidade por consumidores esclarecidos sobre seus direitos. Estas transformações têm refletido na saúde dos indivíduos de forma intensa, resultando em "mudanças profundas na organização, nas condições e nas relações de trabalho" (Elias, Navarro, 2006).

$\mathrm{Na}$ área da saúde, não ocorre de forma diferente. O avanço tecnológico e a busca pela qualidade assistencial, associados à exigência por alta produtividade e à precarização do trabalho, são fatores que têm influenciado significativamente o perfil de morbidade dos trabalhadores (Baptista, 2014).

Sabe-se que o trabalho pode produzir efeitos antagônicos na vida do homem, podendo ser negativo ou positivo, interferindo diretamente nas condições de saúde. Dentre outros aspectos, pode ser positivo quando é gratificante, promovendo realização profissional e bem-estar, mostrando-se promotor de saúde; e pode ser negativo ao expor o indivíduo aos riscos presentes no ambiente laboral, podendo gerar o adoecimento e a morte (Antunes, 2005; Mendes, Dias, 1999).

A par de todas essas transformações no processo de trabalho em saúde, pesquisas nacionais e internacionais relacionam o adoecimento físico e/ou psíquico dos trabalhadores de enfermagem (Carlotto et al., 2014; Borges, Ferreira, 2014; Queirós et al., 2013; Borges, 2012; Hoe et al., 2012; Martinato et al., 2010; Tinubu BMS et al., 2010; Fonseca et al., 2008; Leite, Silva, Merighi, 2007; Elias, Navarro, 2006).

O sofrimento psíquico está entre as principais causas de adoecimento e absenteísmo na enfermagem, estando representado pelos transtornos mentais e comportamentais (Sancinetti et al., 2009; Nogueira, 2007). 
Pesquisadores nacionais (Santos, Sousa, Rueda, 2015; Bezerra, Silva, Ramos, 2012; Rosa, Carlotto, 2005) e internacionais (Lee et al., 2014; Spence Laschinger, Leiter, 2006; Aiken et al., 2001) têm investigado a presença do estresse ocupacional e da síndrome de burnout nos trabalhadores de enfermagem, uma vez que têm impacto não apenas na qualidade de vida dos trabalhadores, como na qualidade do trabalho executado e, consequentemente, na segurança dos pacientes.

O estresse ocupacional é um processo permanente de adaptação (Schaufeli, Buunk, 2003) que pode culminar na síndrome de burnout, caracterizada por uma resposta prolongada a estressores crônicos emocionais e interpessoais decorrentes do trabalho. Resulta numa erosão do compromisso com o trabalho, que se torna insatisfatório e sem significado, e desencadeia estados emocionais negativos, como cólera e tristeza, surgindo a exaustão emocional, o cinismo e a perda da realização profissional (Maslach, Schaufel, Leiter, 2001; Maslach, Leiter,1997; Freudenberger, 1974). Desta forma, burnout "envolve atitudes e condutas negativas com os usuários, clientes, organização e trabalho", gradualmente e subjetivamente resultando em "problemas práticos e emocionais no trabalhador e na organização" (Murofuse, Abranches, Napoleão, 2005, p.255).

Nesse aspecto, a satisfação no trabalho e a percepção do clima organizacional favorável são construtos importantes para a gênese do adoecimento psíquico.

O trabalho da enfermagem também pode proteger a saúde deste trabalhador, ao se mostrar prazeroso e satisfatório, pelo reconhecimento profissional por parte de pacientes, familiares, supervisão e colegas, assim como pela possibilidade de amenizar o sofrimento e contribuir para melhora do quadro de saúde dos pacientes. A sensação de ser reconhecido para executar uma tarefa pela sua competência específica e a participação no projeto de desenvolvimento da organização, incluindo os desafios e a necessidade de inovação, também representam fatores geradores de realização e satisfação no trabalho (Kessler, Krug, 2012; Melo, Barbosa, Souza, 2011; Nunes et al., 2010; Gallo, 2005).

Nessa direção, estudo internacional realizado em 5 países constatou que mais de um terço dos enfermeiros estavam insatisfeitos com seu trabalho e com 
altos níveis de burnout. Nos hospitais onde a proporção do número de pacientes por enfermeiro era mais alta, houve aumento de $78 \%$ de chance de esgotamento profissional e $26 \%$ na taxa de mortalidade de pacientes, indicando que a insatisfação no trabalho e o burnout estão associados à piora da qualidade da assistência (Aiken et al., 2001).

O clima organizacional, "uma condição temporária formada pelos significados construídos pelos indivíduos, que guiam suas decisões e ações no ambiente organizacional" (Menezes et al., 2009, p. 308), refere-se às influências do ambiente laboral no comportamento dos trabalhadores e está relacionado "às percepções e interpretações comuns das dimensões das atividades, do ambiente e das políticas que caracterizam a organização" (Martins et al., 2004, p.41).

A análise do clima organizacional pode representar uma ferramenta a ser utilizada pelas instituições com o intuito de monitorar e avaliar a percepção dos seus trabalhadores a respeito do ambiente de trabalho, respaldando a preconização de ações para melhorar a qualidade de vida desses trabalhadores, bem como interferir na eficácia do desempenho das tarefas a eles confiadas (Massano, 2012).

A avaliação positiva do clima organizacional nas instituições de trabalho está relacionada, dentre outros fatores, à existência de ambiente agradável, com bom relacionamento entre os trabalhadores, incluindo aqueles que exerçam cargos superiores (Menezes, 2008), sendo necessária, para a sua avaliação, a verificação de itens como liderança, desenvolvimento profissional e espírito de equipe, relação com a comunidade, segurança no trabalho, estratégia e remuneração" (Menezes et al., 2009).

Um ambiente de trabalho favorável, incluindo recursos adequados, bom relacionamento interpessoal com colegas e apoio da gestão, está associado a menores índices de burnout, maior satisfação no trabalho, entre trabalhadores hospitalares de enfermagem, e melhores resultados na qualidade da assistência em diversos países (Zhang et al., 2014; Aiken et al., 2011), repercutindo, inclusive, na diminuição do número de óbitos em pacientes (Aiken et al., 2008).

A literatura nacional também aponta que trabalhadores da atenção primária à saúde, que atribuíram maiores pontuações ao clima organizacional, 
obtiveram melhores desempenhos nas atividades de trabalho (Cruvinel, 2011). Esta literatura também sinaliza que o clima organizacional desfavorável pode influenciar negativamente na saúde dos trabalhadores hospitalares, por apresentar correlação com a dimensão exaustão emocional do burnout (Santos, Sousa, Rueda, 2015).

Observa-se que as questões de adoecimento no trabalho e a insatisfação têm representado um sério problema em âmbitos nacional e internacional, evidenciado pelo elevado índice de absenteísmo, presenteísmo e incapacidades laborais temporárias e permanentes, os quais comprometem o funcionamento das instituições e impactam na qualidade e na segurança dos serviços prestados (Zhang et al., 2014; Paschoalin, Griep, Lisboa, 2012; Umann, Guido, Grazziano, 2012; Martinato et al., 2010; Sancinetti et al., 2009; Silva, Carlotto, 2008; Nogueira, 2007; Rosa, Carlotto, 2005).

Nesse sentido, o esgotamento emocional, a satisfação no trabalho e o clima organizacional são fatores relevantes para a compreensão dos resultados insatisfatórios dos serviços de saúde, uma vez que podem influenciar a concentração, a vigilância e a capacidade de supervisão (Cimmioti, Aiken, 2011; Aiken, Clarke, Sloane, 2002).

A preocupação com os recursos humanos em saúde é mundial, tanto pela falta de profissionais como pelo desequilíbrio da sua distribuição, pois geralmente se concentram nos grandes centros. Segundo a Organização Mundial de Saúde (OMS) e a Aliança Global para a Força de Trabalho em Saúde (Global Health Workforce Alliance) (WHO, 2013), atualmente faltam, no mundo, 7,2 milhões de trabalhadores de saúde e, se não forem realizados investimentos nesta área, a perspectiva é de que, em 2035, este déficit atinja cerca de 12,9 milhões.

O Brasil possui cerca de 1,8 milhão de trabalhadores de enfermagem, estando 56,5\% concentrados na região sudeste (FIOCRUZ/COFEN, 2013), dos quais 460.187 no estado de São Paulo (COREN-SP, 2015). Nos últimos anos, houve crescimento desordenado do número de enfermeiros no Brasil, devido à expansão do ensino superior, com aumento do número de cursos e de vagas, majoritariamente em instituições de ensino particulares. De 2001 para 2010, o número de egressos de graduação em enfermagem passou de 6.177 para 47.114 (Teixeira et al., 2013). 
Cabe ressaltar que, na região sudeste, a quantidade de vagas ofertadas excede a soma das vagas oferecidas pelas outras regiões, colaborando para o desequilíbrio da distribuição destes profissionais, pressupondo dificuldade de inserção dos egressos no mercado de trabalho e desemprego (Teixeira et al., 2013). Pesquisa realizada em 2013, com trabalhadores de enfermagem no âmbito nacional, identificou que 4,5\% estavam desempregados e 10,1\% havia enfrentado o desemprego nos últimos 12 meses. No estado de São Paulo, dos 10,3\% que ficaram desempregados nos últimos 12 meses, 77,3\% referiram dificuldade em encontrar emprego (FIOCRUZ/COFEN, 2013).

Ademais, os trabalhadores de enfermagem enfrentam condições inadequadas de trabalho, com escassez de materiais, dimensionamento inadequado de recursos humanos (com consequente sobrecarga de trabalho e ritmo acelerado), baixa remuneração e pressão do mercado de trabalho (evidenciada pelo receio do desemprego), configurando a precarização do trabalho e, consequentemente, adoecimento e incapacidade laboral para essa categoria (Neto et al., 2014, Kessler, Krug, 2012; Meneghini, Paz, Lautert, 2011; Souza et al., 2009).

Assim, partindo da premissa que a satisfação no trabalho e o clima organizacional são fatores de proteção contra o burnout, acredita-se que investigar estes construtos seja relevante para compreender esta relação, utilizando-a como ferramenta que pode subsidiar gerentes de enfermagem e administradores de instituições de saúde na elaboração e na adoção de estratégias de gestão, com políticas organizacionais pró-ativas, para a construção de ambiente laboral que seja promotor da saúde dos trabalhadores de enfermagem, além de contribuir para menor rotatividade nos locais de trabalho e melhor qualidade da assistência.

Considerando os dados descritos anteriormente, associado às questões preocupantes acerca da força de trabalho em saúde e à carência de estudos que relacionam a percepção do clima organizacional, a satisfação no trabalho e a ocorrência de burnout em trabalhadores de enfermagem, tanto da atenção básica como da rede hospitalar, propõe-se o presente estudo, buscando elucidar as seguintes hipóteses: 
- Existe associação entre as características sociodemográficas com satisfação no trabalho, clima organizacional e síndrome de burnout.

- A satisfação no trabalho e a percepção de clima organizacional favorável se constituem como fator de proteção contra a síndrome de burnout em trabalhadores de enfermagem. 


\section{Contextualizanda a}

Satisfaçãa na Trabalha. - Clima Organizacional e a Sindrame de Burnout 


\section{CONTEXTUALIZANDO A SATISFAÇÃO NO TRABALHO, O CLIMA ORGANIZACIONAL E A SÍNDROME DE BURNOUT}

\subsection{REVISITANDO CONCEITOS}

\subsubsection{Satisfação no Trabalho}

A satisfação no trabalho é um evento complexo, subjetivo, podendo variar para uma mesma pessoa e entre os sujeitos no decorrer do tempo e conforme as circunstâncias (Carlotto, Câmara, 2008).

O conceito de satisfação no trabalho é permeado por diversas abordagens teóricas. Para este estudo, adotou-se o conceito do psicólogo organizacional, Edwin A. Locke, que revisou diversas teorias e modelos causais relacionados à satisfação no trabalho. É uma definição amplamente utilizada em pesquisas, por ser abrangente e apresentar coerência teórica.

Locke $(1984,1976)$ define a satisfação no trabalho como uma resposta emocional agradável e positiva resultante da avaliação dos diversos elementos do trabalho; é permeada por valores e experiências do sujeito com relação ao trabalho, congruente a suas necessidades físicas e psicológicas. Já a insatisfação se constitui em resposta emocional negativa, tendo como produto a frustração e a negação dos valores laborais do indivíduo (Locke, 1969).

No entanto, embora as respostas sejam individuais, há similaridade entre o que um grupo de trabalhadores deseja ou espera de seu trabalho; ou seja, os elementos causais de satisfação no trabalho possuem grande semelhança (Henne, Locke, 1985; Locke 1984).

A Teoria de Locke postulou que os elementos causais de satisfação no trabalho estão inter-relacionados em dois grupos principais: agentes e eventos e condições. 


\section{Figura 1- Elementos causais da satisfação no trabalho - Teoria de Locke.}

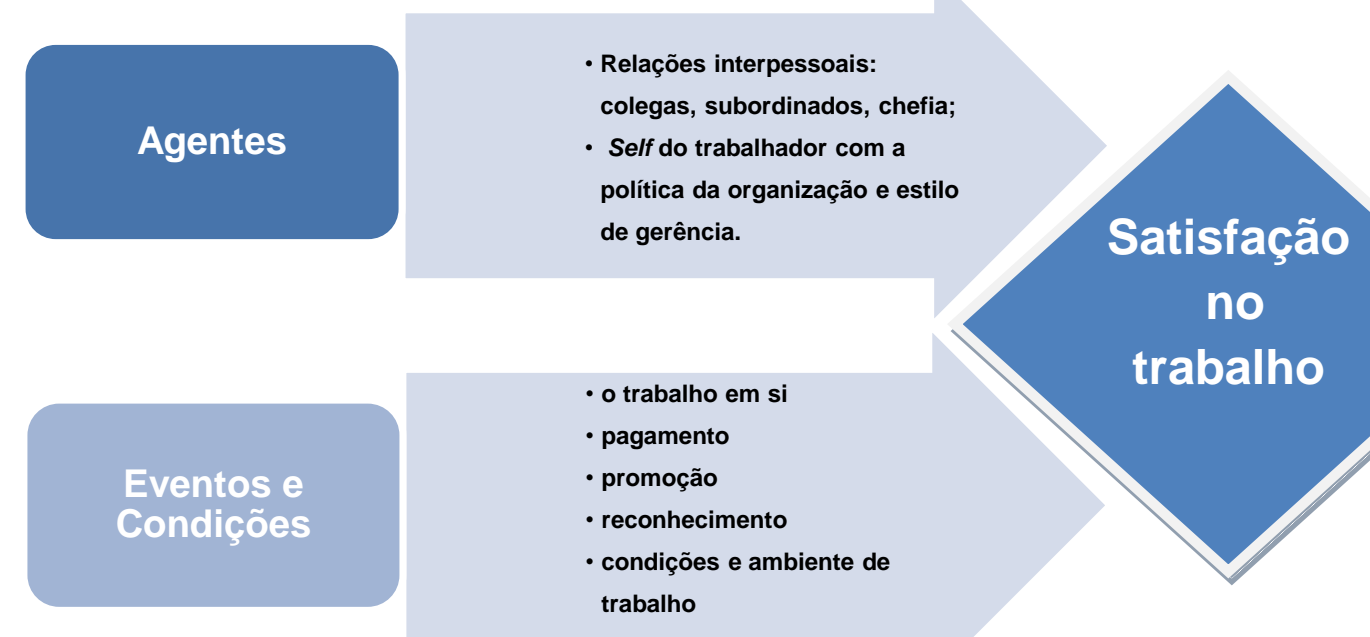

O grupo "agentes" abrange elementos das relações interpessoais com colegas, chefia e subordinados, além do self do indivíduo com a política organizacional, a supervisão e o gerenciamento. Acredita-se que colegas e subordinados convivem melhor quando possuem relação de amizade, são educados, confiáveis, colaborativos, competentes e partilham dos mesmos valores. $\mathrm{O}$ apoio aos gestores e supervisores se dará à medida que facilitem o alcance dos valores dos sujeitos, sendo atenciosos, competentes, agindo com justiça, reconhecendo e recompensando o desempenho dos subordinados, realizando gestão participativa, demonstrando respeito, ética e comunicando de forma adequada as informações. O respeito pelos empregados e seus valores, o cumprimento da política de benefícios e pagamentos, bem como a demonstração de respeito à competência e valores organizacionais cabem às organizações (Locke, 1984, 1976).

Quanto ao grupo "eventos e condições", este compreende os seguintes elementos (Locke, 1984, 1976):

- O trabalho em si: diz respeito ao próprio conteúdo do trabalho e as características valorizadas pelo trabalhador. Este deve atender os interesses pessoais, ser significativo, com variedade de atribuições e clareza de papéis; espera-se responsabilidade, ausência de fadiga física, valorização das 
experiências e habilidades, propiciando integração interpessoal, possibilitando crescimento e estimulando o aperfeiçoamento e o sentimento de realização e sucesso.

- Pagamento: deve ser justo e igualitário, em relação às atividades profissionais realizadas na organização - e quando comparado a outras instituições, incluindo benefícios e estabilidade, atendendo as despesas.

- Promoção: relacionada à oportunidade de crescimento e de sucesso profissional; como está atrelada ao aumento de responsabilidades, deve ser justa, clara e de livre escolha do trabalhador.

- Reconhecimento: pode ser demonstrado por elogios em público, anúncios, comentários, promoção e aumento salarial e autonomia.

- Condições e ambiente de trabalho: relacionados à presença de estrutura e recursos físicos para realização do trabalho, envolvendo equipamentos, suporte, ruído, umidade, ventilação, bem como número de horas trabalhadas, pausas para descanso, turnos e segurança.

Assim, a multicausalidade da satisfação no trabalho, em suma, está relacionada ao conteúdo do trabalho, ao reconhecimento e às possibilidades de crescimento/promoção, às relações interpessoais no trabalho, bem como às condições de trabalho e do ambiente de trabalho, às características da gestão e às políticas e competências da empresa (Locke, 1984).

Para avaliação da satisfação no trabalho dos trabalhadores de enfermagem, este estudo utiliza-se do questionário de Satisfação no Trabalho S20/S23, uma versão reduzida do Cuestionario General de Satisfacción em Organizaciones Laborales (S4/82), fundamentado no modelo teórico de Locke (1984).

\subsubsection{Clima Organizacional}

O clima organizacional "corresponde a um dos atributos mais relevantes à detecção dos elementos reguladores e orientadores do comportamento humano dentro de organizações" e é caracterizado "por um conjunto de percepções 
compartilhadas por trabalhadores sobre diferentes aspectos do ambiente organizacional” (Menezes, Gomes, 2010, p.159).

Pesquisas utilizando o termo "clima organizacional" tiveram início na década de 1950, com Argyris, que trouxe a noção de clima organizacional atrelado à cultura organizacional, dificultando uma definição consensual. O construto estaria vinculado a diferentes variáveis e níveis de análise; portanto, avaliar o clima organizacional significaria "investigar fatores individuais associados diretamente aos valores, às necessidades e aos tipos de personalidade dos indivíduos, bem como em analisar políticas, normas e códigos que representam a cultura da organização" (Menezes, Gomes, 2010).

Diversos estudos contribuíram para a diferenciação entre clima organizacional e cultura organizacional. No entanto, cultura e clima se interrelacionam e oferecem perspectivas sobrepostas para compreensão das experiências dos indivíduos em relação à configuração do trabalho e da organização (Schneider, Ehrhart, Macey, 2013; Menezes, Gomes, 2010), visto que as práticas e os valores normativos vigentes na empresa influenciarão na concepção de ambiente apreendida pelos funcionários (Menezes, Gomes, 2010).

A cultura organizacional é mais estável que o clima, refere-se às premissas básicas e aos valores que norteiam a vida dentro das organizações (Schneider, Ehrhart, Macey, 2013); é formada por valores, crenças, códigos e regras de natureza coletiva e ideacional que determinam as normas comportamentais nas organizações e são compartilhadas entre trabalhadores e organizações (Moran, Volkwein, 1992; Hofstede et al., 1990). 
Figura 2 - Diferença entre clima organizacional e cultura organizacional.
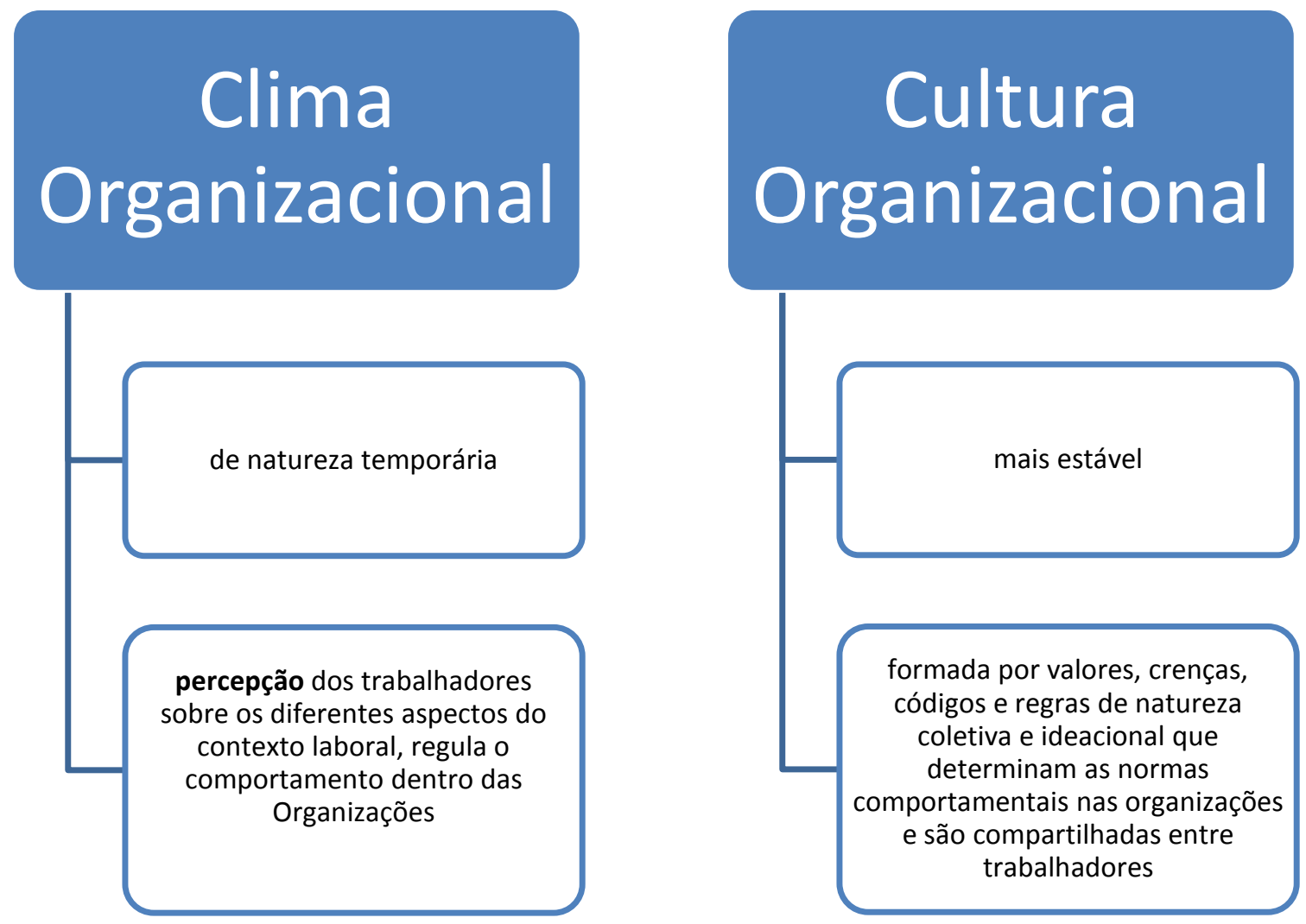

O clima organizacional é a expressão ou a manifestação da própria cultura com natureza temporária; é composto por componentes cognitivos, como a percepção que o trabalhador possui em relação ao contexto do trabalho, regulando as ações dos trabalhadores na organização (Rueda, Santos, 2011; Martins, 2008). É também definido como a atmosfera que paira nas organizações, resultante da percepção dos trabalhadores em relação às práticas, aos procedimentos e às recompensas, estando ligada diretamente a como os gestores se comportam e às ações por estes recompensadas (Schneider, Salvaggio, Subirats, 2002).

Assim, o clima organizacional emerge nas organizações por meio de um processo de informação social que diz respeito ao significado que os trabalhadores atribuem às políticas, às práticas e aos procedimentos que experimentam e aos comportamentos que observam como recompensado, apoiado e esperado (Schneider, Ehrhart, Macey, 2013). 
Em revisão histórica sobre o construto clima organizacional, Menezes e Gomes (2010, p.167) concluíram que:

[...] enquanto o clima organizacional é uma condição temporária formada por meio dos significados construídos pelos indivíduos, que guiam suas decisões e ações no ambiente organizacional, a cultura organizacional cumpre um papel mais normativo, voltado ao compartilhamento de valores que fornecem uma identidade à organização e, consequentemente, favorecem uma maior capacidade adaptativa e de autodesenvolvimento interno e externo.

Contudo, a realização de pesquisas de clima organizacional deve-se à possibilidade de avaliar características complexas, como liderança, relacionamento interpessoal, reconhecimento, recompensa, entre outras, com base nas percepções dos trabalhadores da organização (Menezes, Gomes, 2010), fornecendo um diagnóstico institucional para possíveis intervenções.

\subsubsection{Síndrome de Burnout}

O burnout surgiu na literatura científica no final da década de $1960 \mathrm{com}$ Bradley, que utilizou o termo staff burn-out, referindo-se ao desgaste profissional e sugerindo medidas organizacionais de enfrentamento (Schaufeli, Enzmann, 1998 apud Benevides-Pereira, 2003, p.4). Foi consolidado na década de 1970, nos Estados Unidos, com estudos de Hebert Freudenberger e, posteriormente, Christina Maslach, responsáveis pela difusão e pelo interesse por este construto, que ganhou destaque internacional, principalmente após os anos 1980, com o surgimento de doenças físicas e mentais decorrentes das mudanças tecnológicas no mundo do trabalho (Benevides-Pereira, 2003; Maslach, Schaufeli, 1993). No cenário nacional, a primeira publicação sobre a síndrome de burnout é de França e ocorreu em 1987 (Benevides-Pereira, 2002).

Considerada como uma doença emergente no âmbito laboral, no Brasil, em 1999, por meio do Decreto 3.048, que trata sobre a regulamentação da Previdência Social, a síndrome de burnout passou a ser reconhecida como uma doença do trabalho (doença relacionada ou adquirida devido às condições em que o trabalho é realizado) (Brasil, 1999) e, consequentemente, como acidente de trabalho, conforme o artigo 20, da Lei 8.213/1991 (Brasil, 1991). Atualmente, no 
Anexo II do Decreto 6.957/2009, que alterou o Regulamento da Previdência Social, a síndrome de burnout consta na lista de transtornos mentais e do comportamento relacionados ao trabalho, no inciso XII, como "Sensação de Estar Acabado ("Síndrome de Burn-Ouf", "Síndrome do Esgotamento Profissional" (Z73.0))", relacionada com os seguintes fatores de risco de natureza ocupacional: "ritmo de trabalho penoso (Z56.3)" e "Outras dificuldades físicas e mentais relacionadas com o trabalho" (Z56.6) (Brasil, 2009). No entanto, o desconhecimento sobre esta síndrome ainda se perpetua entre os trabalhadores e as avaliações formais pelos serviços de medicina ocupacional ainda são frágeis na investigação desse acometimento.

O burnout é uma síndrome de instalação gradual e lenta (Lautert, 1995), um fenômeno psicossocial resultante do estresse laboral crônico, levando o trabalhador a atitudes e sentimentos negativos (Maslach, Schaufeli, Leiter, 2001). Os trabalhadores mais suscetíveis à síndrome de burnout são os que lidam diretamente com o público, prestando algum tipo de assistência, dentre eles profissionais de saúde (Maslach, Jackson, Leiter, 1996).

A síndrome de burnout é um construto multidimensional caracterizado por exaustão emocional, despersonalização ou cinismo e reduzida realização profissional (Maslach, Jackson, Leiter, 1996; Maslach, Jackson, 1981). A dimensão exaustão emocional refere-se à falta de energia para realização das atividades laborais, ao sentimento de estar sobrecarregado, com fadiga e esgotamento físico e mental (Maslach, Schaufeli, Leiter, 2001). É resultante da sobrecarga de trabalho e de conflitos no relacionamento interpessoal (Maslach, 2005). A despersonalização leva o trabalhador a uma resposta negativa no contexto interpessoal, tratando as pessoas destinatárias do seu trabalho com cinismo ou frieza, como se fossem objetos, como os responsáveis pelos seus problemas (Maslach, Schaufeli, Leiter, 2001; Maslach, Jackson, 1985). Trata-se de uma forma de enfrentamento, uma tentativa de se distanciar dos receptores do seu trabalho devido à exaustão emocional (Maslach, Schaufeli, Leiter, 2001). Consequentemente, o trabalhador diminui o ritmo laboral, passando a realizar o mínimo possível de suas atividades laborais, diminuindo seu desempenho e a qualidade do trabalho (Maslach, 2005).

A reduzida realização profissional é resultante de processo de autoavaliação, quando o trabalhador sente-se incompetente, fracassado, com baixa 
autoestima e com baixo desempenho no trabalho (Benevides-Pereira, 2002; Maslach, Schaufeli, Leiter, 2001); tal fato está atrelado à falta de apoio social e de oportunidades de crescimento profissional (Maslach, 2005).

Figura 3 - Características da Síndrome de Burnout.

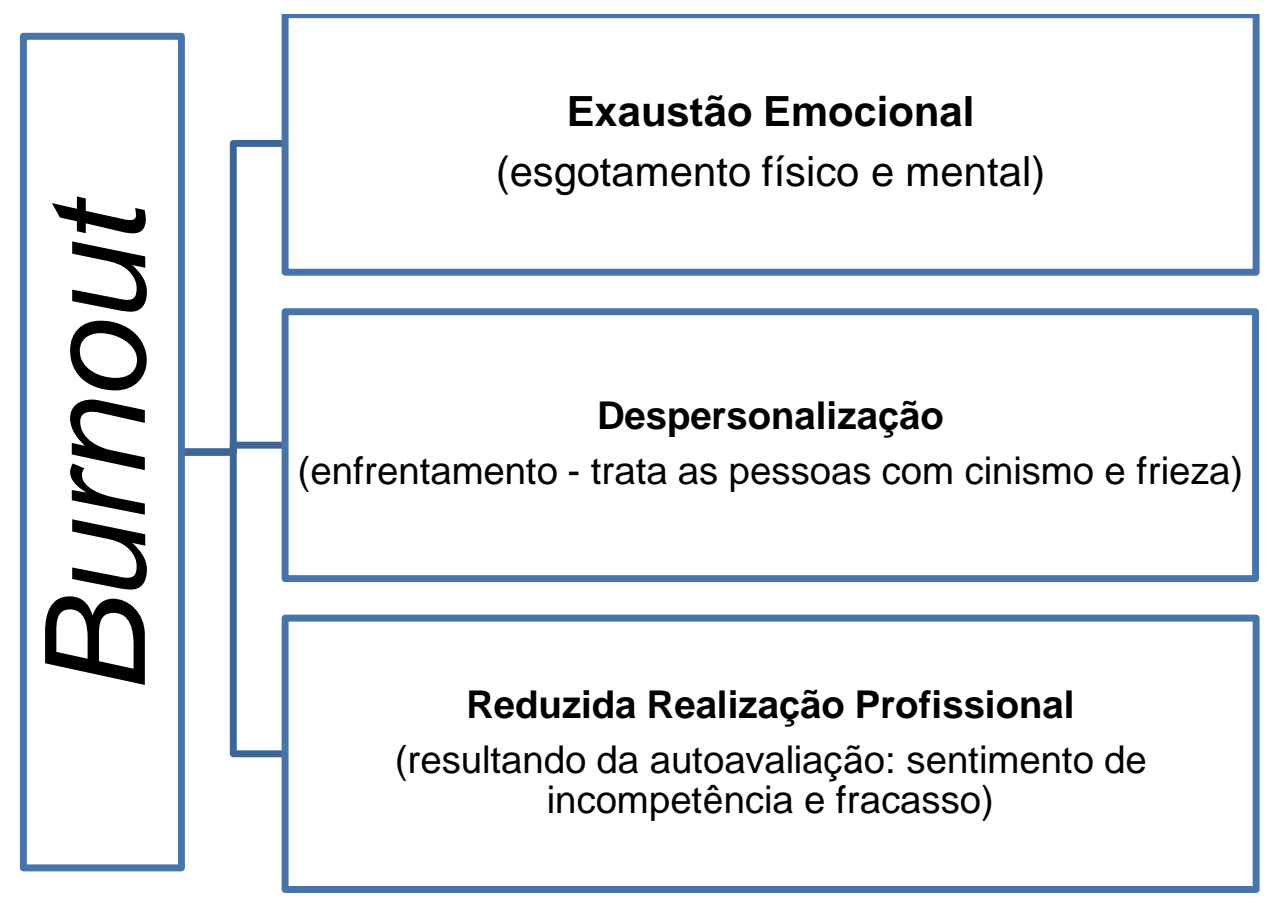

Benevides-Pereira (2002) compilou, na literatura, uma variedade de sintomas associados ao burnout:

- $\quad$ Sintomas Físicos: fadiga constante e progressiva, dores osteomusculares, distúrbios do sono, cefaleia e enxaquecas em geral, perturbações gastrointestinais, imunodeficiência, transtornos cardiovasculares, distúrbios do sistema respiratório, disfunções sexuais e alterações menstruais nas mulheres.

- Sintomas Psíquicos: falta de atenção e concentração, alterações da memória, lentidão do pensamento, sentimento de alienação, sentimento de solidão, impaciência, sentimento de impotência, labilidade emocional, dificuldade de autoaceitação, baixa autoestima, astenia, desânimo, disforia, depressão, desconfiança e paranoia.

- Sintomas Comportamentais: negligência ou escrúpulo excessivo, irritabilidade, incremento da agressividade, incapacidade para relaxar, dificuldade na 
aceitação de mudanças, perda da iniciativa, aumento do consumo de substâncias como café, fumo tranquilizantes e até drogas ilícitas, comportamento de alto risco (busca atividades de alto risco tentando sobressair-se) e suicídio.

- Sintomas Defensivos: tendência ao isolamento, sentimento de onipotência, perda do interesse pelo trabalho ou até pelo lazer, absenteísmo, ímpetos de abandonar o trabalho, ironia, cinismo.

Tanto fatores individuais quanto situacionais contribuem para 0 surgimento da síndrome de burnout (Maslach, Schaufeli, Leiter, 2001). Dentre estes, destacam-se as características do ambiente de trabalho, como presença de elevados níveis de conflitos (Leiter, Maslach, 1988); exigências quantitativas com sobrecarga de trabalho; baixa autonomia e pouca participação no processo decisório da organização (Maslach, Schaufeli, Leiter, 2001); e os fatores interpessoais, como sexo feminino, que possui maior risco de burnout (Benevides-Pereira, 2002; Maslach, Schaufeli, Leiter, 2001), devido ao envolvimento emocional com os problemas dos pacientes e com as necessidades emocionais da família e pela maior propensão em trabalhar em profissões que necessitam de contato direto com pessoas (Maslach, Jackson, 1985); nível educacional, visto que pessoas com maior escolaridade geralmente possuem expectativas maiores sobre o futuro de sua carreira (Maslach, Schaufeli, Leiter, 2001; Maslach, Jackson, 1985); e idade, já que a síndrome é mais frequente no início de carreira, nos jovens com menos de trinta anos (Maslach, 2005; Maslach, Schaufeli, Leiter, 2001).

\subsection{INFLUÊNCIA DA SATISFAÇÃO NO TRABALHO E PERCEPÇÃO DO CLIMA ORGANIZACIONAL NA SÍNDROME DE BURNOUT EM TRABALHADORES DE ENFERMAGEM}

No desenvolvimento da sua atividade laboral, os trabalhadores estão expostos a fatores desgastantes e potencializadores, determinantes do processo saúde-doença e da qualidade de vida no trabalho (Rocha, Felli, 2004). Este dilema também é vivenciado pelos trabalhadores de enfermagem, que vivenciam, tanto a satisfação da atividade laboral como também estão expostos a fatores desgastantes relacionados às condições de trabalho e ao contexto social e organizacional. 
A satisfação no trabalho mostra-se com um importante construto, por produzir impacto tanto no trabalhador quanto na organização, incluindo a qualidade de vida no trabalho e a saúde física e mental dos trabalhadores (Sartoreto, 2013; Martinez, Paraguai, 2003), estando, nos profissionais de saúde, também relacionada à qualidade dos serviços prestados (Kvist et al., 2014; McHugh et al., 2011), repercutindo, consequentemente, na segurança dos pacientes. Assim, na enfermagem, é possível inferir que a satisfação no trabalho pode proteger a saúde física e mental do trabalhador, além de propiciar melhor assistência ao paciente, representando, portanto, um indicador da qualidade do gerenciamento de recursos humanos em enfermagem (Siqueira, Kurcgant, 2012).

Uma revisão integrativa sobre satisfação no trabalho da enfermagem aponta que a insatisfação no trabalho "está mais frequentemente relacionada aos elementos que a organização oferece ao trabalhador, considerados em relação às suas expectativas". Nesse sentido, foram identificados diversos fatores que interferem na satisfação ou insatisfação destes trabalhadores, como condições de trabalho, infraestrutura, políticas, organização e administração da instituição, disponibilidade de recursos humanos e materiais, técnicos e de suporte, estabilidade no emprego, remuneração, organização do processo de trabalho, investimento em capacitação no trabalho, possibilidade de desenvolvimento pessoal e profissional, reconhecimento (dos colegas de trabalho, chefia, pacientes, sociedade), valorização, autonomia, recompensas, apoio da comunidade, relacionamento interpessoal com a equipe, gerência e paciente (Sartoreto, 2013).

Pereira, Galvão e Chanes (2005, p. 439) afirmam que o "clima organizacional reflete os sentimentos/sensações internos, mostrando, em indicadores, a situação positiva ou negativa derivada da satisfação dos funcionários". Assim, o clima organizacional, resultante da percepção do trabalhador sobre o contexto laboral, está intimamente ligado à satisfação no trabalho.

Estudo realizado por Oviedo e Calderón (1994), com trabalhadores de um hospital pediátrico no México, aponta que o clima organizacional interfere na satisfação no trabalho. Em outro estudo, com trabalhadores de um centro médico em Porto Alegre, a satisfação no trabalho e o clima organizacional mostraram correlação positiva relevante (Hernandez, Melo, 2003). 
Portanto, o ambiente de trabalho é influenciado pelo clima organizacional e este repercute no compromisso e no desempenho dos trabalhadores, impactando na qualidade de vida no trabalho e na qualidade dos serviços (González, Melo, Limón, 2015; Muñoz-Seco et al., 2006).

Em relação às causas de absenteísmo do trabalhador de enfermagem, um estudo que analisou os afastamentos por doença em profissionais de enfermagem de um hospital universitário, no período de um ano, verificou que os transtornos mentais e comportamentais representaram 3.393 dias $(28,4 \%)$ de licença por doença, sendo a segunda causa de ausências no trabalho, precedida apenas pelas doenças do sistema osteomuscular e do tecido conjuntivo (4.957 dias; 41,5\%) (Sancinetti et al., 2009).

Dados semelhantes foram encontrados em estudo com 135 profissionais de enfermagem de um ambulatório de uma instituição oncológica, onde os transtornos mentais e comportamentais foram a segunda causa de afastamento, com $22,2 \%$, precedidos apenas pelas doenças do sistema osteomuscular, com $48,9 \%$ (Nogueira, 2007).

Outro estudo, que avaliou as licenças de saúde com tempo igual ou superior a 15 dias entre trabalhadores de enfermagem de um hospital universitário no período de um ano, verificou que os transtornos mentais e comportamentais foram a terceira maior causa de afastamentos (17,26\%) (Carvalho et al.,2010).

Nas últimas décadas, o burnout tem se destacado como sofrimento psíquico nos trabalhadores de enfermagem. Estudo realizado com 43.329 enfermeiros de 711 hospitais nos Estados Unidos, Canadá, Alemanha, Inglaterra e Escócia constatou altos níveis de burnout, variando de 34 a 54\% (Aiken et al., 2001).

No Brasil, pesquisa realizada com 63 enfermeiros assistenciais de um hospital do Recife, utilizando o Maslach Burnout Inventory (MBI), constatou que 4,7\% apresentavam burnout. Foram verificados altos níveis de exaustão emocional $(49,2 \%)$, associados à realização de tarefas com muita rapidez e salário incompatível com o esforço empregado; altos níveis de despersonalização (27,0\%), associados ao tempo de profissão (até 5 anos) e por efetuar as tarefas com muita rapidez; e baixo nível de realização profissional (4,8\%). Em 27\% dos entrevistados, 
pelo menos duas das três dimensões avaliadas apontavam alta propensão ao burnout (Galindo et al., 2012).

Outro estudo utilizando o $\mathrm{MBI}$ com profissionais de enfermagem verificou associações estatísticas significantes para síndrome de burnout com sobrecarga de trabalho, falta de motivação para o trabalho, conflito de valores pessoais e institucionais, falta de possibilidades de recompensa, entre outros. Os autores concluíram que a permanência de condições adversas no trabalho gera estresse e que, se o trabalhador não desenvolver mecanismos adaptativos eficazes, poderá culminar na síndrome de burnout (Meneghini, Paz, Lautert, 2011).

No cenário organizacional, as consequências da síndrome de burnout em trabalhadores de enfermagem estão atreladas os altos índices de absenteísmo (França et al., 2012; Gil-Monte, 2002; Leiter, Harvie, Frizzle,1998), presenteísmo (Hyeda, Handar, 2011), ao turnover (saída voluntária do emprego) (Trigo, Teng, Hallar, 2007; O'Brien-Pallas et al., 2006), à intenção de deixar a profissão (Warshawsky, Havens, 2014) e prejuízos na qualidade da assistência prestada (O'Brien-Pallas et al., 2006; Vahey et al., 2004; Aiken et al.,2001).

Cabe ressaltar que o absenteísmo e o presenteísmo, além de elevarem os custos na instituição e diminuírem a produtividade e a qualidade do atendimento ao paciente (Grazziano, Bianchi, 2010), aumentam a sobrecarga dos profissionais sadios, formando um ciclo do adoecimento, uma vez que os trabalhadores sobrecarregados poderão adoecer e se tornar absenteístas ou presenteístas (Baptista, 2014). Uma das medidas necessárias para interromper este ciclo é a realização de um diagnóstico da instituição a respeito da satisfação no trabalho, percepção do clima organizacional e níveis de burnout, com objetivo de intervir nos pontos frágeis e prevenir o adoecimento psíquico do trabalhador.

A segurança do paciente também pode estar comprometida quando este é assistido por profissionais com burnout. Estudo com 111 pacientes e 287 trabalhadores de enfermagem de Unidades de Terapia Intensiva de um hospital em São Paulo (Brasil), encontrou, na análise descritiva dos dados, maior média de ocorrência de eventos adversos/incidentes nas unidades com maior sobrecarga de trabalho, estresse ou burnout (Andolhe, 2013). Outro estudo, com 8.597 enfermeiros 
do Canadá, verificou que a segurança do paciente está relacionada com o burnout e a qualidade do ambiente de trabalho da enfermagem (Spence Laschinger, Leiter, 2006).

Considerando que a satisfação no trabalho e a percepção do clima organizacional favorável possam proteger a saúde do trabalhador de enfermagem em relação ao burnout, algumas pesquisas verificaram a associação entre estes construtos.

Estudo realizado com 173 enfermeiros de cuidados a longo prazo de Taiwan verificou que maior satisfação no trabalho está relacionada com diminuição do estresse no trabalho e menor intenção de deixar o emprego (Kuo, Lin, Li, 2014).

Pesquisa realizada com profissionais de uma instituição hospitalar da região sul do Brasil encontrou associação significativa entre burnout e satisfação no trabalho. Foi verificado que existe relação entre satisfação no trabalho e exaustão emocional, visto que a insatisfação com a estrutura física, com a função que exerce, com ausência de participação nas decisões e com a supervisão desencadeia o sentimento de desgaste emocional. Também foi observado que a realização profissional está relacionada com a satisfação com a supervisão, com a presença de benefícios e políticas organizacionais e com o próprio trabalho. Desta forma, estar satisfeito com o trabalho pode ser entendido como fator de proteção para o burnout e, consequentemente, poderá interferir positivamente na prestação de cuidados e na qualidade do cuidado oferecido, já que afeta diretamente o cuidador (Rosa, Carlotto, 2005).

Estudo recente com 52 trabalhadores de enfermagem de um hospital público, ao associar as dimensões do burnout com as de satisfação no trabalho, encontrou que o fator satisfação com o ambiente reduz a exaustão emocional; o aumento com a satisfação com o trabalho e oportunidade de crescimento reduz as dimensões exaustão emocional e despersonalização; e também aumenta a realização profissional. Os autores consideram que "políticas de mudança do contexto organizacional podem interferir no número de ocorrência da síndrome de burnout", sendo importante a reorganização do trabalho "pautado pela criação de ambientes físicos seguros e compatíveis com o tipo de trabalho desenvolvido; 
jornada de trabalho adequada; e definição clara e transparente de objetivos e metas, permitindo, com isso, que o profissional de enfermagem possa alcançá-las como meio de crescimento e de reconhecimento profissional" (Sá, Martins-Silva, Funchal, 2014).

O burnout em enfermeiros, além de estar associado com o nível de satisfação no trabalho e a resultados insatisfatórios dos serviços de saúde, principalmente devido ao esgotamento emocional, que pode alterar a concentração, a vigilância e a capacidade de supervisão, também está relacionado com o clima organizacional (Cimmioti, Aiken, 2011; Aiken, Clarke, Sloane, 2002).

A relação entre síndrome de burnout e o clima organizacional foi estudada em 565 profissionais de um hospital do interior de São Paulo, encontrando que quanto melhor a percepção global que os trabalhadores possuem do ambiente de trabalho, menos susceptíveis eles são a exaustão emocional e, assim, menos propensos ao burnout (Santos, Sousa, Rueda, 2015).

Nesse sentido, correlacionar esses construtos e investigá-los em profundidade nos trabalhadores de enfermagem representa uma maneira de compreender como, e em qual medida, tais aspectos podem ser importantes para a gênese do adoecimento ou de mecanismos de proteção e promoção à saúde no ambiente de trabalho. 
3 Oljetivas 


\section{OBJETIVOS}

\subsection{Geral}

- Analisar a associação entre clima organizacional, satisfação no trabalho e burnout nos trabalhadores de enfermagem do litoral norte de São Paulo e propor estratégias para promoção de clima organizacional favorável e da satisfação no trabalho.

\subsection{Específico}

- Avaliar o clima organizacional segundo a percepção dos trabalhadores de enfermagem do litoral norte de São Paulo.

- Avaliar a satisfação no trabalho dos trabalhadores de enfermagem do litoral norte de São Paulo.

- Verificar a ocorrência de burnout nos trabalhadores de enfermagem do litoral norte de São Paulo.

- Identificar junto aos trabalhadores de enfermagem estratégias para melhoria do clima organizacional e da satisfação no trabalho.

- Construir propostas de intervenção para promoção de clima organizacional favorável e da satisfação no trabalho. 
4 Métada 


\section{MÉTODO}

\subsection{TIPO DE PESQUISA}

Trata-se de um estudo correlacional, de campo, transversal, com abordagem quantitativa.

\subsection{LOCAL DO ESTUDO}

O cenário de estudo foram os estabelecimentos públicos/filantrópicos de saúde das cidades do Litoral Norte de São Paulo: Ubatuba, Caraguatatuba, São Sebastião e llhabela.

O Litoral Norte de São Paulo localiza-se a $182 \mathrm{~km}$ da capital, tomando como base Caraguatatuba (Prefeitura Municipal de Caraguatatuba-SP, 2013). Segundo o censo demográfico 2010, do Instituto Brasileiro de Geografia e Estatística (IBGE), a região possui 1.956,139 $\mathrm{Km}^{2}$ e 281.779 habitantes, com a maior parte residente na área urbana (Brasil, 2014).

Figura 4- Mapa do Litoral Norte de São Paulo.

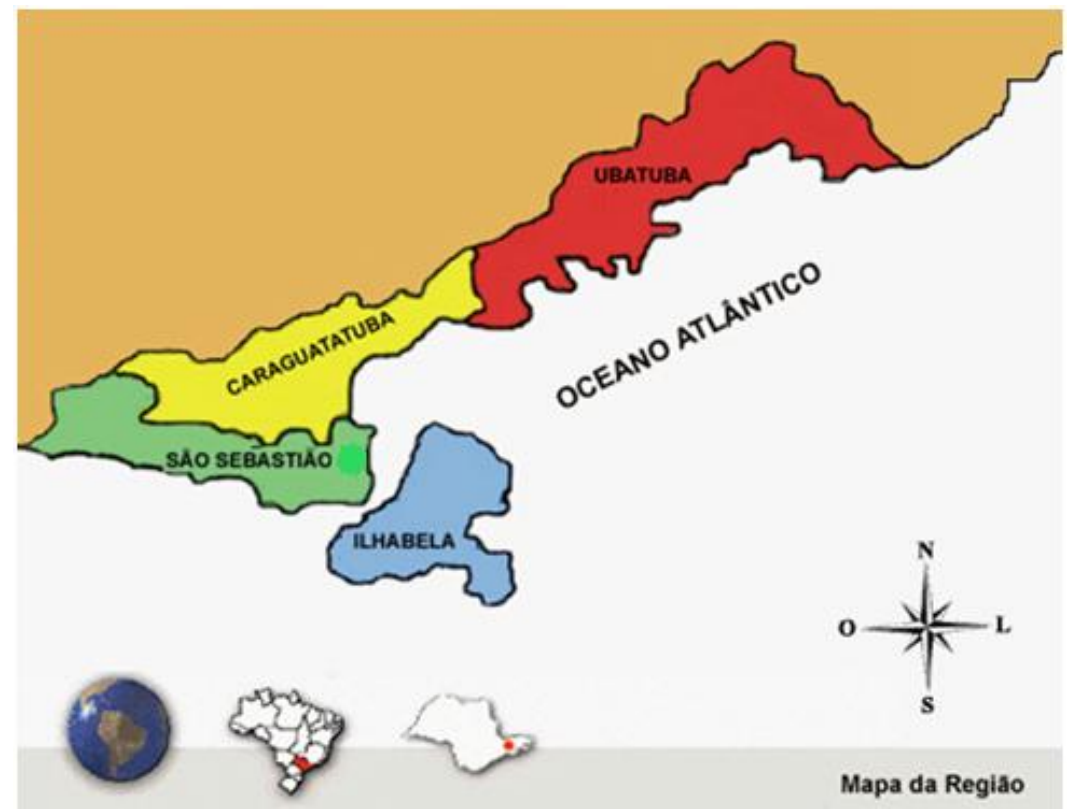

Fonte: Domínio público- http://www.sitiosaofrancisco.org.br/cdr/files/localizacao/mapa_regiao.gif 
As quatro cidades possuem pelo menos uma instituição hospitalar pública/filantrópica e a atenção básica à saúde é exercida pela Estratégia Saúde da Família (ESF) e pelas unidades de apoio, como ambulatórios de especialidades médicas.

Dados do Departamento de Atenção Básica à Saúde indicam que Ilhabela possui 9 equipes de Estratégia Saúde da Família (ESF), São Sebastião 21 ESF, Caraguatatuba 22 ESF e Ubatuba 22 ESF (Brasil, 2016 ${ }^{\mathrm{a}}$ ). Segundo a Secretaria de Atenção à Saúde - DataSUS (CNES-NET), em dezembro de 2015, o litoral norte de São Paulo contava com o seguinte quadro de trabalhadores de enfermagem em estabelecimentos públicos/filantrópicos (Brasil, 2016 ${ }^{b}$ ):

\begin{tabular}{|l|l|c|c|c|}
\hline Cidades & $\begin{array}{l}\text { Trabalhadores } \\
\text { enfermagem }\end{array}$ & $\begin{array}{c}\text { Atenção } \\
\text { Básica }\end{array}$ & $\begin{array}{c}\text { Instituição } \\
\text { Hospitalar/ UPA }\end{array}$ & Total \\
\hline \multirow{2}{*}{ Caraguatatuba } & Enfermeiro & 58 & 80 & 138 \\
\cline { 2 - 5 } & Auxiliar/Técnico de Enfermagem & 124 & 261 & 385 \\
\hline \multirow{2}{*}{ Ilhabela } & Enfermeiro & 16 & 20 & 36 \\
\cline { 2 - 5 } & Auxiliar/Técnico de Enfermagem & 56 & 63 & 119 \\
\hline \multirow{2}{*}{ São Sebastião } & Enfermeiro & 51 & 41 & 92 \\
\cline { 2 - 5 } & Auxiliar/Técnico de Enfermagem & 121 & 193 & 314 \\
\hline \multirow{2}{*}{ Ubatuba } & Enfermeiro & 50 & 36 & 232 \\
\cline { 2 - 5 } & Auxiliar/Técnico de Enfermagem & 88 & 144 & 1.402 \\
\hline
\end{tabular}

\subsection{AMOSTRA}

Foram convidados a participar deste estudo, a totalidade de trabalhadores dos respectivos serviços, por meio de contato com as gerentes de enfermagem pessoalmente e via contato telefônico. Em seguida, a pesquisadora percorreu todos os serviços, acessando individualmente ou em pequenos grupos, cada trabalhador, obtendo um total de 949 instrumentos entregues aos trabalhadores de enfermagem, correspondendo a $67,68 \%$ dos 1.402 atuantes em estabelecimentos de saúde público/filantrópicos dos municípios do litoral norte de São Paulo. Destes, 534 responderam e entregaram os questionários, 400 não devolveram os questionários, 7 se recusaram verbalmente a participar e 8 entregaram os questionários com dados incompletos. 
Assim, a amostra deste estudo foi constituída por 534 trabalhadores de enfermagem.

\subsection{COLETA DE DADOS}

\subsubsection{Procedimentos éticos}

Este estudo é parte do Projeto Multicêntrico "Dos contextos de trabalho à saúde ocupacional dos profissionais de enfermagem, um estudo comparativo entre Portugal, Brasil e Espanha", sob coordenação da Prof. Dra. Patricia Campos Pavan Baptista, submetido e aprovado pelo Comitê de Ética em Pesquisa da Escola de Enfermagem da USP- Parecer 912.483 de 17/11/2014 (ANEXO 1).

Antes do início da coleta de dados, foi solicitada autorização dos responsáveis pelos estabelecimentos de saúde pública/filantrópica das cidades do litoral norte de São Paulo. A Secretaria Municipal de Saúde de um dos municípios solicitou a exposição oral do projeto de pesquisa aos membros da Comissão de Ética e para todos os enfermeiros da atenção básica, antes de conceder autorização, o que foi realizado durante três reuniões.

A Secretaria Municipal de Saúde de outro município negou autorização institucional para coleta de dados nos estabelecimentos de saúde da atenção básica, devido a mudança maciça no quadro de trabalhadores. A coleta de dados foi realizada apenas nos estabelecimentos de saúde que deram parecer favorável.

Os sujeitos da pesquisa assinaram o Termo de Consentimento Livre e Esclarecido (TCLE), em duas vias, que foi elaborado segundo os preceitos da Resolução 466/2012 (Brasil, 2012).

\subsubsection{Procedimento de coleta}

A coleta de dados foi realizada pela pesquisadora no período de agosto de 2015 a junho de 2016, seguindo as etapas abaixo descritas. 
Após autorização do Comitê de Ética e Pesquisa da Escola de Enfermagem da Universidade de São Paulo e autorização das secretarias municipais de saúde das cidades, das entidades gestoras da ESF e dos responsáveis pelas instituições hospitalares, a coleta de dados foi realizada pela própria pesquisadora nos estabelecimentos de saúde.

Previamente, foram acordados com os gerentes dos estabelecimentos de saúde os dias e horários mais propícios para convidar os trabalhadores de enfermagem a participar do estudo, bem como entregar o TCLE, Instrumento de Coleta de Dados e combinar a data para entrega dos mesmos.

Estabeleceu-se a seguinte rotina de coleta de dados: no primeiro contato, os trabalhadores foram convidados a participar do estudo, recebendo, individualmente ou em pequenos grupos, todas as informações pertinentes, como os objetivos, a não obrigatoriedade de participação, a garantia de sigilo e confidencialidade dos dados e demais aspectos constantes no TCLE. Aqueles que concordaram verbalmente em participar do estudo receberam um envelope contendo o instrumento de coleta de dados juntamente com os TCLE, sendo combinados dia e horário para devolução dos mesmos preenchidos. Os trabalhadores foram orientados: a ficar com uma via do TCLE, assinar e devolver a outra via; devolver o questionário preenchido exclusivamente para a pesquisadora em envelope lacrado, sem identificação externa. Este procedimento buscou garantir o sigilo e a confiabilidade das informações, visto que muitos trabalhadores se mostraram receosos no preenchimento, devido ao teor da pesquisa. Posteriormente, a pesquisadora retornou para buscar os questionários preenchidos por até três vezes, obtendo um retorno de 56,26\%, dos 949 instrumentos entregues.

A coleta de dados foi realizada em 4 Instituições hospitalares (1 de grande porte (157 leitos), 2 de médio porte (79 leitos e 101 leitos) e 1 de pequeno porte (49 leitos)), 1 Unidade de Pronto Atendimento (UPA), 1 Serviço de Atendimento Móvel de Urgência (SAMU) e em 51 estabelecimentos que realizam a atenção básica à saúde (Unidades Básicas de Saúde (UBS), Unidades de Saúde da Família (USF), Ambulatórios de Especialidades, Centro de Apoio Psicossocial (CAPS) e Setores Técnico Administrativo/ Apoio (Diretorias, Almoxarifado, Vigilância Epidemiológica). 


\subsubsection{Instrumentos}

Para a coleta de dados, foram utilizados cinco instrumentos: Questionário de Caracterização dos Sociodemográfica e Profissional, Escala de Clima Organizacional para Organizações de Saúde (ECOOS), Questionário de Satisfação no Trabalho - S20/23, Maslach Burnout Inventory - Human Services Survey (MBIHSS) e Instrumento para elaboração de estratégias para promoção de um clima organizacional favorável e da satisfação no trabalho.

\subsubsection{Questionário de Caracterização Sociodemográfica e Profissional (APÊNDICE A)}

No questionário de caracterização sociodemográfica e profissional; constam informações sobre idade, sexo, estado civil, idade dos filhos, renda pessoal e familiar, participação na vida econômica da família, escolaridade/formação profissional, tempo de formação na área que atua, local de trabalho, cargo, tempo de atuação na equipe atual, tipo de contrato de trabalho, média de horas trabalhadas por semana, tipo de turno, existência de outro vínculo empregatício, se considera o trabalho estressante, se realiza alguma atividade física/lazer e possui dependente na qual presta cuidados.

\subsubsection{Escala de Clima Organizacional para Organizações de Saúde (ECOOS) (APÊNDICE B)}

Para verificar a percepção do Clima Organizacional, foi utilizada a ECOOS, elaborada e validada por Menezes, Sampaio, Gomes, Teixeira e Santos (2009), que consiste em 64 itens, distribuídos em 7 fatores: 


\begin{tabular}{|c|c|c|}
\hline Fator & Descrição & Itens \\
\hline 1 Liderança (LD) & $\begin{array}{l}\text { Diz respeito à competência de influenciar atitudes, crenças, } \\
\text { comportamentos e sentimentos de outras pessoas, assim } \\
\text { como o grau de feedback e orientação fornecido ao } \\
\text { subordinado sobre seu desempenho e assuntos de seu } \\
\text { interesse }\end{array}$ & 1 a 17 \\
\hline $\begin{array}{l}2 \text { Desenvolvimento } \\
\text { Profissional (DP) }\end{array}$ & $\begin{array}{l}\text { Consiste no conjunto de estratégias organizacionais voltadas } \\
\text { para o desenvolvimento das competências dos seus } \\
\text { trabalhadores em áreas e funções específicas }\end{array}$ & 18 a 28 \\
\hline $\begin{array}{l}3 \text { Relacionamento } \\
\text { e Espírito de } \\
\text { Equipe (ReEE) }\end{array}$ & $\begin{array}{l}\text { Compreende a cooperação, o apoio, a confiança, a qualidade } \\
\text { do relacionamento e o nível de liberdade de expressão entre } \\
\text { os membros da equipe, a troca de informações e de } \\
\text { ensinamentos e as possibilidades de aprendizagem entre } \\
\text { eles }\end{array}$ & 29 a 37 \\
\hline $\begin{array}{l}4 \text { Relação com a } \\
\text { Comunidade (RC) }\end{array}$ & $\begin{array}{l}\text { É caracterizada pela qualidade do relacionamento } \\
\text { estabelecido entre os servidores e a comunidade a qual } \\
\text { utiliza os serviços }\end{array}$ & 38 a 45 \\
\hline $\begin{array}{l}5 \text { Segurança no } \\
\text { Trabalho (ST) }\end{array}$ & $\begin{array}{l}\text { Diz respeito às condições do ambiente de trabalho e } \\
\text { equipamentos que asseguram a integridade física dos } \\
\text { trabalhadores }\end{array}$ & 46 a 52 \\
\hline 6 Estratégia (EST) & $\begin{array}{l}\text { Corresponde aos componentes do planejamento estratégico } \\
\text { que caracterizam a atuação de uma determinada } \\
\text { organização }\end{array}$ & 53 a 59 \\
\hline $\begin{array}{l}7 \quad \text { Remuneração } \\
\text { (REM) }\end{array}$ & $\begin{array}{l}\text { Aborda a compatibilidade entre a remuneração recebida na } \\
\text { organização e as exigências e responsabilidades inerentes } \\
\text { ao trabalho realizado nesta, além da consistência entre a } \\
\text { remuneração na organização e a remuneração praticada no } \\
\text { mercado para trabalhos similares. }\end{array}$ & 60 a 64 \\
\hline
\end{tabular}

A ECOOS adota a escala tipo Likert, com cinco intervalos de resposta, variando de "discordo totalmente" (1) a "concordo totalmente" (5). A percepção do Clima Organizacional foi avaliada pela média do escore geral e pela média da somatória das respostas obtidas em cada fator. 


\subsubsection{Questionário de Satisfação no Trabalho - S20/23 (APÊNDICE C)}

Para avaliação da Satisfação no Trabalho, utilizou-se o Questionário de Satisfação no Trabalho - S20/S23, elaborado por Meliá e Peiró (1989), versão brasileira de Carlotto e Câmara (2008). O S20/S23 contém 20 itens, avaliados numa escala de 5 pontos que variam de "Totalmente insatisfeito" (1) até "Totalmente satisfeito" (5). É composta por três dimensões:

\begin{tabular}{|c|c|c|}
\hline Fator & Descrição & Questões \\
\hline $\begin{array}{l}\text { Satisfação com Relações } \\
\text { Hierárquicas }(\mathrm{SRH})\end{array}$ & $\begin{array}{l}\text { Avalia como o trabalhador se sente em } \\
\text { relação ao seu superior, como seu } \\
\text { trabalho é avaliado e julgado, incluindo } \\
\text { sentimentos de igualdade, justiça e } \\
\text { autonomia. }\end{array}$ & $\begin{array}{l}13,14,15,16,17 \\
18,19,20,21,22 \\
\text { e } 23\end{array}$ \\
\hline $\begin{array}{l}\text { Satisfação com Ambiente } \\
\text { Físico de Trabalho (SAFT) }\end{array}$ & $\begin{array}{l}\text { Avalia a satisfação com ambiente físico, } \\
\text { como higiene e salubridade, iluminação, } \\
\text { ventilação e climatização do ambiente de } \\
\text { trabalho. }\end{array}$ & $\begin{array}{l}06,07,08,09 \mathrm{e} \\
10\end{array}$ \\
\hline $\begin{array}{l}\text { Satisfação Intrínseca no } \\
\text { Trabalho (SIT) }\end{array}$ & $\begin{array}{l}\text { Avalia a satisfação em relação ao } \\
\text { trabalho desenvolvido, oportunidades } \\
\text { que o trabalho oferece em desenvolver } \\
\text { atividades nas quais o indivíduo gosta e } \\
\text { se destaca e como o trabalhador se } \\
\text { sente em relação aos objetivos e às } \\
\text { metas estipuladas. }\end{array}$ & $01,02,03$ e 05 \\
\hline
\end{tabular}

A ocorrência de Satisfação no Trabalho foi avaliada pela média geral dos escores e pela média dos pontos obtidos em cada dimensão.

\subsubsection{Maslach Burnout Inventory - Human Services Survey (MBI-HSS) (APÊNDICE D)}

Para avaliar a presença da Síndrome de Burnout nos trabalhadores de enfermagem, foi utilizado o MBI-HSS, elaborado por Maslach e Jackson (1981) e 
traduzido e validado para o português por Lautert (1995). É constituído por 22 itens, distribuídos numa escala de 5 pontos, que varia de "nunca" (0) até "diariamente" (4). Avalia como é a vivência do trabalhador no seu trabalho, em três dimensões:

\begin{tabular}{|l|l|}
\hline Dimensões & Questões \\
\hline Exaustão Emocional (EE) & $1,2,3,6,8,13,14,16$ e 20 \\
\hline Despersonalização (DE) & $5,10,11,15$ e 22 \\
\hline Realização Profissional (RP) & $4,7,9,12,17,18,19$ e 21 \\
\hline
\end{tabular}

Neste estudo, foi realizado o cálculo das médias em cada dimensão. Adota-se que pontuações elevadas nas dimensões Exaustão Emocional e Despersonalização, associadas à baixa pontuação na dimensão Realização Profissional indicam Burnout (Lautert, 1995).

\subsubsection{Instrumento para elaboração de estratégias para promoção de Clima Organizacional favorável e da Satisfação no Trabalho (APÊNDICE E)}

Este instrumento, elaborado pela própria pesquisadora, contém 1 questão aberta que objetivou conhecer as sugestões dos trabalhadores de enfermagem para proposição de um Clima Organizacional favorável e da Satisfação no Trabalho.

\subsection{ANÁLISE DOS DADOS}

Os dados foram inseridos na planilha do programa de computador Microsoft Office Excel® 2007, em forma de banco de dados eletrônico, com dupla digitação independente. Após a correção de erros e inconsistências, os dados foram exportados para o Software Statistical Package for the Social Sciences for Windows (SPSS $\AA$ ) versão 22.0 , estabelecendo-se as análises descritivas e inferenciais pertinentes ao estudo. 
A caracterização sociodemográfica e ocupacional dos trabalhadores de enfermagem, a escala de Clima Organizacional, de Satisfação no Trabalho e Síndrome de Burnout foram tratados com análise descritiva simples, por meio de frequências relativas e absoluta para as variáveis qualitativas e média, desvio padrão, valores mínimos e máximos dos escores para variáveis quantitativas.

Foi efetuado análises de consistência interna (alfa de Cronbach) para confirmação das qualidades psicométricas dos construtos.

Para análise das associações entre as dimensões do Clima Organizacional, Satisfação no Trabalho e Síndrome de Burnout utilizou-se a correlação de Pearson, assim como para correlações entre variáveis quantitativas contínuas sociodemográficas e ocupacionais com as dimensões dos construtos. Para identificar e ordenar a magnitude das correlações, consideraram-se os valores das correlações entre 0,30 e 0,50 como moderada e, acima de 0,50, forte (Ajzen, Fishbein, 1980).

Para as correlações entre as dimensões dos construtos e as variáveis categóricas dicotômicas sociodemográficas e ocupacionais sexo, possuir filhos, realização de atividade física/lazer, possuir dependentes que presta cuidados e, regime de trabalho foi utilizado o teste Wilcoxon-Mann-Whitney; para associação com as variáveis categóricas (com três ou mais categorias) estado conjugal, maior nível de escolaridade, local de trabalho e, cargo, o teste de Kruskal Wallis; e para correlação com o número de empregos, devido a variável ordinal, a correção de Kendal (teste de Jonckheere-Terpstra).

Em todas as análises, as associações foram considerados estatisticamente significativos os resultados com $p \leq 0,05$.

Os dados provenientes da questão aberta foram agrupados por temas e subtemas e tratados quantitativamente. 
5 Resultados 


\section{RESULTADOS}

Os resultados foram apresentados sob a forma de tabelas e figuras, organizados da seguinte forma:

5.1 Caracterização sociodemográfica e ocupacional dos trabalhadores de enfermagem.

5.2 Análise descritiva da escala de Clima Organizacional.

5.3 Análise descritiva do Questionário de Satisfação no Trabalho.

5.4 Análise descritiva do Maslach Burnout Inventory.

5.5 Análise das correlações entre Clima Organizacional, Satisfação no Trabalho e Síndrome de Burnout.

5.6 Análise das correlações entre as variáveis sociodemográficas e ocupacionais com Clima Organizacional, Satisfação no Trabalho e Síndrome de Burnout

5.7 Estratégias para promoção do Clima Organizacional favorável e da Satisfação no Trabalho.

\subsection{CARACTERIZAÇÃO SOCIODEMOGRÁFICA E OCUPACIONAL DOS TRABALHADORES DE ENFERMAGEM.}

A Tabela 1 apresenta as características sociodemográficas dos participantes do estudo. 
Tabela 1 - Caracterização dos trabalhadores de enfermagem segundo variáveis categóricas sociodemográficas. São Paulo, 2015/2016.

\begin{tabular}{|c|c|c|c|}
\hline Variável & & $\mathbf{N}$ & $\%$ \\
\hline \multirow{6}{*}{ Sexo } & Feminino & 483 & 90,45 \\
\hline & Masculino & 49 & 9,18 \\
\hline & Não respondeu & 2 & 0,37 \\
\hline & Total & 534 & 100,00 \\
\hline & Solteiro(a) & 128 & 23,97 \\
\hline & Casado(a) ou amasiado(a) & 336 & 62,92 \\
\hline \multirow[t]{3}{*}{ Estado Conjugal } & Divorciado(a), separado(a) ou viúvo(a) & 68 & 12,74 \\
\hline & Não respondeu & 2 & 0,37 \\
\hline & Total & 534 & 100,00 \\
\hline \multirow{4}{*}{ Filhos } & $\operatorname{Sim}$ & 370 & 69,29 \\
\hline & Não & 163 & 30,52 \\
\hline & Não respondeu & 1 & 0,19 \\
\hline & Total & 534 & 100,00 \\
\hline \multirow{6}{*}{ Idade dos Filhos } & Menor de 1 ano & 16 & 4,32 \\
\hline & Entre 1 e 10 anos & 162 & 43,79 \\
\hline & Entre 11 e 18 anos & 78 & 21,08 \\
\hline & Mais de 18 anos & 77 & 20,81 \\
\hline & Não respondeu & 37 & 10,00 \\
\hline & Total & 370 & 100,00 \\
\hline \multirow{6}{*}{$\begin{array}{l}\text { Participação na Renda } \\
\text { familiar }\end{array}$} & É responsável pelo sustento da Família & 207 & 38,75 \\
\hline & Contribui parcialmente & 287 & 53,75 \\
\hline & Contribui esporadicamente & 23 & 4,31 \\
\hline & Não contribui & 9 & 1,69 \\
\hline & Não respondeu & 8 & 1,50 \\
\hline & Total & 534 & 100,00 \\
\hline \multirow{7}{*}{ Nível de Escolaridade } & Ensino fundamental/técnico & 5 & 0,94 \\
\hline & Ensino médio/técnico & 253 & 47,37 \\
\hline & Ensino superior incompleto & 85 & 15,92 \\
\hline & Ensino superior completo & 135 & 25,28 \\
\hline & Pós-graduação & 45 & 8,43 \\
\hline & Não respondeu & 11 & 2,06 \\
\hline & Total & 534 & 100,00 \\
\hline \multirow{4}{*}{$\begin{array}{l}\text { Realização de } \\
\text { atividade física/lazer }\end{array}$} & Sim & 275 & 51,50 \\
\hline & Não & 249 & 46,63 \\
\hline & Não respondeu & 10 & 1,87 \\
\hline & Total & 534 & 100,00 \\
\hline
\end{tabular}


Tabela 1 - Caracterização dos trabalhadores de enfermagem segundo variáveis categóricas sociodemográficas. São Paulo, 2015/2016.

\begin{tabular}{clrrr}
\hline Variável & & N & (continuação) \\
\hline \multirow{2}{*}{$\begin{array}{c}\text { Presença de } \\
\text { dependentes que } \\
\text { presta cuidados }\end{array}$} & Sim & Não & 114 & Não respondeu \\
& Total & 283 & 21,35 \\
& & 137 & 53,00 \\
& & 534 & 25,65 \\
& & & (conclusão)
\end{tabular}

Os dados analisados evidenciam que a maioria dos trabalhadores de enfermagem estudados pertence ao sexo feminino (90,45\%), com estado conjugal estável (casado ou amasiado) (62,92\%) e filhos (69,29\%). A maioria $(92,5 \%)$ é responsável ou contribui parcialmente para o sustento da família.

Quanto ao grau de escolaridade, 47,37\% possui ensino médio/técnico, $33,71 \%$ nível superior com ou sem pós-graduação.

Em relação à atividade física, pouco mais da metade $(51,50 \%)$ referiu realizar atividade física e/ou de lazer frequentemente e não possuir pessoas dependentes de cuidados, sob sua responsabilidade (53,00\%) (Tabela 2).

A faixa etária média dos trabalhadores de enfermagem foi de 37,69 anos, variando de 19 a 67 anos $(\mathrm{dp}=8,88)$. A média da renda pessoal mensal declarada foi de $R \$ 2.136,72$ ( $d p=1.283,00$ ), variando de $R \$ 600,00$ a $R \$ 10.000,00$, e a média da renda familiar líquida mensal foi de $R \$ 4.111,21$ ( $d p=3796,36$; mínimo $=R \$ 940,00$; máximo $=R \$ 60.000,00$ ), equivalentes a 4,67 salários mínimos (salário mínimo vigente no Brasil em janeiro de $2016=R \$ 880,00$ reais).

Na Tabela 2 está apresentada a estatística descritiva das variáveis ocupacionais qualitativas. 


\section{Tabela 2 - Caracterização dos trabalhadores de enfermagem segundo variáveis categóricas relacionadas ao trabalho. São Paulo, 2015/2016.}

\begin{tabular}{|c|c|c|c|}
\hline Variável & & $\mathrm{n}=534$ & $\%$ \\
\hline \multirow{5}{*}{$\begin{array}{l}\text { Local de } \\
\text { Trabalho }\end{array}$} & 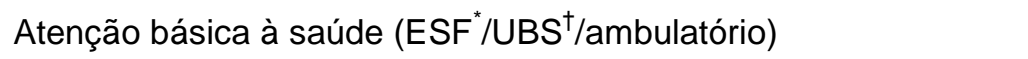 & 227 & 42,51 \\
\hline & Atenção pré-hospitalar & 11 & 2,06 \\
\hline & Atenção hospitalar (hospitais e UPA ${ }^{\ddagger}$ ) & 279 & 52,24 \\
\hline & Setores técnico-administrativo/apoio (diretoria/VE§/almoxarifado) & 16 & 3,00 \\
\hline & Não respondeu & 1 & 0,19 \\
\hline \multirow{4}{*}{ Cargo } & Auxiliar/Técnico de enfermagem & 386 & 72,28 \\
\hline & Enfermeiro assistencial & 114 & 21,35 \\
\hline & Enfermeiro supervisor/coordenador/diretor & 31 & 5,81 \\
\hline & Não respondeu & 3 & 0,56 \\
\hline \multirow{3}{*}{$\begin{array}{l}\text { Regime de } \\
\text { Trabalho }\end{array}$} & Sem estabilidade & 411 & 76,97 \\
\hline & Com estabilidade & 117 & 21,91 \\
\hline & Não respondeu & 6 & 1,12 \\
\hline \multirow{3}{*}{$\begin{array}{l}\text { Turno de } \\
\text { Trabalho }\end{array}$} & Fixo & 495 & 92,70 \\
\hline & Rotativo & 14 & 2,62 \\
\hline & Não respondeu & 25 & 4,68 \\
\hline \multirow{7}{*}{$\begin{array}{c}\text { Período e } \\
\text { Quantidade } \\
\text { de Horas } \\
\text { Diárias } \\
\text { Trabalhadas }\end{array}$} & Matutino (6h) & 12 & 2,25 \\
\hline & Vespertino (6h) & 4 & 0,75 \\
\hline & Diurno (8h) & 251 & 47,00 \\
\hline & Diurno (12h) & 50 & 9,36 \\
\hline & Noturno (12h) & 62 & 11,61 \\
\hline & Noturno ou diurno (12h) & 4 & 0,75 \\
\hline & Não respondeu & 151 & 28,28 \\
\hline \multirow{4}{*}{$\begin{array}{l}\text { Número de } \\
\text { Empregos }\end{array}$} & Hum & 449 & 84,08 \\
\hline & Dois & 73 & 13,67 \\
\hline & Três & 3 & 0,56 \\
\hline & Não respondeu & 9 & 1,69 \\
\hline \multirow{3}{*}{$\begin{array}{c}\text { Considera o } \\
\text { Trabalho } \\
\text { Estressante }\end{array}$} & Sim & 384 & 71,91 \\
\hline & Não & 135 & 25,28 \\
\hline & Não respondeu & 15 & 2,81 \\
\hline
\end{tabular}

*Estratégia Saúde da Família

†Unidade Básica de Saúde

${ }^{\ddagger}$ Unidade de Pronto Atendimento

§Vigilância Epidemiológica 
Verifica-se que 52,24\% atuam na atenção hospitalar e 42,51\% na atenção básica à saúde. Quanto ao cargo, identificou-se $72,28 \%$ de auxiliares/técnicos de enfermagem, seguido de enfermeiros assistenciais (21,35\%) (Tabela 2).

O tempo médio de formação profissional na área em que atua foi de 10,29 anos $(\mathrm{dp}=7,44 ;$ mínimo=0,25; máximo=33,67) e o tempo de atuação no local de trabalho atual foi de 6,02 anos ( $\mathrm{dp}=6,34$; mínimo=0,01; máximo=30,17). Observouse que a maior proporção não possui estabilidade de emprego (76,97\%), trabalha em turno fixo $(92,70 \%)$, possui um vínculo empregatício $(84,08 \%)$ e considera o trabalho estressante $(71,91 \%)$. A carga horária de 8 horas diárias foi a mais prevalente $(47,00 \%)$ e a média da jornada de trabalho semanal foi de 39,74 horas $(\mathrm{dp}=4,58)$, variando de 30 a 84 horas entre os trabalhadores.

\subsection{ANÁLISE DESCRITIVA DA ESCALA DE CLIMA ORGANIZACIONAL.}

Os resultados encontrados relativos ao Clima Organizacional são apresentados na Tabela 3 e Gráfico 1.

Tabela 3 - Estatística descritiva da Escala de Clima Organizacional para Organizações de Saúde (ECOOS) em trabalhadores de enfermagem. São Paulo, 2015/2016.

Fatores/ Escore Total

$\alpha$ de Cronbach

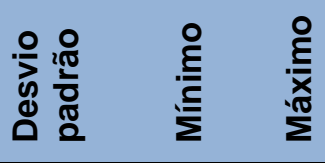
no

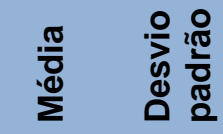

$\begin{array}{llllll}0,95 & 517 & 3,60 & 1,01 & 1,00 & 5,00 \\ 0,95 & 518 & 3,24 & 1,15 & 1,00 & 5,00 \\ 0,92 & 511 & 3,93 & 0,92 & 1,00 & 5,00 \\ 0,89 & 511 & 3,37 & 0,95 & 1,00 & 5,00 \\ 0,94 & 511 & 3,18 & 1,18 & 1,00 & 5,00 \\ 0,92 & 509 & 2,86 & 1,09 & 1,00 & 5,00 \\ 0,91 & 514 & 2,16 & 1,16 & 1,00 & 5,00 \\ 0,97 & 527 & 3,32 & 0,78 & 1,00 & 5,00\end{array}$


Os alfas de Cronbach encontrados em todos os fatores da ECOOS indicam fidedignidade, demonstrando a capacidade de medição na amostra, visto que sua confiabilidade interna pode ser considerada alta. A exclusão de qualquer questão dos fatores não acarretaria um melhor resultado. Os valores encontrados superam os do estudo de validação realizado por Menezes e colaboradores (2009) (Escore Total $\alpha=0,93 ; 1$-LD $\alpha=0,87$; 2-DP $\alpha=0,93$; 3-ReEE e 4-RC $\alpha=83$; 5-ST $\alpha=0,77 ; 6$-EST $\alpha=0,81 ; 7-$ REM $\alpha=0,83$ ).

Observa-se na Tabela 3 que a média do escore total para o Clima Organizacional foi 3,32. Em relação aos fatores que compõe a ECOOS, o Fator 7Remuneração (REM) foi o que apresentou menor média $(\bar{x}=2,16 ; \mathrm{dp}=1,16)$ e o que apresentou maior média foi o Fator 3- Relacionamento e Espírito de Equipe (ReEE) $(\bar{x}=3,93 ; \mathrm{dp}=0,92)$. 


\section{Gráfico 1 - Média do escore dos itens da Escala de Clima Organizacional para Organizações de Saúde (ECOOS) em trabalhadores de enfermagem. São Paulo, 2015/2016.}

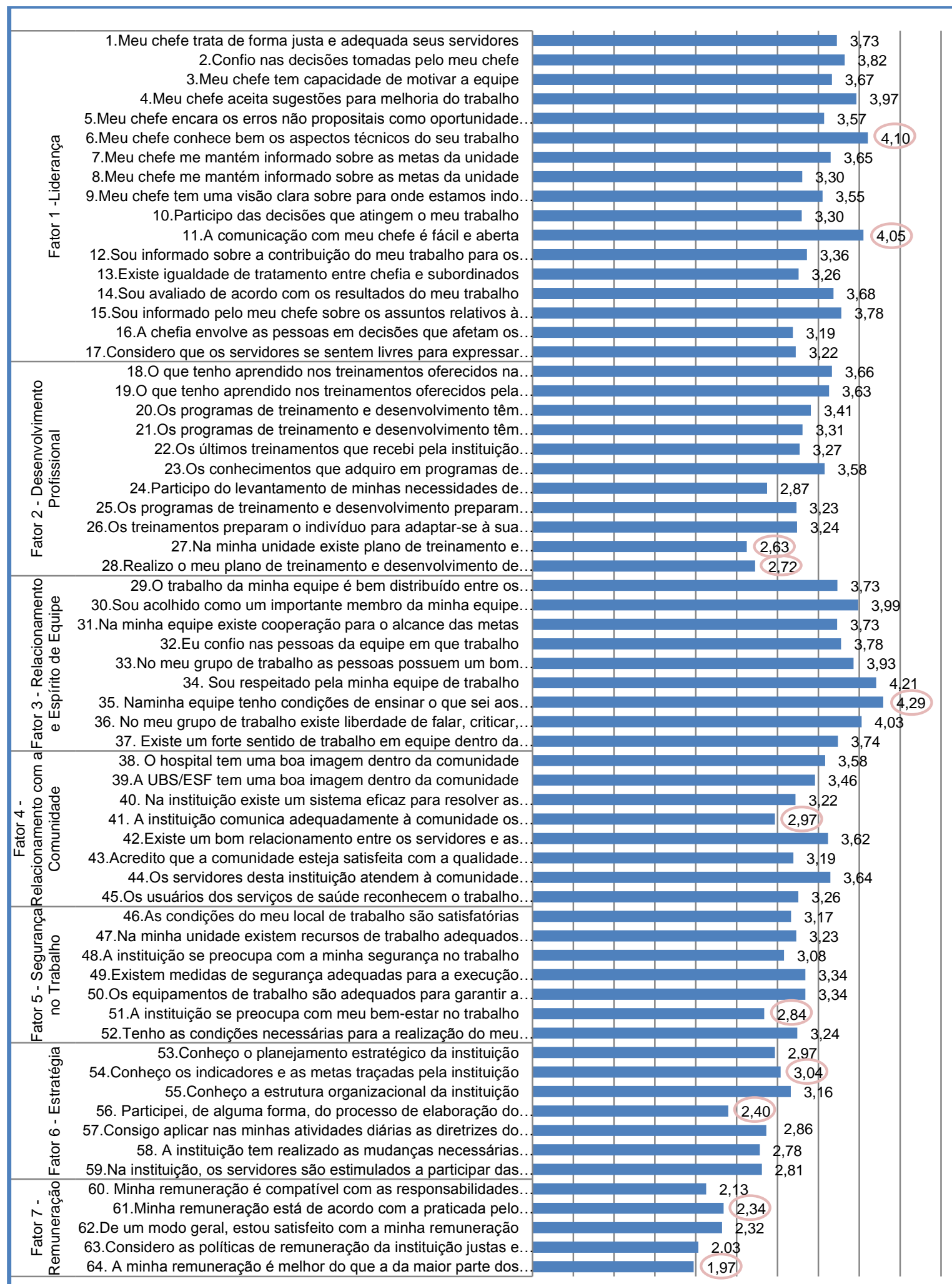


O Gráfico 1 analisa os itens que compõe cada fator da ECOOS, onde pode-se verificar que no Fator 1- Liderança (LD), as maiores médias obtidas estão nas questões 6 e 11, "Meu chefe conhece bem os aspectos técnicos do seu trabalho" ( $\bar{x}=4,10)$ e "A comunicação com meu chefe é fácil e aberta" $(\bar{x}=4,05)$, respectivamente. A menor média foi encontrada na questão 16 "A chefia envolve as pessoas em decisões que afetam os diferentes aspectos do trabalho" ( $\bar{x}=3,19)$.

No Fator 2- Desenvolvimento Profissional (DP), as menores pontuações médias estão nas questões 27 "Na minha unidade existe plano de treinamento e desenvolvimento para todos os servidores" e 28 "Realizo o meu plano de treinamento e desenvolvimento de forma negociada", com 2,63 e 2,72 respectivamente. O Fator 3- Relacionamento e Espírito de Equipe (ReEE) pontuou a maior média na questão 35 "Na minha equipe tenho condições de ensinar o que sei aos meus colegas e aprender com eles", com 4,29.

Quanto ao Fator 4- Relação com a Comunidade (RC) a questão 41 "A instituição comunica adequadamente à comunidade os seus projetos, investimentos e realizações" apresentou a menor média $(2,97)$. Já no Fator 5 - Segurança no Trabalho (ST), a menor média $(2,84)$ foi encontrada na questão 51 "A instituição se preocupa com meu bem-estar no trabalho".

Os Fatores 6- Estratégia (EST) e 7- Remuneração (REM) foram os que apresentaram os menores escores médios. No Fator 6- EST observa-se menor média $(2,40)$ na questão 56 "Participei, de alguma forma, do processo de elaboração do planejamento estratégico" e maior média $(3,04)$ na questão 54 "Conheço os indicadores e as metas traçadas pela instituição". O Fator 7- REM apresenta a menor média $(1,97)$ na questão 64 "A minha remuneração é melhor do que a da maior parte dos meus colegas de trabalho" e a maior média $(2,34)$ na questão 61 "Minha remuneração está de acordo com a praticada pelo mercado". 


\subsection{ANÁLISE DESCRITIVA DO QUESTIONÁRIO DE SATISFAÇÃO NO TRABALHO}

Na Tabela 4 e no Gráfico 2 estão os dados relativos a Satisfação no Trabalho, pontuados pelos trabalhadores de enfermagem.

Tabela 4 - Estatística descritiva do Questionário de Satisfação no Trabalho S20/23 em trabalhadores de enfermagem. São Paulo, 2015/2016.

Fatores/ Escore Total

a de Cronbach
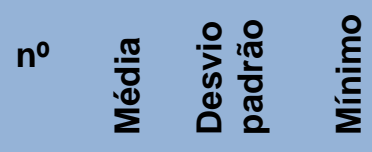

1-Satisfação com Relações Hierárquicas (SRH)

2-Satisfação com Ambiente Físico no Trabalho (SAFT)

3-Satisfação Intrínseca no Trabalho (SIT)

Escore Total- Satisfação no Trabalho

\begin{tabular}{|c|c|c|c|c|}
\hline 0,93 & $522 \quad 3,40$ & 0,98 & 1,00 & 5,0 \\
\hline 0,88 & 3,27 & 1,13 & 1,00 & 5,0 \\
\hline 0,82 & $523 \quad 3,61$ & 0,93 & 1,00 & \\
\hline 93 & 3,41 & 0,88 & 1,17 & \\
\hline
\end{tabular}

Quanto à consistência interna, verifica-se que todos os fatores do S20/S23 apresentaram alfas de Cronbach satisfatórios, com valores acima de 0,82 (Tabela 4), sendo estes superiores aos encontrados por Carlotto e Câmara em 2008, no estudo de validação (Escore Total $\alpha=0,91$; 1 -SRH $\alpha=0,92 ; 2-S A F T \alpha=0,86$; 3-SIT $\alpha=0,77)$.

$\mathrm{Na}$ Tabela 4 é possível observar que, entre os trabalhadores de enfermagem que participaram do estudo, o escore total médio para Satisfação no Trabalho foi 3,41 , variando de 1,17 a 5,00. A pontuação média nos fatores que compõe o Questionário de Satisfação no Trabalho (S20/S23) foram: 3,61 para Fator 3- Satisfação Intrínseca no Trabalho (SIT), seguido de 3,40 para Fator 1- Satisfação com Relações Hierárquicas (SRH) e 3,27 para Fator 2- Satisfação com Ambiente Físico de Trabalho (SAFT). 


\section{Gráfico 2 - Média do escore dos itens do Questionário de Satisfação no Trabalho - S20/23 em trabalhadores de enfermagem. São Paulo, 2015/2016.}

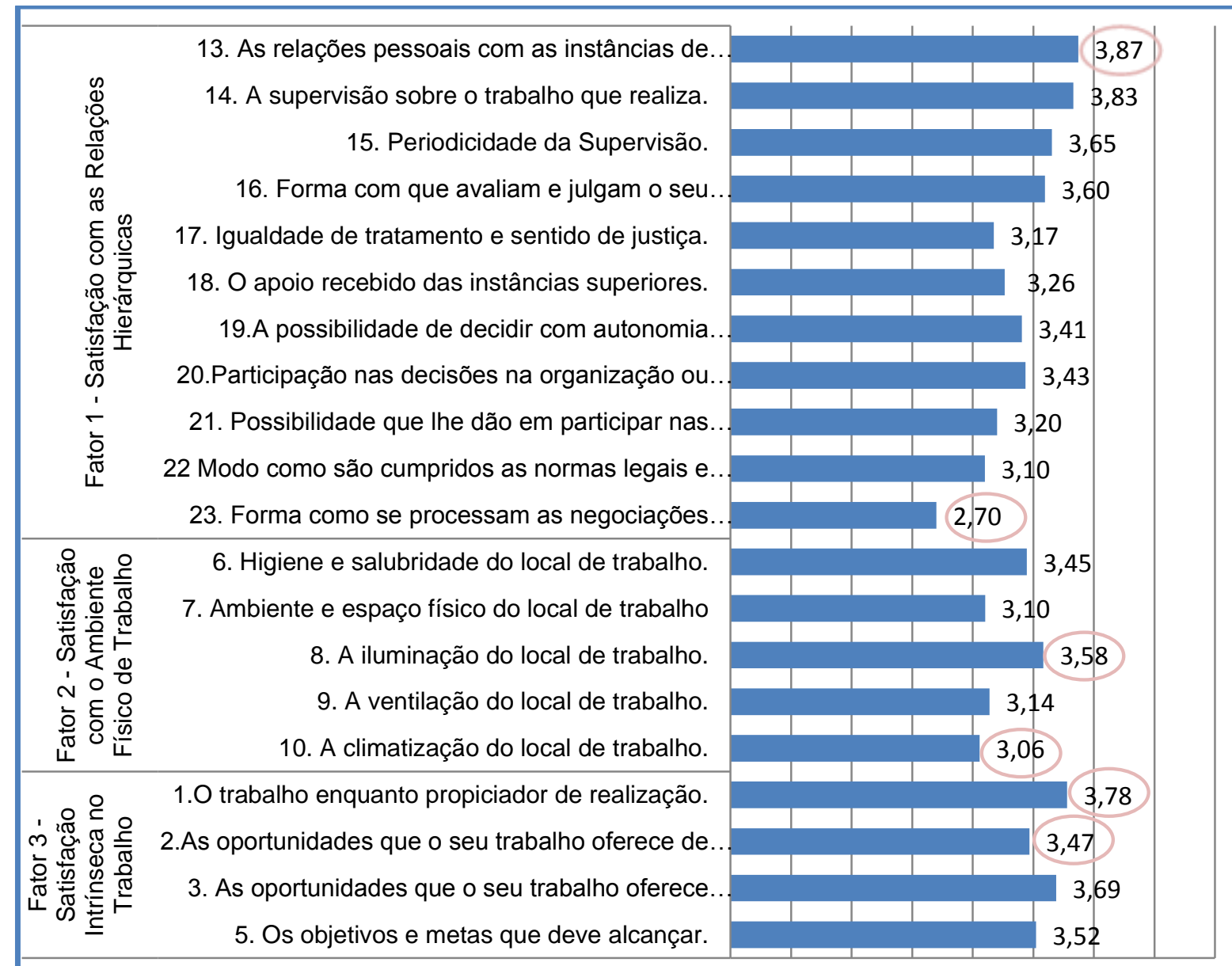

$1,00 \quad 1,50 \quad 2,00 \quad 2,50 \quad 3,00 \quad 3,50 \quad 4,00 \quad 4,50 \quad 5,00$

O Gráfico 2 apresenta a distribuição dos itens por fatores e seus respectivos escores médios. No Fator 1-Satisfação com as Relações Hierárquicas $(\mathrm{SRH})$, a questão 23 "Forma como se processam as negociações sobre a contratação de benefícios" apresentou a menor média $(2,70)$ e a maior média $(3,87)$ foi pontuada na questão 13 "As relações pessoais com as instâncias de poder (seus superiores / chefes)". 
No Fator 2- Satisfação com Ambiente Físico de Trabalho (SAFT), o menor escore médio $(3,06)$ foi obtido na questão 10 "A climatização do local de trabalho" e o maior escore $(3,58)$ na questão 8 "A iluminação do local de trabalho".

Quanto ao Fator 3- Satisfação Intrínseca no Trabalho (SIT), a menor pontuação média $(3,47)$ foi na questão 2 "As oportunidades que o seu trabalho oferece de fazer coisas nas quais se destaca" e a maior $(3,78)$ na questão 1 "O trabalho enquanto propiciador de realização".

\subsection{ANÁLISE DESCRITIVA DO MASLACH BURNOUT INVENTORY}

A Tabela 5 e o Gráfico 3 mostram os resultados relativos a Síndrome de Burnout entre trabalhadores de enfermagem.

Tabela 5 - Estatística descritiva do Maslach Burnout Inventory - Human Services Survey (MBI-HSS) em trabalhadores de enfermagem. São Paulo, 2015/2016.

\begin{tabular}{|c|c|c|c|c|c|c|}
\hline Dimensões & $\begin{array}{c}\alpha \text { de } \\
\text { Cronbach }\end{array}$ & $\mathbf{N}$ & $\frac{\pi}{\frac{\pi}{0}}$ & 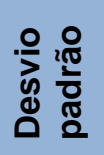 & & 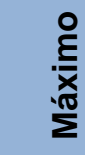 \\
\hline Exaustão Emocional (EE) & 0,89 & 525 & 1,67 & 0,89 & 0,00 & 3,89 \\
\hline Despersonalização (DE) & 0,66 & 524 & 0,86 & 0,76 & 0,00 & 3,00 \\
\hline Realização Profissional (RP) & 0,74 & 525 & 2,94 & 0,73 & 0,00 & 4,00 \\
\hline
\end{tabular}

A confiabilidade do Maslach Burnout Inventory (MBI-HSS) foi analisada para cada uma de suas dimensões e apresentou alfas de Cronbach satisfatórios, acima de 0,66 (Tabela 5). A dimensão Despersonalização (DE), apresentou alpha de Cronbach 0,66 , sendo que a exclusão da questão 15 "Sinto que realmente não me importo com o que ocorre com as pessoas as quais tenho que atender profissionalmente. Com que frequência sente isso?" levaria a uma pequena melhoria 
do resultado $(\alpha=0,68)$. Os alfas encontrados na amostra atual são semelhantes ao estudo de validação realizado por Lautert em 1995 (EE $\alpha=0,86$; DE $\alpha=0,69$; RP $\alpha=0,76)$.

Verifica-se na Tabela 5 que as médias para as dimensões Despersonalização (DE) e Exaustão Emocional (EE) foram as menores, 0,86 e 1,67 respectivamente. A dimensão Realização Profissional (RP) apresentou escore médio de 2,94 ( $\mathrm{dp}=0,73)$, variando de 0 a 4,00.

\section{Gráfico 3 - Média do escore dos itens das dimensões do Maslach Burnout Inventory - Human Services Survey (MBI-HSS) em trabalhadores de enfermagem. São Paulo, 2015/2016.}

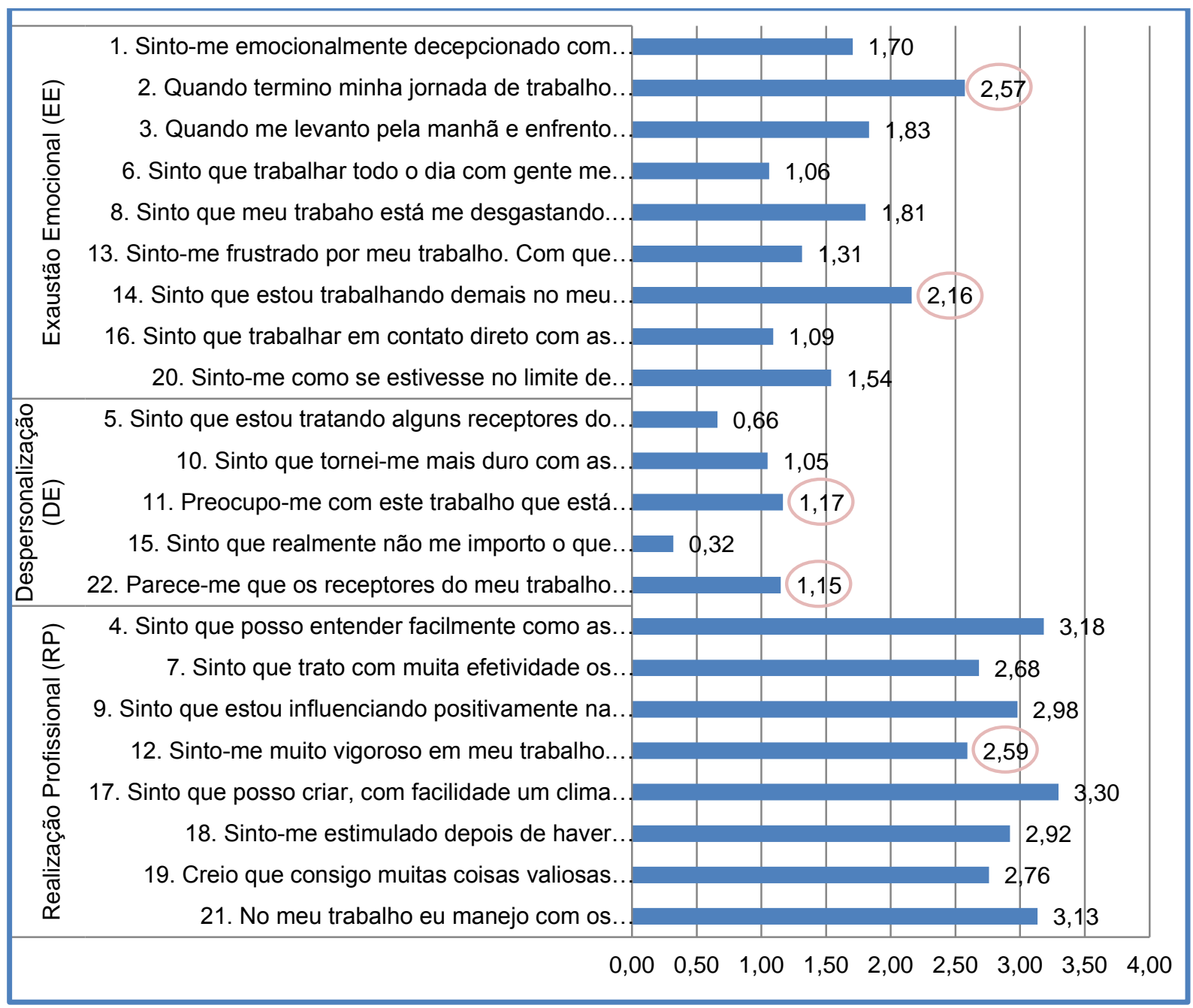

No Gráfico 3 é possível observar que na dimensão Exaustão Emocional (EE) as questões com maior pontuação são as de número 2 "Quando termino minha 
jornada de trabalho sinto-me esgotado. Com que frequência sente isso?" e 14 "Sinto que estou trabalhando demais no meu trabalho. Com que frequência sente isso?", com média de 2,57 e 2,16 respectivamente. Na dimensão Despersonalização (DE) as maiores médias foram encontradas nas questões 11 "Preocupo-me com este trabalho que está endurecendo-me emocionalmente. Com que frequência sente isso?" $(\bar{x}=1,17)$ e 22 "Parece-me que os receptores do meu trabalho culpam-me por alguns dos seus problemas. Com que frequência sente isso?" $(\bar{x}=1,15)$.

Quanto a Realização Profissional (RP) o menor escore médio $(2,59)$ foi identificado na questão 12 "Sinto-me muito vigoroso em meu trabalho. Com que frequência sente isso?".

\subsection{ANÁLISE DAS CORRELAÇÕES ENTRE CLIMA ORGANIZACIONAL, SATISFAÇÃO NO TRABALHO E SÍNDROME DE BURNOUT}

As Tabelas 6 e 7 apresentam as análises das correlações entre Clima Organizacional, Satisfação no Trabalho e Síndrome de Burnout.

Tabela 6 - Análise das correlações entre o escore total da Escala de Clima Organizacional para Organizações de Saúde (ECOOS) e Questionário de Satisfação no Trabalho (S20/23) e as dimensões do Maslach Burnout Inventory - Human Services Survey (MBI-HSS) em trabalhadores de enfermagem. São Paulo, 2015/2016.

\begin{tabular}{|c|c|c|c|}
\hline & Escore Total/ Dimensões & Clima Organizacional & Satisfação no Trabalho \\
\hline \multirow{4}{*}{ 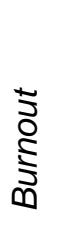 } & Satisfação no Trabalho & $0,673^{\mathrm{x}}$ & 1 \\
\hline & Exaustão Emocional- EE & $-0,408^{*}$ & $-0,457^{*}$ \\
\hline & Despersonalização- DE & $-0,298^{x x}$ & $-0,319^{x * \pi}$ \\
\hline & Realização Profissional- RP & $0,193^{* x}$ & $0,146^{\prime *}$ \\
\hline
\end{tabular}


Considerando como correlação moderada, valores entre 0,300 e 0,500 e correlação forte, valores superiores a 0,500 , verifica-se na Tabela 6: correlação positiva forte entre Satisfação no Trabalho e Clima Organizacional ( $r=0,673)$; correlação negativa moderada entre Exaustão Emocional (MBI-HSS) e Clima Organizacional ( $r=-0,408)$; correlação negativa moderada entre Exaustão Emocional (MBI-HSS) e Satisfação no Trabalho $(r=-0,457)$; e correlação negativa moderada entre Despersonalização (MBI-HSS) e Satisfação no Trabalho ( $r=-0,319)$.

A Tabela 7 apresenta as correlações entre as dimensões de cada construto, a fim de possibilitar ao leitor, melhor visualização do impacto de cada item das escalas.

Tabela 7 - Análise das correlações entre as dimensões da Escala de Clima Organizacional para Organizações de Saúde (ECOOS) e Questionário de Satisfação no Trabalho (S20/S23) e Maslach Burnout Inventory - Human Services Survey (MBI-HSS) em trabalhadores de enfermagem. São Paulo, 2015/2016.

\begin{tabular}{|c|c|c|c|c|c|c|c|}
\hline & \multirow[b]{2}{*}{ Variáveis } & \multicolumn{3}{|c|}{ Satisfação no Trabalho } & \multicolumn{3}{|c|}{ Burnout } \\
\hline & & Fator $1 \mathrm{SRH}$ & Fator 2 SAFT & Fator 3 SIT & EE & DE & $\mathrm{RP}$ \\
\hline \multirow{7}{*}{ 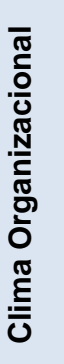 } & Fator 1- LD & $0,634^{\pi *}$ & 0,320 & 0,406 & $-0,278^{* *}$ & $-0,247^{* *}$ & $0,163^{* \star}$ \\
\hline & Fator 2- DP & 0,404 & $0,266^{* *}$ & $0,347^{*}$ & $-0,255^{\ldots *}$ & $-0,151^{* *}$ & $0,112^{*}$ \\
\hline & Fator 3- ReEE & 0,446 & $0,286^{* *}$ & 0,352 & $-0,308^{*}$ & $-0,232^{* *}$ & $0,119^{* *}$ \\
\hline & Fator 4- RC & 0,460 & $0,423^{*}$ & 0.367 & $-0,396$ & $-0,337$ & $0,146^{* *}$ \\
\hline & Fator 5- ST & 0,506 & 0,576 & $0,415^{*}$ & $-0,343^{*}$ & $-0,273^{* *}$ & $0,156^{* *}$ \\
\hline & Fator 6- EST & 0,475 & $0,375^{*}$ & 0,384 & $-0,308$ & $-0,177^{\star *}$ & $0,144^{* *}$ \\
\hline & Fator 7- REM & 0,324 & 0,332 & 0,348 & $-0,265^{* *}$ & $-0,087^{*}$ & $-0,018$ \\
\hline \multirow{3}{*}{ ఏ్ } & EE & 0,410 & $-0,337^{*}$ & $-0,449$ & & & \\
\hline & $\mathrm{DE}$ & $-0,311^{*}$ & $-0,238^{* *}$ & $-0,243^{* *}$ & & & \\
\hline & $\mathrm{RP}$ & $0,132^{* *}$ & 0,062 & $0,207^{* *}$ & & & \\
\hline
\end{tabular}

Teste- Correlação de Pearson

*Nível de significância 0,05.

**Nível de significância 0,01. 
A Tabela 7 evidencia que ao associar as dimensões das construtos de Clima Organizacional, Satisfação no Trabalho e Síndrome de Burnout observa-se:

\section{Correlação positiva forte entre}

- Fator 1- Liderança (LD) da Escala de Clima Organizacional e Fator 1- Satisfação com Relações Hierárquicas (SRH) $(r=0,634)$ do Questionário de Satisfação no Trabalho; e

- Fator 5- Segurança no Trabalho (ST) da Escala de Clima Organizacional e Fator 1- Satisfação com Relações Hierárquicas (SRH) $(r=0,506)$ e Fator 2- Satisfação com Ambiente Físico no Trabalho (SAFT) $(r=0,576)$ do Questionário de Satisfação no Trabalho.

\section{Correlação positiva moderada entre}

- Fator 1-Liderança (LD) da Escala de Clima Organizacional e Fator 2-Satisfação com Ambiente Físico no Trabalho (SAFT) $(r=0,320)$ e Fator 3-Satisfação Intrínseca no Trabalho (SIT) $(r=0,406)$ do Questionário de Satisfação no Trabalho;

- Fator 2- Desenvolvimento Profissional (DP) da Escala de Clima Organizacional e Fator 1-Satisfação com Relações Hierárquicas (SRH) $(r=0,404)$ e Fator-3 Satisfação Intrínseca no Trabalho (SIT) $(r=0,347)$ do Questionário de Satisfação no Trabalho;

- Fator 3- Relacionamento e Espírito de Equipe (ReEE) da Escala de Clima Organizacional e Fator 1- Satisfação com Relações Hierárquicas (SRH) ( $r=0,446)$ e Fator 3- Satisfação Intrínseca no Trabalho (SIT) $(r=0,352)$ do Questionário de Satisfação no Trabalho;

- Fator 4- Relacionamento com a Comunidade (RC) da Escala de Clima Organizacional e Fator 1- Satisfação com Relações Hierárquicas ( $\mathrm{SRH})(\mathrm{r}=0,460)$ e Fator-2 Satisfação com Ambiente Físico no Trabalho (SAFT) $(r=0,423)$ e Fator 3- Satisfação Intrínseca no Trabalho (SIT) $(r=0,367)$ do Questionário de Satisfação no Trabalho;

- Fator 5- Segurança no Trabalho (ST) da Escala de Clima Organizacional e Fator 3- Satisfação Intrínseca no Trabalho (SIT) $(r=0,415)$ do Questionário de Satisfação no Trabalho; 
- Fator 6- Estratégia (EST) da Escala de Clima Organizacional e Fator 1- Satisfação com Relações Hierárquicas (SRH) $(r=0,475)$ e Fator 2- Satisfação com Ambiente Físico no Trabalho (SAFT) $(r=0,375)$ Fator 3- Satisfação Intrínseca no Trabalho (SIT) $(r=0,384)$ do Questionário de Satisfação no Trabalho; e

- Fator 7-Remuneração (REM) da Escala de Clima Organizacional e Fator 1Satisfação com Relações Hierárquicas (SRH) $(r=0,324)$ e Fator 2- Satisfação com Ambiente Físico no Trabalho (SAFT) ( $r=0,332)$ e Fator 3- Satisfação Intrínseca no Trabalho (SIT) $(r=0,348)$ do Questionário de Satisfação no Trabalho.

\section{Correlação negativa moderada entre}

- Fator 3- Relacionamento e Espírito de Equipe (ReEE) da Escala de Clima Organizacional e Exaustão Emocional (EE) $(r=-0,308)$ do Maslach Burnout Inventory;

- Fator 4- Relacionamento com a Comunidade (RC) da Escala de Clima Organizacional e Exaustão Emocional (EE) ( $r=-0,396)$ e Despersonalização (DE) $(\mathrm{r}=-0,337)$ do Maslach Burnout Inventory;

- Fator 5- Segurança no Trabalho (ST) da Escala de Clima Organizacional e Exaustão Emocional (EE) ( $r=-0,343)$ do Maslach Burnout Inventory;

- Fator 6- Estratégia (EST) da Escala de Clima Organizacional e Exaustão Emocional (EE) ( $r=-0,308)$ do Maslach Burnout Inventory;

- Exaustão Emocional (EE) do Maslach Burnout Inventory e Fator 1- Satisfação com Relações Hierárquicas (SRH) $(r=-0,410)$ e Fator 2- Satisfação com Ambiente Físico no Trabalho (SAFT) ( $r=-0,337)$ e Fator 3- Satisfação Intrínseca no Trabalho (SIT) ( $r=-0,449)$ do Questionário de Satisfação no Trabalho; e

- Despersonalização (DE) do Maslach Burnout Inventory e Fator 1- Satisfação com Relações Hierárquicas (SRH) $(r=-0,311)$ do Questionário de Satisfação no Trabalho. 


\subsection{ANÁLISE DAS CORRELAÇÕES ENTRE AS VARIÁVEIS SOCIODEMOGRÁFICAS E OCUPACIONAIS COM CLIMA ORGANIZACIONAL, SATISFAÇÃO NO TRABALHO E BURNOUT}

\subsubsection{Análise das correlações entre as variáveis categóricas} sociodemográficas e Clima Organizacional, Satisfação no Trabalho e Burnout

Ao correlacionar as as variáveis categóricas sociodemográficas e as dimensões da Escala de Clima Organizacional para Organizações de Saúde (ECOOS), Escala de Satisfação no Trabalho (S20/S23) e Maslach Burnout Inventory - Human Services Survey (MBI-HSS) encontrou-se resultados estatisticamente significativos na associação entre:

- Sexo e o Fator 7-Remuneração (REM) $(p=0,049)$ da ECOOS, onde as mulheres atribuiram escores menores $(\bar{x}=2,13)$ para remuneração do que os homens $(\bar{x}=2,45)$;

- Estado Conjugal e o Fator 6-Estratégia (EST) $(p=0,020)$ da ECOOS e Realização Profissional (RP) $(p=0,017)$ do MBI-HSS. Trabalhadores de enfermagem solteiros e com união conjugal estável pontuaram escores maiores ( $\bar{x}=2,90$, respectivamente) para estratégia do que os divorciados, separados ou viúvos $(\bar{x}=2,51)$. Já quanto a realização profissional, observase que os trabalhadores solteiros obtiveram as menores médias $(2,77)$, quando comparados aos com união conjugal estável e divorciados, separados ou viúvos ( $\bar{x}=3,00$, respectivamente);

- Possuir Filhos e Despersonalização (DE) ( $p=0,017)$ e Realização Profissional (RP) $(p<0,000)$ do MBI-HSS, onde os trabalhadores que possuem filhos possuem menor despersonalização $(\bar{x}=0,81)$ e maior realização profissional $(\bar{x}=3,04)$, do que os que não possuem filhos (DE: $\bar{x}=0,98$ e RP: $\bar{x}=2,71$ ) 
- Nível de Escolaridade e Fator 5- Segurança no Trabalho (ST) $(p=0,044)$ da ECOOS e Despersonalização (DE) $(p=0,004)$ do MBI-HSS. Verifica-se que os trabalhadores de enfermagem que possuem graduação e pós graduação atribuiram menores escores à segurança no trabalho (pós-graduação: $\bar{x}=3,02$; superior completo: $\bar{x}=3,00$; superior incompleto: $\bar{x}=3,29$; médio/técnico: $\bar{x}=3,27 ; \quad$ fundamental/técnico: $\bar{x}=3,50$ ), estando estes indivíduos com maior despersonalização (pós-graduação: $\bar{x}=1,05$; superior completo: $\bar{x}=0,95$; superior incompleto: $\bar{x}=0,88$; médio/técnico: $\bar{x}=0,78$; fundamental/técnico: $\bar{x}=0,80$ );

- Realização de Atividade Física/lazer e o Fator 6-Estratégia (EST) $(p=0,022)$ da ECOOS, onde os trabalhadores de enfermagem que realizam alguma atividade física ou de lazer rotineiramente atribuíram maiores pontuações $(\bar{x}=2,96)$ para estratégia quando comparados aos que não realizam $(\bar{x}=2,72)$;

- Possuir Dependentes que Presta Cuidados e Exaustão Emocional (EE) $(p=0,042)$ do $\mathrm{MBI}-\mathrm{HSS}$, onde os trabalhadores que possuem familiares dependentes na qual presta cuidados possuem maior exaustão emocional $(\bar{x}=1,80)$ do que os que não possuem $(\bar{x}=1,61)$.

\subsubsection{Análise das correlações entre as variáveis categóricas ocupacionais e Clima Organizacional, Satisfação no Trabalho e Burnout}

Nas Tabelas 8, 9, 10 e 11 estão apresentados os resultados referentes às correlações entre as variáveis categóricas ocupacionais e as dimensões da Escala de Clima Organizacional, Questionário de Satisfação no Trabalho e o Maslach Burnout Inventory. 
Tabela 8 - Análise das correlações entre a variável categórica Local de Trabalho e as dimensões da Escala de Clima Organizacional para Organizações de Saúde (ECOOS), Questionário de Satisfação no Trabalho (S20/S23) e Maslach Burnout Inventory - Human Services Survey (MBI-HSS). São Paulo, 2015/2016.

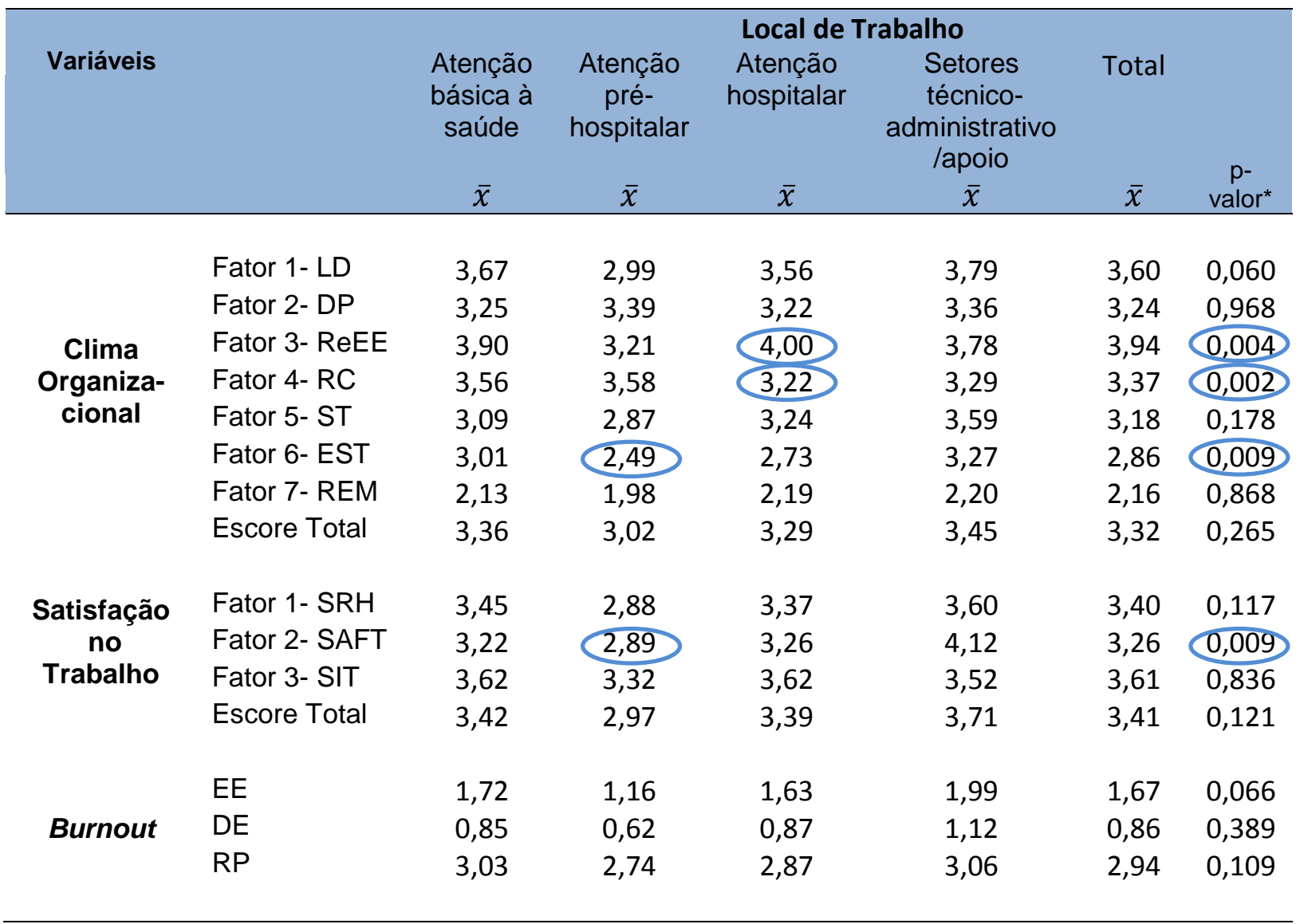

${ }^{*}$ Kruskal-Wallis Test

$\bar{x}$ - média

A Tabela 8 mostra que a variável Local de Trabalho está associada com os Fatores 3-Relação e Espírito de Equipe (ReEE) ( $p=0,004)$, 4-Relação com a Comunidade $(R C)(p=0,002)$ e 6 -Estratégia (EST) $(p=0,009)$ da ECOOS, bem como com o Fator 2-Satisfação com Ambiente Físico no Trabalho (SAFT) $(p=0,009)$ do S20/S23: os trabalhadores de enfermagem da atenção hospitalar atribuíram maiores pontuações para relacionamento e espírito de equipe $(\bar{x}=4,00)$ e menores pontuações para a relação com a comunidade $(\bar{x}=3,22)$; os trabalhadores da atenção pré-hospitalar obtiveram as menores pontuações para estratégia $(\bar{x}=2,49)$, correspondente aos componentes do planejamento estratégico da organização, assim como pontuaram os menores índices de satisfação com ambiente físico de trabalho $(\bar{x}=2,89)$, se referindo a base onde aguardam os chamados. 
Tabela 9 - Análise das correlações entre a variável categórica Cargo e as dimensões da Escala de Clima Organizacional para Organizações de Saúde (ECOOS), Questionário de Satisfação no Trabalho (S20/S23) e Maslach Burnout Inventory - Human Services Survey (MBI-HSS). São Paulo, 2015/2016.

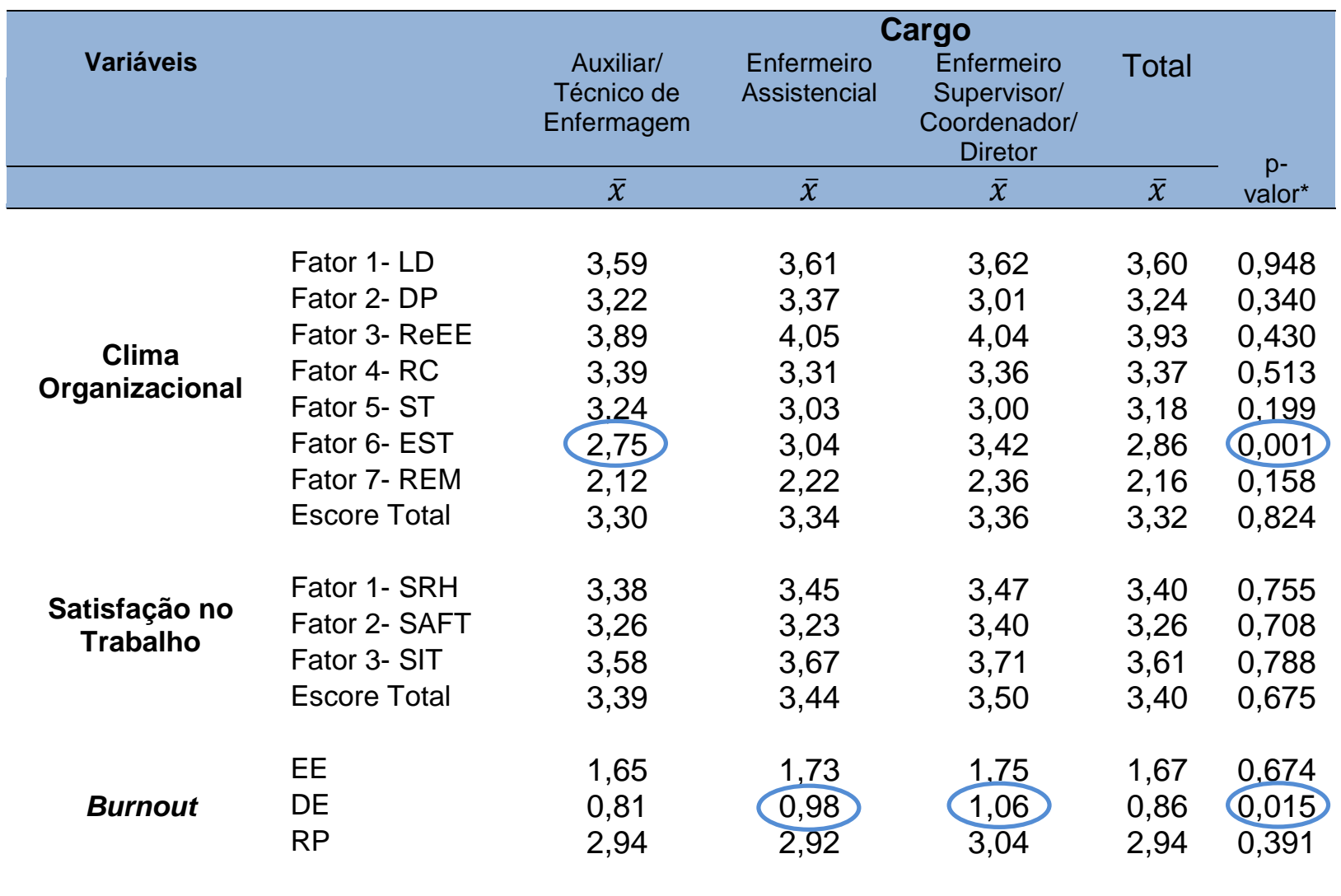

${ }^{*}$ Kruskal-Wallis Test $\bar{x}$ - média

Na Tabela 9 observa-se que a variável ocupacional Cargo está associada ao Fator 6-Estratégia $(E S T)(p=0,001)$ da ECOOS e a Despersonalização (DE) $(p=0,015)$ do MBI-HSS. Os auxiliares/técnicos de enfermagem pontuaram as menores médias para estratégia $(\bar{x}=2,75)$ e os enfermeiros supervisor/coordenador/diretor as maiores médias para despersonalização $(\bar{x}=1,06)$. 
Tabela 10 - Análise das correlações entre a variável categórica Regime de Trabalho e as dimensões da Escala de Clima Organizacional para Organizações de Saúde (ECOOS), Questionário de Satisfação no Trabalho (S20/S23) e Maslach Burnout Inventory - Human Services Survey (MBI-HSS). São Paulo, 2015/2016.

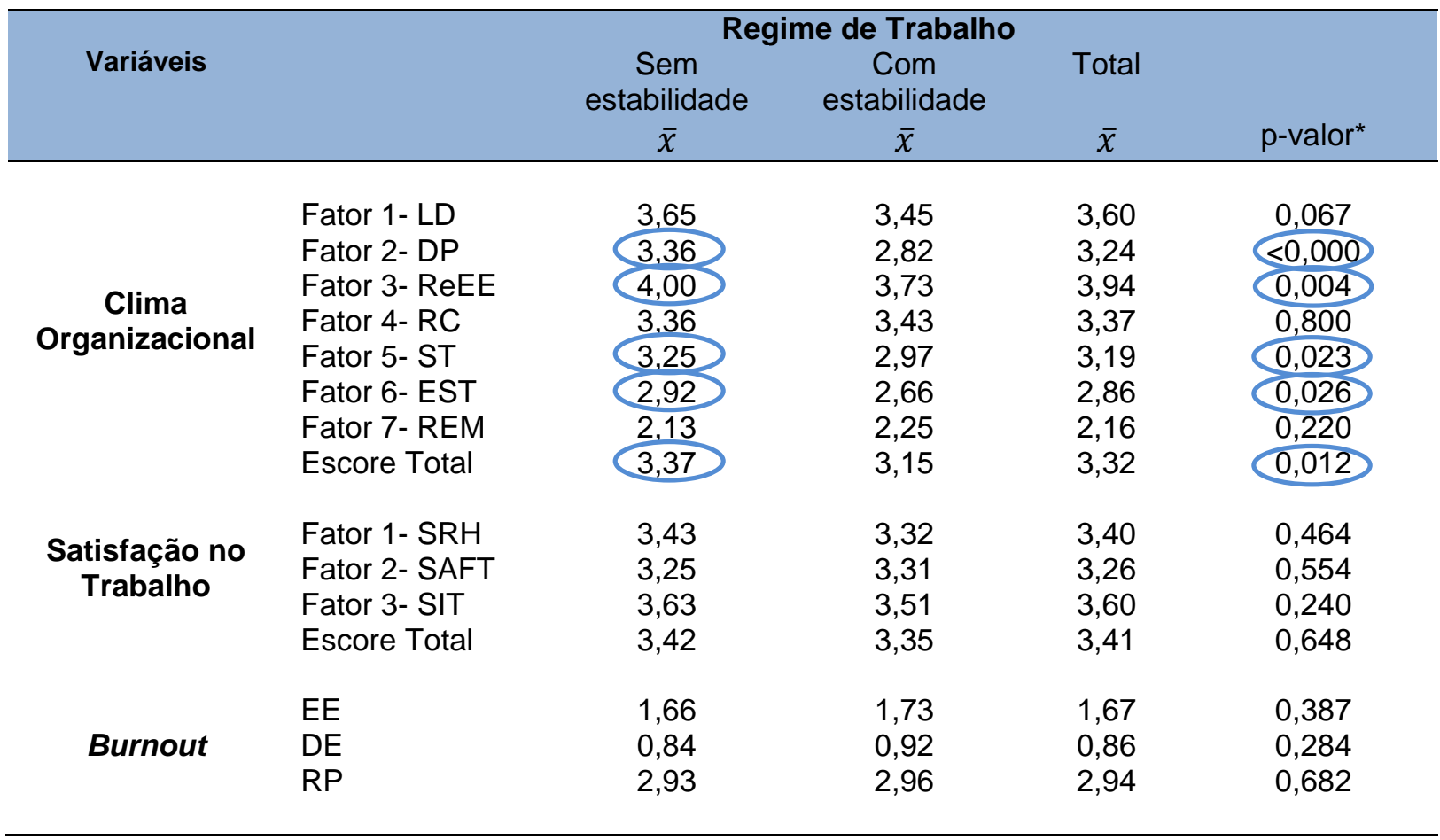

*Mann-Whitney Test

$\bar{x}$ - média

Verifica-se na Tabela 10 que a variável Regime de Trabalho está associada com o Escore Total de Clima Organizacional ( $p=0,012)$, assim como, com os Fatores 2- Desenvolvimento Profissional (DP) ( $p=<0,001)$, 3-Relacionamento e Espírito de Equipe (ReEE) ( $p=0,004), 5$ - Segurança no Trabalho (ST) $(p=0,023)$ e 6Estratégia $(E S T)(p=0,026)$ deste construto: os trabalhadores de enfermagem sem estabilidade, ou seja em regime de trabalho CLT (Consolidação das Leis Trabalhistas) atribuiram maiores pontuações para clima organizacional $(\bar{x}=3,37)$, desenvolvimento profissional $(\bar{x}=3,36)$, relacionamento e espírito de equipe $(\bar{x}=4,00)$, segurança no trabalho $(\bar{x}=3,25)$ e estratégia $(\bar{x}=2,92)$, quando comparados aos trabalhadores que possuem estabilidade no emprego.

Verificou-se, na análise das correlações, que não há evidência estatística para dizer que o Número de Empregos está correlacionado com as dimensões da ECOOS, S20/S23 e MBI-HSS. 


\subsubsection{Análise das correlações entre as variáveis quantitativas contínuas sociodemográficas e ocupacionais e Clima Organizacional, Satisfação no Trabalho e Burnout}

Não se encontrou evidência estatística ao analisar as correlações entre as variáveis quantitativas sociodemográficas e ocupacionais (idade, número de filhos, renda pessoal e familiar, tempo de formação profissional, tempo de atuação no local de trabalho e número de horas trabalhadas por semana) com os Escores Total da Escala de Clima Organizacional para Organizações de Saúde (ECOOS) e Questionário de Satisfação no Trabalho (S20/S23), assim como com as dimensões da Escala de Clima Organizacional para Organizações de Saúde (ECOOS), Escala de Satisfação no Trabalho (S20/S23) e Maslach Burnout Inventory - Human Services Survey (MBI-HSS).

\subsection{ESTRATÉGIAS PARA PROMOÇÃO DO CLIMA ORGANIZACIONAL FAVORÁVEL E DA SATISFAÇÃO NO TRABALHO.}

Dentre os 534 trabalhadores de enfermagem que participaram deste estudo, 284 sugeriram estratégias para promoção do Clima Organizacional favorável e da Satisfação no Trabalho. Essas sugestões foram analisadas quantitativamente, e estão apresentadas no Quadro 1 e no Gráfico 4. 


\section{Quadro 1- Estratégias sugeridas pelos trabalhadores de enfermagem para promoção do Clima Organizacional favorável e da Satisfação no Trabalho. São Paulo, 2015/2016.}

\begin{tabular}{|c|c|c|c|c|}
\hline & & & & \\
\hline Categorias & Subcategorias & Itens & $\mathbf{n}$ & $\%$ \\
\hline \multirow{22}{*}{$\begin{array}{l}\text { Políticas de } \\
\text { Recursos } \\
\text { Humanos } \\
417 \\
63,09 \%\end{array}$} & \multirow{6}{*}{$\begin{array}{c}\text { Remuneração e } \\
\text { Benefícios } \\
140 \\
21,18 \%\end{array}$} & Melhorar o salário & 87 & 13,16 \\
\hline & & $\begin{array}{l}\text { Implementar plano de cargos e carreira e } \\
\text { bonificações }\end{array}$ & 28 & 4,24 \\
\hline & & $\begin{array}{l}\text { Equiparar o salário de estatutários e } \\
\text { celetistas }\end{array}$ & 9 & 1,36 \\
\hline & & Melhorar vale alimentação/cesta básica & 8 & 1,21 \\
\hline & & Oferecer plano de saúde/odontológico & 7 & 1,06 \\
\hline & & Pagar horas-extras & 1 & 0,15 \\
\hline & \multirow{4}{*}{$\begin{array}{c}\text { Gestão de } \\
\text { Conflitos// } \\
\text { Comunicação } \\
124 \\
18,76 \%\end{array}$} & $\begin{array}{l}\text { Melhorar a comunicação entre gestores e } \\
\text { servidores (realização de reuniões, } \\
\text { espaço para escuta dos trabalhadores, } \\
\text { chefia mais próxima dos trabalhadores, } \\
\text { feedback positivo ou negativo) }\end{array}$ & 44 & 6,66 \\
\hline & & $\begin{array}{l}\text { Fortalecer o trabalho da equipe } \\
\text { multidisciplinar (respeito, união, } \\
\text { colaboração, mesmos objetivos, } \\
\text { comunicação efetiva) }\end{array}$ & 37 & 5,60 \\
\hline & & $\begin{array}{l}\text { Fortalecer o trabalho da equipe de } \\
\text { enfermagem (cooperação, união, respeito } \\
\text { mútuo, independente do tipo de vínculo) }\end{array}$ & 24 & 3,63 \\
\hline & & $\begin{array}{l}\text { Incentivar/fortalecer o respeito mútuo } \\
\text { entre servidores e chefia (ética } \\
\text { profissional; não ser repreendido na } \\
\text { frente dos outros funcionários) }\end{array}$ & 19 & 2,87 \\
\hline & \multirow[b]{2}{*}{$\begin{array}{c}\text { Treinamento e } \\
\text { Desenvolvimento } \\
76 \\
11,50 \%\end{array}$} & Investir em treinamentos/aprimoramentos & 72 & 10,89 \\
\hline & & $\begin{array}{l}\text { Incentivar o estudo e qualificação } \\
\text { profissional (apoio aos estudantes, } \\
\text { liberação para realização de estágios, } \\
\text { bolsa para cursos e pós graduação) }\end{array}$ & 4 & 0,61 \\
\hline & \multirow{5}{*}{$\begin{array}{c}\text { Reconhecimento } \\
\text { Profissional } \\
64 \\
9,68 \%\end{array}$} & Valorizar os profissionais/ fazer elogios & 43 & 6,51 \\
\hline & & $\begin{array}{l}\text { Motivar/incentivar para melhorar o } \\
\text { desempenho }\end{array}$ & 11 & 1,66 \\
\hline & & Reconhecimento da população & 4 & 0,61 \\
\hline & & $\begin{array}{l}\text { Oferecer oportunidades de lazer para } \\
\text { trabalhadores e familiares/ Realizar } \\
\text { confraternizações, fornecer brindes em } \\
\text { datas comemorativas. }\end{array}$ & 4 & 0,61 \\
\hline & & $\begin{array}{l}\text { Oferecer oportunidade de } \\
\text { promoção/processo seletivo interno para } \\
\text { enfermeiro }\end{array}$ & 2 & 0,30 \\
\hline & \multirow{4}{*}{$\begin{array}{c}\text { Avaliação } \\
9 \\
1,36 \%\end{array}$} & $\begin{array}{l}\text { Avaliar de forma qualitativa e quantitativa } \\
\text { o trabalho executado pelos servidores. }\end{array}$ & 4 & 0,61 \\
\hline & & $\begin{array}{l}\text { Cobrar quanto ao cumprimento das } \\
\text { atribuições dos trabalhadores }\end{array}$ & 3 & 0,45 \\
\hline & & $\begin{array}{l}\text { Realizar avaliações periódicas dos } \\
\text { servidores }\end{array}$ & 1 & 0,15 \\
\hline & & $\begin{array}{l}\text { Implementar indicadores de qualidade do } \\
\text { trabalho }\end{array}$ & 1 & 0,15 \\
\hline & $\begin{array}{c}\text { Seleção de } \\
\text { Pessoal } \\
4 \\
0,61 \%\end{array}$ & $\begin{array}{l}\text { Contratar profissionais qualificados; } \\
\text { melhor seleção de pessoal. }\end{array}$ & 4 & 0,61 \\
\hline
\end{tabular}




\section{Quadro 1- Estratégias sugeridas pelos trabalhadores de enfermagem para promoção do Clima Organizacional favorável e da Satisfação no Trabalho. São Paulo, 2015/2016.}

\begin{tabular}{|c|c|c|c|c|}
\hline & & & & \\
\hline Categorias & Subcategorias & Itens & $\mathbf{n}$ & $\%$ \\
\hline \multirow{10}{*}{$\begin{array}{c}\text { Políticas de Saúde } \\
\text { do Trabalhador } \\
106 \\
16,04 \%\end{array}$} & \multirow{7}{*}{$\begin{array}{l}\text { Condições de } \\
\text { Trabalho } \\
95 \\
14,37 \%\end{array}$} & $\begin{array}{l}\text { Melhorar a estrutura física e adquirir } \\
\text { equipamentos e materiais/insumos de } \\
\text { qualidade. }\end{array}$ & 44 & 6,66 \\
\hline & & Reduzir a jornada de trabalho & 17 & 2,57 \\
\hline & & $\begin{array}{l}\text { Melhorar a divisão de tarefas e } \\
\text { responsabilidades (divisão equitativa, } \\
\text { justa, observando qualidades e } \\
\text { afinidades) }\end{array}$ & 15 & 2,27 \\
\hline & & $\begin{array}{l}\text { Dispor de local para descanso/área de } \\
\text { estar (dormitório, sala com sofás, } \\
\text { revistas, jogos)/ Cozinha-refeitório } \\
\text { adequados }\end{array}$ & 8 & 1,21 \\
\hline & & Investir em segurança no trabalho & 8 & 1,21 \\
\hline & & $\begin{array}{l}\text { Respeitar carga horária/ Cumprir com } \\
\text { contrato de trabalho ( } 2 \text { folgas mensais } \\
\text { para carga horária de } 12 / 36 \mathrm{~h} \text { ) }\end{array}$ & 2 & 0,30 \\
\hline & & Fornecer Uniforme & 1 & 0,15 \\
\hline & \multirow{3}{*}{$\begin{array}{c}\text { Vigilância à } \\
\text { Saúde do } \\
\text { Trabalhador } \\
11 \\
1,66 \%\end{array}$} & $\begin{array}{l}\text { Realizar avaliação periódica do estado } \\
\text { físico e mental dos trabalhadores ( } \\
\text { equipe multidisciplinar) }\end{array}$ & 6 & 0,91 \\
\hline & & $\begin{array}{l}\text { Fornecer suporte psicológico para os } \\
\text { trabalhadores }\end{array}$ & 4 & 0,61 \\
\hline & & $\begin{array}{l}\text { Fornecer Serviço de Fisioterapia para os } \\
\text { trabalhadores }\end{array}$ & 1 & 0,15 \\
\hline \multirow{5}{*}{$\begin{array}{c}\text { Instrumentalização } \\
\text { para Gestão } \\
\text { Participativa } \\
84 \\
12,71 \%\end{array}$} & \multirow{3}{*}{$\begin{array}{c}\text { Gestão } \\
\text { Compartilhada } \\
79 \\
11,95 \%\end{array}$} & $\begin{array}{l}\text { Tratar os servidores com igualdade e } \\
\text { justiça; abolir o favoritismo político. }\end{array}$ & 36 & 5,45 \\
\hline & & 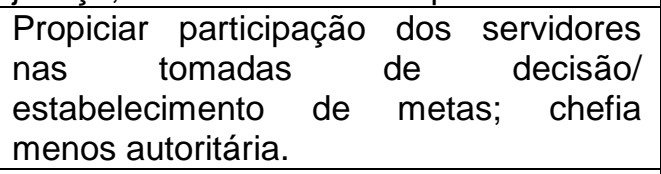 & 27 & 4,08 \\
\hline & & Humanização para com o servidor & 16 & 2,42 \\
\hline & \multirow{2}{*}{$\begin{array}{c}\text { Liderança } \\
5 \\
0,76 \%\end{array}$} & $\begin{array}{l}\text { Capacitação da Liderança (liderança } \\
\text { ativa e capacitada) }\end{array}$ & 4 & 0,61 \\
\hline & & $\begin{array}{l}\text { Fornecer autonomia e respaldo } \\
\text { administrativo para liderança (maior } \\
\text { poder de resolutividade). }\end{array}$ & 1 & 0,15 \\
\hline \multirow{4}{*}{$\begin{array}{c}\text { Planejamento } \\
29 \\
4,39 \%\end{array}$} & \multirow{4}{*}{$\begin{array}{l}\text { Organização do } \\
\text { Trabalho } \\
29 \\
4,39 \%\end{array}$} & $\begin{array}{l}\text { Padronizar de fluxos, protocolos clínicos } \\
\text { de atendimento, escalas de gerentes e } \\
\text { servidores }\end{array}$ & 16 & 2,42 \\
\hline & & Melhorar gerenciamento do bem público & 6 & 0,91 \\
\hline & & $\begin{array}{l}\text { Clareza na estrutura organizacional e } \\
\text { das funções de cada servidor }\end{array}$ & 4 & 0,61 \\
\hline & & Maior investimento financeiro em saúde & 3 & 0,45 \\
\hline \multirow{4}{*}{$\begin{array}{l}\text { Outros } \\
25 \\
3,78 \%\end{array}$} & \multicolumn{2}{|c|}{$\begin{array}{l}\text { Valorização dos pacientes, humanização do cuidado, } \\
\text { atendimento ético (equidade no atendimento, qualidade da } \\
\text { assistência). }\end{array}$} & 14 & 2,12 \\
\hline & \multicolumn{2}{|c|}{ Servidores proativos e comprometidos } & 8 & 1,21 \\
\hline & \multicolumn{2}{|c|}{ Informar a população sobre o papel de cada serviço de saúde } & 2 & 0,30 \\
\hline & \multirow{2}{*}{\multicolumn{2}{|c|}{$\begin{array}{c}\text { Conhecimento de direitos e deveres dos trabalhadores } \\
\text { Total Geral }\end{array}$}} & 1 & 0,15 \\
\hline & & & 661 & 100,00 \\
\hline
\end{tabular}




\section{Gráfico 4 - Distribuição das estratégias sugeridas pelos trabalhadores de enfermagem para promoção do Clima Organizacional favorável e da Satisfação no Trabalho, segundo as categorias. São Paulo, 2015/2016.}

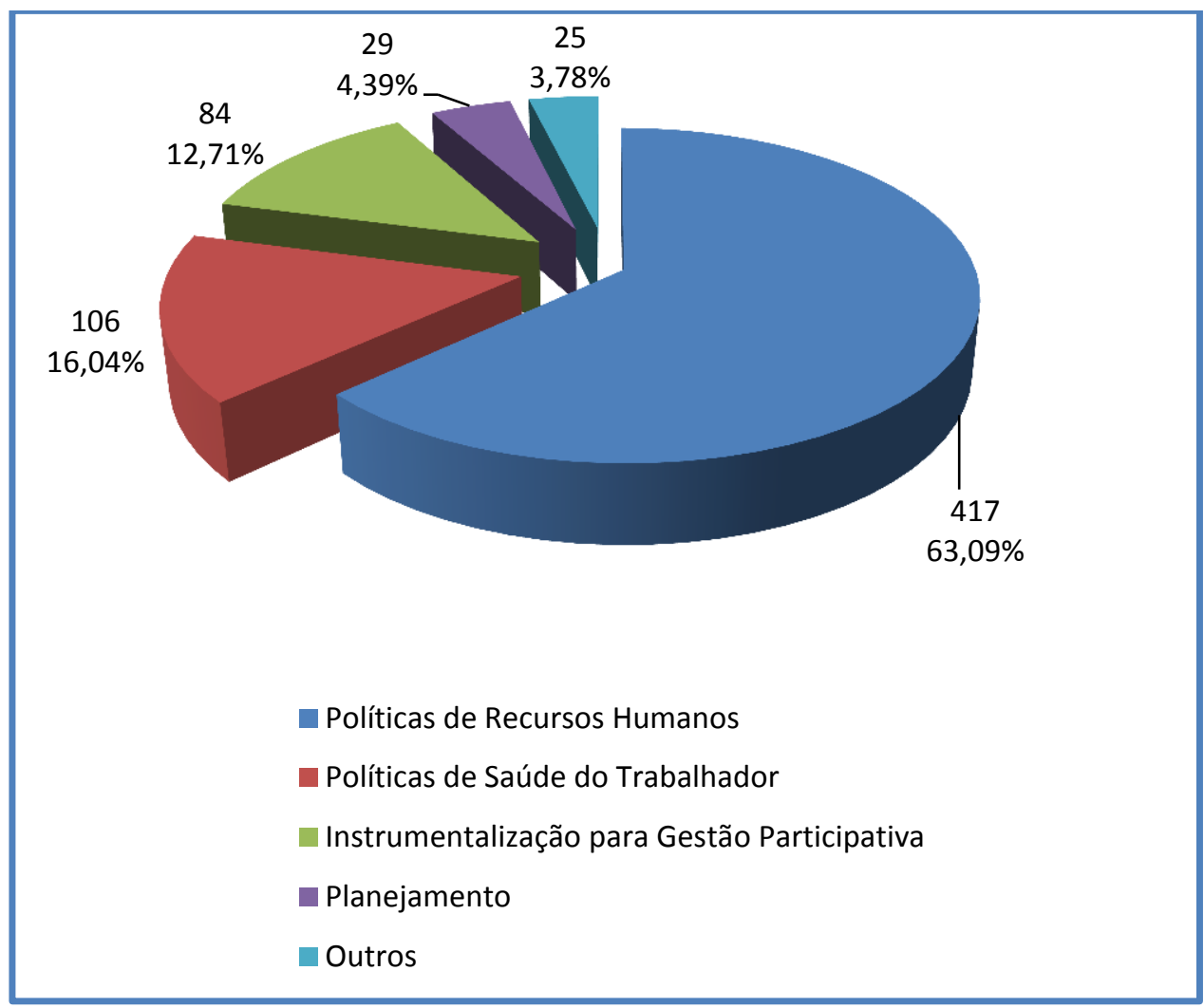

Das Estratégias Propostas para melhoria do Clima Organizacional e da Satisfação no Trabalho, emergiram 5 categorias principais e 11 subcategorias, conforme disposto no Quadro 1.

No Gráfico 4 é possível verificar que nas categorias principais, as sujestões para promoção do Clima Organizacional e da Satisfação no Trabalho estão relacionadas principalmente ao investimento em Políticas de Recursos Humanos (63,09\%), Políticas de Saúde do Trabalhador (16,04\%) e Instrumentalização para Gestão Participativa (12,71\%).

Das Políticas de Recursos Humanos, que abarca mais de 63\% das sugestões para intervenções, destacam-se investimentos em Remuneração e Benefícios (21,18\%), Gestão de Conflitos/Comunicação (18,76\%), Treinamento e Desenvolvimento (11,50\%) e Reconhecimento Profissional (9,68\%) (Quadro 1). 
6 Discussãa 


\section{DISCUSSÃO}

A discussão dos resultados deste estudo está organizada segundo a caracterização sociodemográfica e ocupacional dos trabalhadores de enfermagem, avaliação do clima organizacional, satisfação no trabalho e burnout, com suas respectivas análises de associações. Após, apresenta-se a discussão relacionada às estratégias propostas pelos participantes do estudo para promoção de um clima organizacional favorável.

Pela caracterização sociodemográfica e ocupacional, foi possível obter o perfil dos trabalhadores de enfermagem participantes deste estudo. A predominância de adultos jovens em plena idade produtiva e do sexo feminino está em conformidade com outros estudos realizados no cenário nacional e internacional.

Estudo realizado com 33.659 enfermeiros de 488 hospitais localizados na Bélgica, Inglaterra, Finlândia, Alemanha, Grécia, Irlanda, Holanda, Noruega, Polônia, Espanha, Suécia e Suíça, encontrou a variação de idade média entre 35 e 42 anos e da presença feminina de $89 \%$ a $93 \%$, exceto pela Polônia e Finlândia, que apresentaram porcentagens de enfermeiros do sexo masculino, inferior a 5\% (Aiken, Sloane, Bruyneel, Heede, Sermeus, 2013).

Em Portugal, investigação com 1.157 trabalhadores de enfermagem de quatro hospitais de Porto, verificou que $78 \%$ dos participantes eram mulheres, sendo a idade média de 34,7 anos (Queiros et al., 2013). No mesmo país, estudo com 307 enfermeiros de hospitais públicos e centros de saúde do litoral norte, também encontrou resultados similares (Pereira et al., 2014).

No Brasil, inquérito nacional com trabalhadores de enfermagem identificou que se trata de uma força de trabalho jovem (61,7\% com idade até 40 anos) e hegemonicamente feminina (85,1\%), porém com tendência a masculinização, devido ao aumento do número de trabalhadores do sexo masculino nas últimas décadas (Machado ${ }^{a}$ et al., 2015). 
A evidência da participação da mulher no contexto familiar, também como provedora financeira é demonstrada pelo fato da maioria ser responsável ou participar ativamente do sustento da família. Vale ressaltar que mais da metade informou união conjugal estável e possuir filhos, resultados esses semelhantes a outros estudos (Portero de La Cruz, Vaquero Abellan, 2015; Pereira et al., 2014; Queiros et al., 2013).

Dados do Conselho Federal de Enfermagem (Brasil) de agosto de 2017 apontam que dos 1.990.101 trabalhadores de enfermagem registrados, $76,1 \%$ são auxiliares ou técnicos de enfermagem (COFEN, 2017). Neste estudo verificaram-se percentuais semelhantes, visto que $72,28 \%$ ocupavam o cargo de auxiliares/técnicos de enfermagem, $21,35 \%$ de enfermeiros assistenciais e 5,81\% enfermeiros supervisores/coordenadores/diretores.

Apesar da predominância do ensino médio/técnico (47,37\%), escolaridade mínima exigida para o técnico de enfermagem, é possível verificar crescente escolarização e busca por aprimoramento na qualificação dos participantes do estudo, visto que o nível superior é exigência apenas para os cargos de enfermeiros assistenciais e supervisores/coordenadores/diretores. Encontrou-se que 15,92\% estavam cursando o ensino superior, sendo a maior parte, graduação em enfermagem e, 33,71\% possuíam ensino superior completo ou pós-graduação. Assim, mesmo exercendo cargos de auxiliares/técnicos de enfermagem, muitos possuem escolaridade acima da exigida para o cargo, pois estão cursando ou já possuem graduação em enfermagem, buscando ascensão na carreira de enfermagem e/ou melhor remuneração.

No cenário investigado, muitos trabalhadores de enfermagem além de trabalhar, estudam, são mulheres, com união estável e filhos, tendo que conciliar o trabalho, o estudo e as atividades de vida familiar e domestica, configurando uma dupla ou até mesmo tripla jornada de trabalho.

Outros estudos brasileiros também apontam para a superqualificação da força de trabalho em enfermagem. Estudo recente com 114 trabalhadores de enfermagem de Unidades de Terapia Intensiva de um hospital do interior de São Paulo, encontrou que dos 73 técnicos de enfermagem, 37\% possuíam graduação 
em enfermagem (Guirardello, 2017). Em outra instituição hospitalar da capital de São Paulo também foi verificado excelente nível de qualificação profissional de técnicos de enfermagem, visto que dos 379 trabalhadores de enfermagem, 63,6\% possuíam ensino superior completo, sendo que destes, apenas $36,9 \%$ possuíam cargo de enfermeiros (Silva, 2016).

Pesquisa nacional promovida pelo Conselho Federal de Enfermagem, sobre o perfil da enfermagem brasileira, identificou que $34,3 \%$ dos auxiliares/técnicos de enfermagem possuem ou estão cursando graduação, sendo que a maior parte pretende continuar na área da enfermagem. Ainda destaca que $31,4 \%$ dos enfermeiros atuantes, fizeram curso de auxiliar/técnico de enfermagem antes da graduação (Machado et al., 2016).

No Brasil, a partir de 2001, atrelado a ampliação do acesso ao nível superior, houve um aumento desordenado do número de cursos e vagas de graduação em enfermagem. Em 2001, existiam 207 cursos superiores de enfermagem com 6.177 concluintes; em 2011 o número de cursos já havia passado para 826 e o número de concluintes 47.114 (Teixeira et al., 2013). Dados recentes o Censo da Educação Superior de 2016, revelam que a partir de 2011 houve um decréscimo no número de concluintes, tendo em 2016 se formado 35.195 novos enfermeiros. Apesar disto, o número de ingressantes aumentou de 76.391 em 2012 para 98.617 em 2016, indicando um possível aumento de concluintes nos próximos anos. A enfermagem é o 6ํㅜ curso superior com maior número de ingressantes e $7^{\circ}$ com maior número de concluintes no Brasil (Brasil, Ministério da Educação, 2017).

Assim, apesar do incremento dos postos de trabalho para enfermagem nas últimas décadas pela expansão da Atenção Básica à Saúde por meio da Estratégia Saúde da Família, este ainda é desproporcional ao número de egressos dos cursos de enfermagem, ou seja, a oferta de profissionais no mercado é maior que a demanda. Tal fato traz consequências para categoria profissional, como precarização do trabalho pelo aumento do número de vínculos informais e diminuição da média salarial, visto que muitos trabalhadores, principalmente os recém-formados, se veem obrigados a aceitar condições de trabalho e salários precários (Barros Neto et. al., 2014). Ademais, o medo do desemprego e a crise econômica atual contribuem para a superqualificação do trabalhador, manutenção 
dos baixos salários e condições de trabalho adversas. Pesquisa nacional com trabalhadores de enfermagem identificou que 4,5\% estavam desempregados e $10,1 \%$ havia experimentado o desemprego nos últimos 12 meses, sendo o percentual em enfermeiros (12,4\%) maior do que em auxiliares/técnicos de enfermagem $(9,4 \%)$. Os enfermeiros $(79 \%)$ também relataram maior dificuldade de arrumar emprego do que os auxiliares/técnicos (62\%) de enfermagem (Machado ${ }^{\mathrm{b}}$ et al., 2015).

Contudo, muitos que concluíram a graduação e estão empregados como auxiliares/técnicos de enfermagem, ainda mantêm-se nesses cargos, por dificuldade de conseguir emprego como enfermeiros ou com salários que sejam convidativos à mudança. Vale ressaltar que na região onde este estudo foi desenvolvido não havia cursos de graduação em enfermagem antes de 2008. Atualmente, existem duas instituições de ensino superior particular que ofertam o curso, tendo a primeira turma se formado em 2011, o que contribui também para o aumento da qualificação em enfermagem na região.

O tempo médio de formação profissional no cargo em que atua foi de 10,29 anos $(\mathrm{dp}=7,44)$, similar ao encontrado em outro estudo brasileiro com trabalhadores de enfermagem hospitalar (Guirardello, 2017). No âmbito internacional a média de anos de experiência na profissão apresenta-se superior: na Austrália, estudo com 382 enfermeiros de dois hospitais, identificou média de 14,7 anos de experiência em enfermagem (Perry et al., 2015); na Bélgica, investigação com 587 enfermeiros hospitalares verificou tempo médio de experiência de 17 anos (Geuens, Van Bogaert, Franck, 2015) e; na Espanha, a média de experiência profissional encontrada em uma pesquisa com 258 enfermeiros e técnicos de enfermagem foi de 24,26 anos (Portero de La Cruz, Vaquero Abellan, 2015).

A maioria $(92,70 \%)$ dos trabalhadores de enfermagem trabalha em turnos fixos, e apenas $2,62 \%$ declarou turno rotativo, o que geralmente se refere aos profissionais que cobrem as folgas. No entanto vale ressaltar que os trabalhadores diurnos e noturnos com 12 horas diárias (9,36\% e 11,61\% respectivamente), trabalham em plantões alternados, numa escala de 12/36 horas. 
Sabe-se que a jornada de trabalho é foco de reivindicação dos trabalhadores de enfermagem brasileiros, que almejam aprovação do Projeto de Lei no 2.295 de 2000 que fixa a jornada de trabalho em 6 horas diárias e 30 horas semanais no âmbito nacional (Brasil ${ }^{\mathrm{a}}$, Câmara dos Deputados, 2017). Na prática, vigora a livre negociação, variando de 30 horas, para servidores públicos municipais e estaduais (por meio de leis municipais e estaduais), à 40/44 horas semanais, para os trabalhadores do regime CLT. O estudo sobre o perfil da enfermagem no Brasil apontou que $34,7 \%$ possuem jornada de trabalho entre 31 e 40 horas e $38,6 \%$ acima de 41 horas semanais (Machado ${ }^{b}$ et. al., 2015).

Neste estudo, a média da jornada de trabalho semanal, foi de 39,74 horas, variando de 30 a 84 horas, valores superiores ao encontrado em estudo português e espanhol. Em Portugal, estudo com 307 enfermeiros de hospitais públicos e centros de saúde encontrou que $91 \%$ trabalhavam 35 horas semanais (Pereira et.al., 2014) e na Espanha a média de horas semanais trabalhadas por enfermeiros e técnicos de enfermagem foi de 36,18 horas (Portero de La Cruz, Vaquero Abellan, 2015).

Quanto à quantidade de vínculo empregatício, 13,67\% declararam possuir dois vínculos e $0,56 \%$, três vínculos, percentuais estes inferiores aos encontrados no cenário nacional, onde $25,1 \%$ declarou possuir dois empregos (Machado ${ }^{b}$ et al., 2015). É possível inferir que mesmo almejando possuir mais de um vínculo empregatício, com objetivo de aumentar a renda pessoal, a empregabilidade no mercado de trabalho da enfermagem atual não facilita tal ação.

Somado a baixa oferta de emprego, o trabalho desgastante na enfermagem e a necessidade da jornada de trabalho destinada às tarefas do lar, também são um impeditivo para que esses trabalhadores, em sua maioria, mulheres, mantenham mais de um vínculo empregatício.

Ao analisar o Clima Organizacional pela média total dos escores $(\bar{x}=3,32)$, considerando a escala de 1 a 5 , verificou-se que os trabalhadores de enfermagem consideram o clima organizacional como regular. Considerando a avaliação de cada fator que compõe a escala, identificou-se que a Remuneração e a Estratégia são os nós críticos do Clima Organizacional nas instituições onde a 
pesquisa foi realizada, por receberem as menores pontuações. Já os fatores Relacionamento e Espírito de Equipe $(\bar{x}=3,93)$ e Liderança $(\bar{x}=3,60)$ destacaram-se com as médias mais elevadas, mostrando ser o ponto forte para elevação da média do Clima Organizacional nas instituições investigadas.

A Remuneração foi o fator com menor média $(\bar{x}=2,16)$, demonstrando a insatisfação dos trabalhadores com esse quesito. $\mathrm{Na}$ análise dos itens que integram este fator verifica-se que os trabalhadores de enfermagem não consideram as politicas de remuneração da instituição a que pertencem como justas e motivadores (questão 63- $\bar{x}=2,03$ ), assim como não consideram que a remuneração está de acordo com as responsabilidades do trabalho que realizam (questão $60-\bar{x}=2,13$ ), atribuindo à satisfação geral com a remuneração pontuação baixa (questão 62$\bar{x}=2,32)$. Na associação com as características sociodemográficas e ocupacionais, a Remuneração obteve resultado significativo apenas com o Sexo, onde as mulheres atribuíram menores pontuações a esse quesito do que os homens. No entanto, a remuneração praticada na região é a mesma para homens e mulheres.

Apesar da média da renda líquida pessoal mensal declarada ser de $R \$$ 2.136,72 (DP 1.283,00), verificou-se renda mínima de $R \$ 600,00$, inferior ao salário mínimo (SM) vigente na época, que era de $\mathrm{R} \$ 880,00$, demonstrando o baixo salário praticado no mercado para os trabalhadores de enfermagem da região onde o estudo foi desenvolvido. A variabilidade da renda pessoal também está associada ao cargo na instituição. Auxiliares/técnicos de enfermagem geralmente possuem salários inferiores ao de enfermeiros assistenciais ou daqueles com cargos de gestão. Na região, na época da coleta de dados, a média salarial do auxiliar/técnico de enfermagem era de 1200,00 reais $(1,36$ SM) e do enfermeiro assistencial de 2600,00 reais $(2,95$ SM), com variações entre municípios e instituições.

Tanto no âmbito nacional como no internacional o descontentamento com a remuneração é problema evidenciado nos estudos. Pesquisa multicêntrica realizada com 33.659 enfermeiros médicos-cirúrgicos em 12 países europeus encontrou que mais de uma em cada cinco enfermeiras (11-56\%) estavam insatisfeitas com seus empregos na maioria dos países e a insatisfação foi pronunciada em relação aos salários, oportunidades educacionais e de promoção (Aiken et al., 2013). Estudo brasileiro com técnicos de enfermagem evidenciou 
baixos níveis de satisfação com as condições de trabalho, destacando a remuneração (Vieira, Santos, Mesquita, 2015).

No decorrer dos anos, observa-se uma queda dos salários dos enfermeiros no cenário nacional. Varella (2006), em pesquisa sobre o mercado de trabalho do enfermeiro no Brasil afirma que em 1995 a média salarial era de aproximadamente 7,7 salários mínimos, passando em 2005 para 4,3 salários mínimos.

Atualmente o Projeto de Lei 459 de 2015, que prevê um piso salarial nacional para os enfermeiros de $R \$ 7.880,00$ reais, com $50 \%$ deste valor para técnicos de enfermagem e $40 \%$ para auxiliares de enfermagem aguarda parecer para votação na Câmara Federal dos Deputados (Brasil ${ }^{\mathrm{b}}$, Câmara dos Deputados, 2017). No entanto esta é uma luta antiga da enfermagem que perdura mais de quarenta anos, quando diversos projetos de leis encerraram suas legislaturas sem definição favorável à enfermagem, denotando a falta de força política destes trabalhadores.

A falta de um piso salarial nacional, a crise financeira enfrentada pelo país, o receio do desemprego, a falta de estabilidade e o mercado reserva de profissionais de enfermagem contribuem para manutenção dos baixos salários. Associado a esses fatores, no presente estudo, a maior parte possui dependentes financeiros, ressaltando que cerca $70 \%$ dos filhos possuem idade inferior a 18 anos.

No fator Estratégia $(\bar{x}=2,86)$, correspondente aos componentes do planejamento estratégico da instituição, destaca-se a ausência de participação dos trabalhadores de enfermagem no processo de elaboração do planejamento estratégico (questão 56- $\bar{x}=2,40$ ), a falta de um plano de mudanças visando o crescimento e desenvolvimento (questão 58- $\bar{x}=2,78$ ), além da ausência de estímulos para que os servidores participem do processo de mudanças (questão 59$\bar{x}=2,81)$.

Destarte que a Estratégia, foi o fator que apresentou associação com o maior número de variáveis ocupacionais: local de trabalho, regime de trabalho, e cargo. Os trabalhadores de enfermagem que atuam na atenção pré-hospitalar, os 
auxiliares/técnicos de enfermagem e os trabalhadores que possuem estabilidade são os que atribuíram as menores médias para esse fator.

Sabe-se que a gestão participativa, caracterizada por propiciar ao trabalhador participação nos processos decisórios da empresa, possibilita maior comprometimento do trabalhador com os objetivos organizacionais (Peduzzi, 2007). No entanto, no Brasil, na maior parte das organizações de saúde, "observa-se falta de espaços para escuta do trabalhador e inclusão deste no processo de tomada de decisão com maior autonomia e valorização". Por outro lado, são notórias as dificuldades enfrentadas pelos gestores locais, principalmente de serviços públicos, devido à "restrita autonomia na resolução de problemas, como múltiplos vínculos, deficiência de recursos materiais e humanos e financiamento reduzido". Assim, fazse necessária inovação no modelo de gestão abrangendo todas as esferas da organização (Almeida, Baptista, 2016, p.18).

Estudo que avaliou a percepção dos trabalhadores de um hospital de grande porte da região norte do Brasil, após 5 anos de implantação do processo de gestão participativa, mostrou dentre outros aspectos, corresponsabilidade dos trabalhadores com a gestão, "melhorias no processo de trabalho, efetivação da Política de Educação Permanente, melhoria dos indicadores hospitalares,[...],constituição de colegiados gestores e criação de ouvidoria". Porém ficaram evidenciados entre as dificuldades, o frágil apoio da instância superior (gestão estadual) e a fragmentação da rede de serviços de saúde (Freire et al., 2014, p.34).

Os resultados obtidos com Relacionamento e Espírito de Equipe $(\bar{x}=3,93)$ e Liderança $(\bar{x}=3,60)$ destacaram-se com as médias mais elevadas, mostrando ser o ponto forte para elevação da média do Clima Organizacional, o que denota o bom nível de cooperação, apoio, confiança, qualidade do relacionamento, liberdade de expressão entre os membros da equipe com permuta de informações e possibilidade de aprendizagem, além da capacidade da liderança quanto à competência de influenciar as atitudes, crenças, comportamentos e sentimentos dos liderados, assim como, o grau de feedback e orientação fornecido a estes, sobre seu desempenho e assuntos de seu interesse. 
Quanto ao Relacionamento e Espírito de Equipe é possível observar que os trabalhadores da atenção hopitalar foram que os atribuíram maiores pontuações, seguidos dos da atenção básica, tendo os trabalhadores da atenção pré-hospitalar pontuado a menor média.

Os resultados positivos em relação à Liderança estão em consonância com pesquisa de clima organizacional realizada com 9.590 trabalhadores, sendo 847 auxiliares/técnicos de enfermagem e 859 enfermeiros de 187 unidades de atenção básica à saúde da cidade do Rio de Janeiro (Santos, Paranhos, 2017). De forma semelhante, estudo com 93 técnicos de enfermagem hospitalares em Minas Gerais, encontrou elevado nível satisfação com os relacionamentos no ambiente de trabalho (Vieira, Santos e Mesquita, 2015).

A literatura aponta que o relacionamento positivo com a chefia e equipe de trabalho interfere no comprometimento e motivação para desenvolvimento das atividades laborais, trazendo benefícios para o trabalhador e para a instituição, pelo compartilhamento de informações e recursos, além do comprometimento mútuo na realização das atividades do dia a dia (Brunetto et al., 2013).

Ademais, é consenso que o reconhecimento e valorização no trabalho estão relacionados à satisfação no trabalho, e quando não ocorrem, pode resultar em sofrimento, com consequências para a saúde do trabalhador e para a qualidade do trabalho realizado (Morais et al., 2014; Hanzelman, Pasos, 2010; Prestes et al., 2010; Fernandez Larraguibel, Paravic Klinjn, 2003; Dejours, 2000).

Em relação a Segurança no Trabalho, os trabalhadores de enfermagem que possuem graduação e pós-graduação foram os que atribuiram os menores escores, inferindo que o grau de escolaridade e consequentemente o maior conhecimento sobre aspectos da segurança do trabalhador levaram a esse desfecho, demonstrando a fragilidade da gestão da segurança no cenário organizacional.

A respeito da Segurança no Trabalho, a literatura aponta que para obtenção de sucesso, o compromisso e as estratégias de segurança devem partir da organização e envolver aspectos gerenciais e individuais. A percepção dos trabalhadores e gestores sobre a segurança laboral reflete o clima de segurança na 
instituição; este está relacionado às politicas organizacionais, às decisões gerenciais, à instituição de programas de segurança, colaborando para maior adesão e compromisso por parte dos trabalhadores às normas de segurança, e consequentemente, refletindo no número de acidentes de trabalho (Porto, Marziale, 2016; Zavareze, Cruz, 2010; Smith et al., 2006; Gershon et al., 2000).

A Relação com a Comunidade foi avaliada de forma pior pelos trabalhadores da atenção hospitalar, e melhor pelos trabalhadores da atenção básica. Neste fator a questão com menor pontuação se refere a informação adequada à população pela instituição sobre os seus projetos, investimentos e realizações (questão $41-\bar{x}=2,97$ ) e sobre a percepção da satisfação da população em relação à qualidade dos serviços oferecidos pela instituição (questão 43$\bar{x}=3,19)$.

Na atenção básica à saúde, geralmente o enfermeiro é referência para a comunidade, que quando necessita o procuram para resolução de problemas, seguindo suas orientações e participando de atividades propostas. No entanto, a população muitas vezes desconhece o real papel do enfermeiro, confundindo sua função com a de outros profissionais (Beck et al., 2009), o que gera desconforto e necessidade de afirmação profissional.

$\mathrm{Na}$ verdade, a histórica divisão social do trabalho em enfermagem que perpetuou-se no Brasil, impõe aos trabalhadores de enfermagem essa dicotomia entre o delegar e executar, entre o que possui maior ou menor complexidade, e nesse contexto, estão os profissionais de nível médio e os profissionais de nível superior, misturando-se por vezes, em funções e papéis, dificultando sobremaneira o reconhecimento por parte dos usuários.

Nos serviços de saúde o marketing pode ser utilizado de forma inovadora como uma ferramenta de gestão. Pode contribuir tanto no âmbito interno como externo, como um meio de melhorar a reputação, pela comunicação realizada de forma imparcial e que inspire confiança (Ribeiro, 2004). O desconhecimento por parte da população sobre a função e atividades desenvolvidas por cada organização de saúde, seja da atenção básica, pré hospitalar ou hospitalar, pode resultar em descontentamento com o serviço, gerando insatisfação com o serviço oferecido. 
Por outro lado, também é importante sinalizar as concepções de saúde construídas pelos usuários ao longo das duas últimas décadas, em que a complexidade tecnológica adquire supremacia sobre o saber, conversar, acolher e orientar.

O escore global de Clima Organizacional, juntamente com outros três fatores que compõe a escala, apresentaram-se também estatiticamente associados com o regime de trabalho. Assim, os trabalhadores de enfermagem sem estabilidade, ou seja, em regime de trabalho CLT (Consolidação das Leis Trabalhistas) atribuiram maiores pontuações para Clima Organizacional, Desenvolvimento Profissional, Relacionamento e Espírito de Equipe e Segurança no Trabalho do que os trabalhadores que possuem estabilidade (são concursados).

Uma das dificuldades enfrentadas durante a coleta de dados foi a preocupação por parte dos trabalhadores sobre quem teria acesso aos resultados individuais da pesquisa e que consequencias a mesma poderia trazer para os trabalhadores. Seguiram-se todos os principios éticos para resguardar a identidade de cada sujeito da pesquisa, sendo os dados individuais de acesso apenas da pesquisadora. No entanto, a insegurança do mercado de trabalho e o receio de represália devido ao resultado do estudo pode ter influenciado este aspecto. Os trabalhadores estatutários, por ter estabilidade no emprego se sentem mais seguros para opinar sobre tais aspectos.

Esse dado também assume importância no que se refere aos modelos gerenciais adotados predominantemente na enfermagem, com o estabelecimento de ações mais punitivas do que formativas aos trabalhadores. Condutas punitivas que não reconhecem o trabalhador e não possibilitam que o mesmo se sinta valorizado e parte importante da organização, tendem a comprometer o clima de trabalho.

Cabe ressaltar que estudos em instituições de saúde denotam que o clima organizacional favorável tem se mostrado como um facilitador do desempenho das atividades no trabalho (Cruvinel, 2011) e está correlacionado positivamente com maior compromisso organizacional (Bahrami et al., 2016). 
Ao avaliar a Satisfação no Trabalho, verifica-se pela média geral, que os trabalhadores de enfermagem apresentam níveis médios de satisfação $(\bar{x}=3,40$, em uma escala de 1 a 5 ).

Estudo realizado na Espanha, com 258 enfermeiros e técnicos hospitalares também encontraram níveis médios de satisfação no trabalho (Portero de La Cruz, Vaquero Abellan, 2015), assim como investigação com 1157 enfermeiros de quatro hospitais de Porto (Portugal) (Queirós et al., 2013). De forma semelhante, estudo com 93 técnicos de enfermagem hospitalares no Brasil, encontrou níveis intermediários de satisfação no trabalho (Vieira, Santos e Mesquita, 2015).

$\mathrm{Na}$ análise individual dos fatores da escala separadamente, a Satisfação com o Ambiente Físico de Trabalho recebeu a menor pontuação $(\bar{x}=3,27)$, sendo os principais problemas a climatização do local de trabalho (questão10- $\bar{x}=3,06$ ), 0 ambiente e espaço físico (questão $7-\bar{x}=3,10$ ) e a ventilação do local de trabalho (questão 9- $\bar{x}=3,14$ ).

A Satisfação com Ambiente Físico no Trabalho foi o único fator do Questionário de Satisfação no Trabalho que apresentou significância estatística na correlação com as variáveis ocupacionais. O local de trabalho dos trabalhadores da atenção pré-hospitalar recebeu as menores pontuações, se referindo a base onde aguardavam os chamados para atendimento de urgência/emergência.

Contudo, investir na climatização, ventilação e adequação do espaço físico de trabalho proporcionará aos trabalhadores do cenário investigado melhores índices de satisfação no trabalho. Ressaltando que o local onde o estudo foi realizado é uma região litorânea, com altas temperaturas na maior parte do ano. No entanto, são poucos os locais que possuem um sistema de ar condicionado, e quando existem, são restritos a alguns setores.

No quesito Satisfação com as Relações Hierárquicas $(\bar{x}=3,40)$, os nós críticos são a forma como se processam as negociações sobre a contratação de benefícios (questão 23- $\bar{x}=2,70$ ), o modo como são cumpridos as normas legais e os acordos coletivos (questão 22- $\bar{x}=3,10$ ) e a percepção sobre a igualdade de tratamento e sentido de justiça (questão $17-\bar{x}=3,17$ ). 
À Satisfação Intrínseca no Trabalho $(\bar{x}=3,61)$, foram atribuídas as maiores médias, destacando-se o trabalho enquanto propiciador de realização (questão $1-\bar{x}=$ 3,78 ) e as oportunidades que o trabalho oferece para fazer coisas que gosta (questão 3- $\bar{x}=3,69$ ), possibilitando inferir que mesmo em situações adversas de trabalho, o trabalhador de enfermagem demonstra realização profissional, porque tem apreço pela profissão e gosta do que faz.

Quanto à Síndrome de Burnout, verifica-se uma grande variabilidade na literatura nacional e internacional ao comparar, entre trabalhadores de enfermagem, os níveis de cada dimensão do burnout (Geuens, Van Bogaert, Franck, 2017; Guo et al., 2016; Ríos-Risquez, García-Izquierdo, 2016; Portero de La Cruz, Vaquero Abellan, 2015; Zhang et al., 2014; Gasparino, 2014; Queiros et al., 2013; Poghosyan et al., 2010), talvez por estas estarem relacionadas às particularidades do ambiente laboral, assim como das características pessoais dos sujeitos pesquisados.

Considerando-se que a escala utilizada possui pontuações com variações entre 0 e 4, pelas médias verifica-se que no cenário estudado, os trabalhadores de enfermagem apresentam moderado nível de Exaustão Emocional $(\bar{x}=1,67)$, baixos níveis de Despersonalização $(\bar{x}=0,86)$ e altos níveis de Realização Profissional $(\bar{x}=2,94)$.

A Exaustão Emocional teve suas médias aumentadas por questões como sentir-se esgotado ao término da jornada de trabalho $(\bar{x}=2,57)$ e sentimento de estar trabalhando muito $(\bar{x}=2,16)$. Na Despersonalização, os itens com maiores médias pontuais foram a percepção de estar endurecendo emocionalmente $(\bar{x}=1,17)$ e a culpalização por parte dos pacientes/clientes por problemas pessoais $(\bar{x}=1,15)$.

Assim, observa-se que apesar de níveis baixos de Despersonalização e elevados de Realização Profissional, verificam-se níveis médios de Exaustão Emocional, indicando um fator preventivo importante a ser trabalhado, uma vez que a Exaustão Emocional é considerada o primeiro estágio da Síndrome de Burnout por levar à Despersonalização, podendo interferir na Realização Profissional.

A literatura demonstra que a Exaustão Emocional é resultante da sobrecarga de trabalho e de conflitos no relacionamento interpessoal e relaciona-se à falta de energia para realização das atividades laborais, ao sentimento de estar 
sobrecarregado, fadigado e com esgotamento físico e mental; a Despersonalização é uma forma de enfrentamento da Exaustão Emocional, uma tentativa de se distanciar dos receptores do seu trabalho devido à Exaustão Emocional, o que leva o trabalhador a uma resposta negativa no contexto interpessoal, tratando os receptores do seu trabalho com cinismo ou frieza, como se fossem objetos, como os responsáveis pelos seus problemas e; a reduzida Realização Profissional é resultante de processo de autoavaliação, quando 0 trabalhador sente-se incompetente, fracassado, com baixa autoestima e com baixo desempenho no trabalho (Maslach, Schaufeli, Leiter, 2001).

É importante destacar que a Exaustão Emocional ao comprometer o desempenho no trabalho, pode afetar não apenas a rapidez e eficiência que os procedimentos são executados, mas a concentração e o julgamento dos profissionais para realizar uma série de procedimentos, o que implica na segurança do paciente.

Pesquisa realizada com gerentes de enfermagem do Brasil evidenciou que elas vivenciam angústia e muitos conflitos por perceberem que, em decorrência do desgaste psíquico, muitos trabalhadores têm prejuízo na qualidade do trabalho (Baptista et al., 2015).

Ao associar as características sociodemográficas e ocupacionais com as dimensões do Burnout com o objetivo de verificar se estes aspectos apresentam diferenças estatisticamente significantes verificou-se que a Exaustão Emocional foi maior nos trabalhadores que possuem dependentes que presta cuidados. Pode-se supor que a somatização da sobrecarga de trabalho laboral com as atividades desenvolvidas no lar relacionadas ao cuidado da pessoa dependente, com pouco tempo para descansar, leve a Exaustão Emocional.

Queiros e colaboradores (2013) em estudo realizado com 1157 enfermeiros de Porto, Portugal encontrou dentre os preditores do burnout, a associação da interação entre trabalho-família e exaustão emocional, sugerindo que a partir de um processo cumulativo ao longo do tempo, possa desencadear o burnout. 
Quanto a Despersonalização, os trabalhadores de enfermagem que possuem filhos apresentaram menores índices do que os que não possuem.

A Despersonalização também foi associada ao nível de escolaridade e ao cargo, onde os trabalhadores de enfermagem que possuem graduação e pósgraduação e os enfermeiros supervisor/coordenador/diretor apresentaram maior despersonalização, quando comparados aos demais.

Revisão integrativa sobre depressão e risco de suicídio entre profissionais de enfermagem verificou que os enfermeiros com maior nível educacional são os mais propensos à depressão (Silva et al., 2015).

Em relação ao cargo, resultado análogo foi encontrado em estudo de revisão integrativa onde auxiliares/tecnicos de enfermagem apresentaram níveis relativamente mais altos de burnout (Medeiros-Costa et al., 2017).

Foi possível verificar que aspectos familiares também podem interferir positivamente na Realização Profissional. Maior Realização Profissional foi encontrada em trabalhadores de enfermagem que possuem filhos e nos com união conjugal estável ou divorciado, separado, e viúvos. É possível que não possuir filhos e ser solteiro faça com que o trabalhador concentre todas as suas expectativas no trabalho, fazendo com que se frustre mais facilmente devido à precariedade atual no mundo do trabalho em saúde.

$\mathrm{Na}$ Austrália, estudo com 382 enfermeiros concluiu, dentre outros aspectos, que os trabalhadores com melhor saúde mental eram os que viviam com cônjuge, em vez de sozinhos (Perry et al., 2015). Na literatura, alguns investigadores apontam que possuir uma união estável, se constitui como um fator de proteção ao desgaste emocional, por propiciar uma atitude menos fria no tratamento dos pacientes ou de forma indireta pelo apoio social recebido do parceiro (Molina, Avalos, Giménez, 2005; Albar et al., 2004).

Pelo seu grau de importância e repercussão na saúde do trabalhador e no sucesso organizacional, o adoecimento mental dos trabalhadores de enfermagem tem preocupado a comunidade científica. Revisão integrativa recente sobre depressão e risco de suicídio na enfermagem concluiu que a síndrome de burnout é 
um preditor para risco de suicídio entre os profissionais de enfermagem, estando associada à exaustão emocional, falta de reconhecimento e incentivo profissional, baixa realização pessoal, podendo desencadear sentimentos de incompetência, incapacidade, desânimo, impotência, depressão e ideação suicida (Silva et al., 2015).

Neste estudo, não se encontrou evidência estatística ao correlacionar a idade, o número de filhos, a renda pessoal e familiar, o tempo de formação e atuação no local de trabalho e o número de vínculos empregatícios com as dimensões dos construtos. Embora alguns achados estejam em concordância com estudos anteriormente realizados no âmbito nacional e internacional, outros estão em contradição.

Sá, Martins e Funchal (2014), em investigação sobre o impacto da satisfação no trabalho no burnout em profissionais de enfermagem verificaram que o número de filhos, o tempo de experiência e trabalhar em mais de um local não mostraram significância estatística em relação ao burnout. Tarcan e colaboradores (2017) ao analisarem a relação entre burnout, satisfação no trabalho e fatores sociodemográficos em profissionais de saúde do setor de emergência, verificaram que o fator idade não obteve efeito significativo sobre a satisfação no trabalho.

No entanto, resultados análogos foram encontrados por diversos pesquisadores. Queirós et al (2013) encontraram que os enfermeiros que tinham mais de um emprego, apresentavam níveis maiores de exaustão emocional e que, enfermeiros com maior tempo de experiência profissional, experimentavam níveis mais altos de realização profissional. Os autores atribuem o aumento da Realização Profissional à maior confiança conquistada no decorrer do tempo para o desempenho de suas atribuições e ao melhor manejo no gerenciamento de problemas devido à experiência. Outro estudo sobre burnout e satisfação no trabalho com profissionais da emergência concluiu que a idade interfere no nível de exaustão emocional e na despersonalização (Gokcen et al., 2013). Vieira, Santos e Mesquita (2015) em pesquisa com técnicos de enfermagem, encontraram relação positiva entre idade e satisfação com o trabalho, tendo o tempo de trabalho na instituição apresentado correlação negativa com a satisfação relacionada à 
participação no serviço. Outra investigação encontrou associação positiva entre renda e satisfação no trabalho (Tarcan et al., 2017).

De acordo com os resultados obtidos é possível afirmar que a hipótese de associação positiva entre Satisfação no Trabalho e Clima Organizacional como fatores de proteção da Síndrome de Burnout foi constatada neste estudo.

Os trabalhadores que atribuíram escores maiores à Satisfação Global no Trabalho, também indicaram maiores pontuações para o Clima Organizacional Geral, demonstrando a correlação forte existente entre os dois construtos. $\mathrm{Na}$ análise da associação entre os fatores das duas escalas foi verificada associação significativa e positiva de todos os fatores do Clima Organizacional com Satisfação com as Relações Hierárquicas e Satisfação Intrínseca no Trabalho. A Satisfação com Ambiente Físico no trabalho também foi correlacionada positivamente com Liderança, Relação com a Comunidade, Segurança no Trabalho, Estratégia e Remuneração.

A correlação negativa entre Satisfação Global no Trabalho e Exaustão Emocional encontra-se em consonância com outros estudos realizados em diversos cenários, como no Brasil, interior de São Paulo (Guirardello, 2017; Gasparino, 2014) e região metropolitana de Porto Alegre (Rosa, Carlotto, 2005), em Portugal (Queirós et al, 2013), na Grécia (Ntantana et. al., 2017), na Espanha (Portero de la Cruz, Vaquero Aballán, 2015) e na Turquia (Tarcan et al., 2017).

$\mathrm{Na}$ análise individual da associação dos fatores dos construtos, quanto menor a satisfação com as Relações Hierárquicas, com o Ambiente Físico de Trabalho e com o Trabalho Intrínseco, maior é o desenvolvimento da Exaustão Emocional. Estes dados corroboram parcialmente com Sá, Martins-Silva e Funchal (2014) que em pesquisa com trabalhadores de enfermagem de um hospital público da região Sudeste do Brasil identificaram, por meio de análise de regressão linear, que Satisfação com Ambiente Físico de Trabalho e Satisfação Intrínseca no Trabalho exerce influência negativa na Exaustão Emocional, enquanto a Satisfação com as Relações Hierárquicas não demonstrou influência sobre a Exaustão Emocional. Todavia, em outro estudo os resultados apontaram que a satisfação com 
o relacionamento com a chefia está associada à Exaustão Emocional, reforçando os resultados da presente pesquisa (Silva, Carlotto, 2008).

$\mathrm{Na}$ amostra em estudo, à medida que diminui a Satisfação com as Relações Hierárquicas, aumenta-se a possibilidade de Despersonalização.

Desta forma, o estilo de supervisão e a forma com que os trabalhadores percebem as relações com a chefia, influenciam no desencadeamento da Síndrome de burnout, trazendo consequências para a saúde psíquica do trabalhador e para os indivíduos que por ele são assistidos.

Em relação à associação positiva entre Satisfação Global no Trabalho e Despersonalização, similarmente, outros estudos também apresentaram correlações estatisticamente significativas e negativas (Guirardello, 2017; Rosa, Carlotto, 2005). Acredita-se que a insatisfação no trabalho leve ao trabalhador a distanciar-se dos receptores do seu trabalho como uma forma de enfrentamento do descontentamento (Rosa, Carlotto, 2005).

Entre os trabalhadores de enfermagem que participaram deste estudo, a Realização Profissional não apresentou relação significante com nenhuma das dimensões da Satisfação no Trabalho ou do Clima Organizacional, resultado análogo ao encontrado por outros pesquisadores (Sá, Martins-Silva , Funchal, 2014).

Apesar do interesse crescente da investigação do Clima Organizacional, principalmente por psicólogos organizacionais, ainda há poucos estudos com trabalhadores de enfermagem sobre a relação do Clima Organizacional e o Burnout. $\mathrm{Na}$ presente pesquisa, os trabalhadores de enfermagem que apresentam melhor percepção do Clima Organizacional, são os com menores índices de Exaustão Emocional, dados estes semelhantes aos encontrados em estudo com 565 trabalhadores de um hospital do interior de São Paulo (Santos, Sousa, Rueda, 2015).

Investigação realizada por Rodrigues (2016) avaliou a relação entre estresse ocupacional e clima organizacional entre 319 trabalhadores de enfermagem hospitalares da região nordeste do Brasil e encontrou que os profissionais que 
atribuíram menores escores ao clima organizacional foram os que apresentaram sintomatologia de estresse ocupacional.

Ao analisar individualmente as associações entre as dimensões do Burnout e os fatores do Clima Organizacional, os trabalhadores de enfermagem que percebem o Relacionamento e Espírito de Equipe, a Relação com a Comunidade, a Segurança no Trabalho e a Estratégia organizacional com melhores índices, possuem menos Exaustão emocional, assim como os que os que perceberam a Relação com a Comunidade como positiva, apresentam menor Despersonalização.

No estudo realizado por Tomás (2011) com 91 enfermeiros de uma instituição psiquiátrica, a percepção do Clima Organizacional apresentou relação parcial com as três dimensões do burnout.

Recentemente, um estudo de revisão concluiu que as características desencadeadoras do burnout para os trabalhadores de enfermagem "têm se revelado por questões de baixo clima organizacional nas ações que compõem o rol de trabalho do enfermeiro" (Sanchez, Oliveira, 2016,p.66).

Contudo, é possível inferir que a percepção do clima organizacional favorável torna os trabalhadores de enfermagem menos suscetíveis à exaustão emocional, e consequentemente menos expostos ao burnout.

Constatada a associação entre Clima Organizacional, Satisfação no Trabalho e Síndrome de Burnout, é imprescindível intervir nessa realidade, visto que estudos anteriores demonstram que o burnout é influenciado pela organização do processo de trabalho, produzindo consequências na saúde do trabalhador, na segurança do paciente e no sucesso organizacional, por estar associado à intenção de abandonar a profissão (Warshawsky, Havens, 2014; Zhang et al., 2014), menores níveis de satisfação do paciente (Kutney-Lee et al., 2009), baixa qualidade da assistência de enfermagem (Zhang et al., 2014; Poghosyan et al., 2010) e altos índices de absenteísmo (França et al., 2012) e presenteísmo (Hyeda, Handar, 2011).

Assim, ao apontar correlação positiva forte entre Satisfação no Trabalho e Clima Organizacional, correlação negativa moderada entre Exaustão Emocional e Clima Organizacional, correlação negativa moderada entre Exaustão Emocional e 
Satisfação no Trabalho e, correlação negativa moderada entre Despersonalização e Satisfação no Trabalho, o presente estudo apresenta um retrato aprofundado do contexto de trabalho e saúde dos trabalhadores de enfermagem do litoral de São Paulo, evidenciando a importância do fortalecimento da gestão.

O fortalecimento da gestão, como Estratégia para Promoção do Clima Organizacional favorável e da Satisfação no Trabalho, é reforçado ao analisar as propostas sugeridas pelos próprios trabalhadores investigados, com destaque para investimento em ferramentas como Políticas de Recursos Humanos (63,09\%) e de Saúde do Trabalhador (16,04\%), Instrumentalização para Gestão Participativa $(12,71 \%)$ e Planejamento $(4,39 \%)$.

As sugestões apontaram ainda necessidade de investimento prioritário nas Políticas de Recursos Humanos, incluindo elementos como Remuneração e Benefícios, Gestão de Conflitos/Comunicação, Treinamento e Desenvolvimento, e Reconhecimento Profissional, mostrando que a forma com que se dá gestão do capital humano, influencia na satisfação no trabalho e no clima organizacional.

Nas Políticas de Saúde do Trabalhador, destacam-se as Condições de Trabalho, incluindo melhora da estrutura física e aquisição de equipamentos e materiais/insumos de qualidade, redução da jornada de trabalho e divisão equitativa de tarefas e responsabilidades. Quanto a Instrumentalização para Gestão Participativa, a Gestão Compartilhada também é apontada como uma ferramenta para promoção do Clima Organizacional e da Satisfação no Trabalho.

Assim, o esquema a seguir, apresenta as principais estratégias propostas pelos trabalhadores de enfermagem do litoral norte de São Paulo para a promoção do Clima Organizacional favorável e da Satisfação no Trabalho. 
Figura 5 - Estratégias para promoção do Clima Organizacional favorável e da Satisfação no Trabalho.

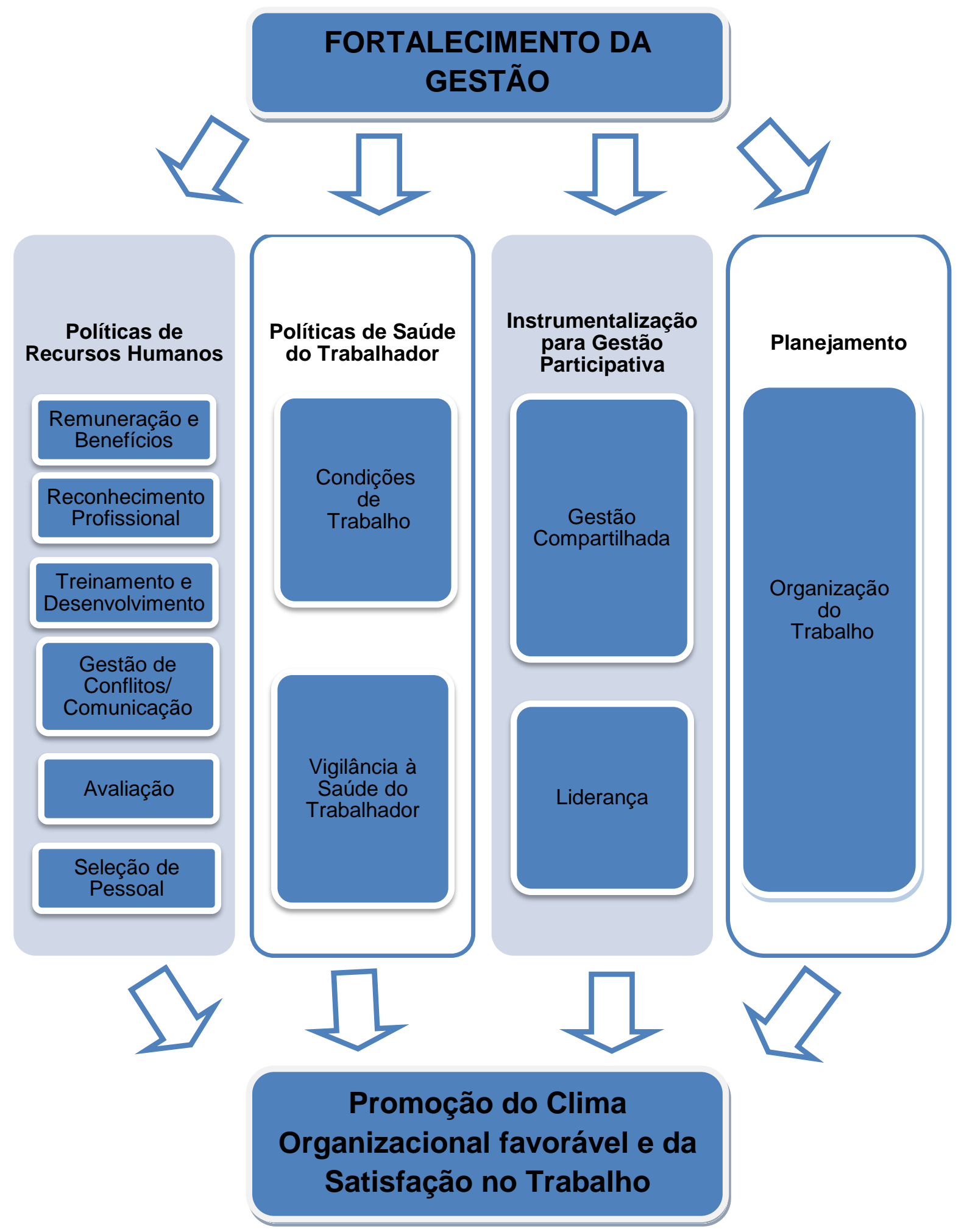

Na literatura é escasso estudos de intervenção que abordam a promoção da satisfação no trabalho e do clima organizacional como protetores contra o 
burnout. Os estudos de intervenção no burnout estão focados principalmente em estratégias individuais (Nowrouzi et al., 2015), como treinamento de intervenção psicossocial (Ewers et al., 2002) e intervenções psicoeducativas, incluindo discussão de fatores de risco específicos para enfermagem, prática com técnicas de relaxamento, meditação, ioga e exploração de padrões de enfrentamento (Alexander et al.,2015; Goodman, Schorling, 2012; Kravits et al.,2010).

Gil-Monte (2005) afirma que os programas de intervenção para prevenção do burnout devem abranger tanto o nível individual como o organizacional. Em concordância, estudo de revisão sobre aspectos mediadores e desencadeadores de burnout em enfermeiros, verificou que "na prevenção e tratamento da síndrome a abordagem deve ser compreendida como um problema coletivo e organizacional e não somente visto e tratado como um problema individual", sendo necessário investir em educação permanente, oferecer suporte social e incentivar a participação nos processos de decisão (Sanches, Oliveira, 2016,p.61).

Duas revisões de estudos de intervenção no burnout, publicadas entre 1995 e 2007 e, entre 2000 e janeiro de 2012, identificaram que a combinação de programas de intervenção que contemplam ações no nível organizacional e individual resulta em efeitos benéficos maiores e mais duradouros sobre o burnout, do que intervenções centradas apenas no indivíduo (Westermann et al., 2014; Awa, Plaumann, Walter, 2010).

A literatura internacional aponta que intervenções organizacionais têm mostrado efeitos positivos nos trabalhadores de enfermagem. No Irã, estudo quase experimental com 70 enfermeiros hospitalares mostrou que a implementação de um treinamento de habilidades de comunicação interpessoal aumentou significativamente o escore médio de satisfação no trabalho no grupo experimental, apontando a necessidade da utilização de tal ferramenta (Dehaghani, Akhormeh, Mehrabi, 2012). Na Austrália, pesquisa com 484 enfermeiros de dois hospitais avaliou o impacto de uma intervenção organizacional na redução do estresse ocupacional por meio de estratégias como o desenvolvimento e a implementação de uma ferramenta para avaliar as cargas de trabalho, o aumento do número de pessoal de enfermagem, aumento do acesso à supervisão clínica, maior acesso ao desenvolvimento profissional, incluindo cursos de pós-graduação e de curta 
duração, entre outros, e obtiveram uma redução significativa no sofrimento psicológico e exaustão emocional e uma melhora importante da satisfação no trabalho (Rickard et al.,2012).

Contudo, no âmbito organizacional, foco do presente estudo, é possível inferir que os programas de intervenção para prevenção do burnout devam ser baseados no diagnóstico situacional realizado pelos trabalhadores sobre o clima organizacional e satisfação no trabalho, focando as intervenções nos nós críticos identificados e nas sugestões dos trabalhadores, envolvendo a gestão, com objetivo de assegurar o compromisso coletivo na busca de êxito nas ações. 
7 Canclusãa 


\section{CONCLUSÃO}

A motivação para esta tese surgiu das evidências científicas apontadas na literatura sobre o impacto da Síndrome de Burnout tanto na qualidade de vida dos trabalhadores de enfermagem como na qualidade do trabalho executado, com repercussões na segurança do paciente e no sucesso organizacional. Assim, este estudo objetivou investigar a correlação do clima organizacional e da satisfação no trabalho com o burnout, buscando estratégias para mudança no panorama atual.

O estudo foi desenvolvido nas quatro cidades do litoral norte de São Paulo, em 4 Instituições hospitalares, 1 Unidade de Pronto Atendimento (UPA), 1 Unidade do Serviço de Atendimento Móvel de Urgência (SAMU) e em 51 estabelecimentos que realizam a atenção básica à saúde (Unidades Básicas de Saúde, Unidades de Saúde da Família, Ambulatórios de Especialidades, Centro de Apoio Psicossocial e Setores Técnico Administrativo/ Apoio (Diretorias, Almoxarifado, Vigilância Epidemiológica)).

Dos 949 convidados a participarem do estudo, obteve-se a participação de 534 trabalhadores de enfermagem, adultos jovens (idade média de 37,69 anos), sendo a maioria $(90,45 \%)$ do sexo feminino; mais da metade $(62,92 \%)$ declarou estado conjugal estável e a maioria $(92,5 \%)$ referiu contribuir financeiramente com o sustento da família. A renda pessoal mensal média declarada foi de $R \$ 2.136,72$ $(\mathrm{dp}=1.283,00)$ e tempo médio de formação profissional de 10,29 anos. Quanto ao cargo, identificou-se $72,28 \%$ de auxiliares/técnicos de enfermagem, seguido de $21,35 \%$ de enfermeiros assistenciais; $52,24 \%$ afirmaram atuar na atenção hospitalar e $42,51 \%$ na atenção básica à saúde.

Considerando a média dos escores, o Clima Organizacional $(\bar{x}=3,32)$ foi avaliado como regular e os trabalhadores de enfermagem apresentam níveis médios de Satisfação no Trabalho $(\bar{x}=3,4)$. Os nós críticos do Clima Organizacional foram os fatores Remuneração $(\bar{x}=2,16)$ e Estratégia $(\bar{x}=2,86)$ que apresentaram os menores 
escores médios. Verificou-se que o menor índice de satisfação foi atribuído à Satisfação com Ambiente Físico de Trabalho $(\bar{x}=3,27)$.

Quanto à Síndrome de Burnout, observaram-se níveis moderados de Exaustão Emocional $(\bar{x}=1,67)$, baixos de Despersonalização $(\bar{x}=0,86)$ e elevados de Realização Profissional $(\bar{x}=2,94)$, indicando a importância de intervir no cenário com a finalidade de minimizar a Exaustão Emocional, diminuindo as chances do adoecimento psíquico desses trabalhadores.

Avaliar o Clima Organizacional, a Satisfação no Trabalho e correlacionar com a Síndrome de Burnout, permitiu a partir da análise individual de cada dimensão reconhecer os fatores de risco que tornam os trabalhadores de enfermagem mais vulneráveis ao desenvolvimento dessa síndrome. Os achados indicam que o Clima Organizacional possui uma forte correlação positiva com a Satisfação no Trabalho $(r=0,673)$ e que tanto o Clima Organizacional $(r=-0,408)$, quanto a Satisfação no Trabalho $(r=-0,457)$ impactam na Exaustão Emocional, por apresentar correlação negativa moderada, mostrando-se como fatores de proteção. A Satisfação no Trabalho também impacta na Despersonalização $(r=-0,319)$, visto que quanto maior a Satisfação no Trabalho, menor a Despersonalização.

As variáveis sociodemográficas e ocupacionais sexo, estado conjugal, possuir filhos, nível de escolaridade, realização de atividade física/lazer, possuir dependentes que presta cuidados, local de trabalho, cargo e regime de trabalho apresentaram resultados estatisticamente significativos na associação com pelo menos um dos fatores dos construtos. No entanto, não há evidência estatística para dizer que idade, número de filhos, renda pessoal e familiar, tempo de formação profissional, tempo de atuação no local de trabalho e número de horas trabalhadas por semana e número de vínculos empregatícios estão correlacionados com Clima Organizacional, Satisfação no Trabalho e Síndrome de Burnout.

As Estratégias para Promoção do Clima Organizacional favorável e da Satisfação no Trabalho estão relacionadas com o fortalecimento da gestão por meio do investimento nas ferramentas gerenciais, incluindo Políticas de Recursos Humanos, Políticas de Saúde do Trabalhador, Instrumentalização para Gestão Participativa e Planejamento. 
A partir desses resultados, pode-se supor que a identificação da percepção do Clima Organizacional e do nível de Satisfação no Trabalho, e a análise dos nós críticos e posterior implementação de políticas resolutivas de mudança do contexto organizacional, podem diminuir a ocorrência da Síndrome de Burnout em trabalhadores de enfermagem, portanto a melhoria do Clima, acarreta não somente a Satisfação como funciona como elemento protetor do adoecimento por Burnout.

Destarte que este é um dos primeiros estudos realizados no Brasil, com trabalhadores de enfermagem tanto da atenção básica como hospitalar, que investiga o impacto do Clima Organizacional e da Satisfação no Trabalho na Síndrome de Burnout. Os resultados auxiliam na gestão dos trabalhadores de enfermagem e na redução do Burnout entre esses, e consequentemente, vai repercutir na saúde do trabalhador e na qualidade dos serviços prestados.

No entanto, faz-se necessário implementar as propostas realizadas pelos trabalhadores de enfermagem para promoção do Clima Organizacional favorável e da Satisfação no Trabalho no cenário investigado e avaliar os efeitos sobre o Burnout, comparando os resultados.

As limitações deste estudo são derivadas do método transversal, que somente permite a análise das associações entre as variáveis, sem poder estabelecer relações de causalidade, além dos resultados obtidos ser referente a uma região geográfica específica. Outro fator relevante diz respeito à participação no estudo apenas de trabalhadores de enfermagem que estavam atuando, excluindo os que estavam de licença médica pela dificuldade de acesso aos mesmos. Além disso, durante a coleta de dados foi possível observar que setores onde os trabalhadores de enfermagem estavam constantemente ocupados com as atividades laborais, como nas clínicas médicas e cirúrgicas dos hospitais, foram os com menor participação no estudo, pela falta de tempo para preencher os instrumentos. Tais fatos podem ter interferido nos resultados deste estudo. 
Referencias 


\section{REFERÊNCIAS}

Aiken LH, Clarke SP, Sloane DM, Lake ET, Cheney T. Effects of hospital care environment on patient mortality and nurse outcomes. J Nurs Adm. 2008;38(5):2239.

Aiken LH, Clarke SP, Sloane DM, Sochalski JA, Busse R, Clarke H, Giovannetti P, Hunt J, Rafferty AM, Shamian J. Nurses' Reports On Hospital Care In Five Countries. Health Affairs (Millwood). 2001; 20(3):43-53.

Aiken LH, Clarke SP, Sloane DM. Hospital staffing, organization, and quality of care: cross-national findings. International Journal for Quality in Health Care. 2002;14(1):513.

Aiken LH, Sloane DM, Bruyneel L, Heede KV, Sermeus W. Nurses' reports of working conditions and hospital quality of care in 12 countries in Europe. Int J Nurs Stud. 2013; 50(2):143-53.

Aiken LH, Sloane DM, Clarke S, Poghosyan L, Cho E, You L, Finlayson M, KanaiPak M, Aungsuroch Y. Importance of work environments on hospital outcomes in nine countries. International Journal for Quality in Health Care. 2011; 23 (4): 357364.

Albar MJ, Romero ME, González MD, Carbayo E, García A, Gutiérrez I, et al. Apoyo social, características sociodemográficas y burnout en enfermeras y auxiliares de hospital. Enferm Clin. 2004;14(5):281-5.

Alexander GK, Rollins K, Walker D, Wong L, Pennings J. Yoga for Self-Care and Burnout Prevention Among Nurses. Workplace Health \& Safety. 2015; 63(10):46270.

Almeida MCS, Baptista PCP. Gestão de pessoas e comportamento organizacional em instituições de saúde. São Paulo: Senac São Paulo, 2016.

Ajzen I, Fishbein M. Understanding Attitudes and Predicting Social Behaviour. Englewood Cliffs, New Jersey: Prentice Hall; 1980.

Andolhe R. Segurança do paciente em Unidades de Terapia Intensiva: estresse, coping e burnout da equipe de enfermagem e ocorrência de eventos adversos e incidentes [tese]. São Paulo: Escola de Enfermagem, Universidade de São Paulo; 2013.

Antunes R. O caracol e a sua concha: ensaios sobre a morfologia do trabalho. São Paulo: Boitempo, 2005. 
Awa WL, Plaumann M, Walter U. Burnout prevention: A review of intervention programs. Patient Education and Counseling. 2010;78: 184-90.

Bahrami MA, Barati O, Ghoroghchian M, Montazer-alfaraj R, Ranjbar Ezzatabadi M. Role of Organizational Climate in Organizational Commitment: The Case of Teaching Hospitals. Osong Public Health and Research Perspectives. 2016;7(2):96-100.

Baptista PCP. Incapacidade no trabalho: a compreensão de gerentes de enfermagem [tese livre docência]. São Paulo: Escola de Enfermagem, Universidade de São Paulo; 2014.

Baptista PCP, Pustiglione M, Almeida MCS, Felli VEA, Garzin ACA, Melleiro MM. Nursing workers health and patient safety: the look of nurse managers.Rev Esc Enferm USP · 2015; 49(Esp2):120-126.

Barros Neto JM, Anjos EA, Silva SEV, Tavares CM, Pedro ANC. A formação do profissional enfermeiro e o mercado de trabalho na atualidade. Revista Eletrônica Gestão \& Saúde. 2014;5(1):176-93.

Beck CLC, Prestes FC, Tavares JP, Silva RM, Prochonow AG, Nonnenmacher CQ. Identidade profissional dos enfermeiros de serviços de saúde municipal. Cogitare Enferm. 2009;14(1):114-9.

Benevides-Pereira AMT. Burnout: $O$ processo de adoecer pelo trabalho. In: Benevides-Pereira AMT (org). Burnout: Quando o trabalho ameaça o bem-estar do trabalhador. São Paulo: Casa do Psicólogo, 2002.

Benevides-Pereira AMT. O Estado da arte do burnout no Brasil. Revista Eletrônica InterAção Psy. 2003;1(1):4-11.

Bezerra FN, Silva TM, Ramos VP. Estresse ocupacional dos enfermeiros de urgência e emergência: Revisão Integrativa da Literatura. Acta Paul Enferm. 2012;25 (NEsp2):151-6.

Borges E, Ferreira TR. Stresse, Ansiedade e Depressão em Enfermeiros [Resumo]. Psicologia, Saúde \& Doenças. 2014;15 (Supl): 190 - 1.

Borges EMN. Qualidade de vida relacionada com o trabalho: stresse e violência psicológica nos enfermeiros [tese]. Porto, Portugal: Instituto de Ciências da Saúde, Universidade Católica Portuguesa; 2012.

Brasil. Decreto n. 3.048, de 06 de maio de 1999. Aprova o Regulamento da Previdência Social, e dá outras providências. Diário Oficial da União, Brasília, 07 e 12 mai 1999 [citado em 11 dez 2016]. Disponível em: http://www010.dataprev.gov.br/sislex/paginas/23/1999/3048.htm. 
Brasil. Decreto n. 6.957, de 09 de setembro de 2009. Altera o Regulamento da Previdência Social, aprovado pelo Decreto no 3.048, de 6 de maio de 1999, no tocante à aplicação, acompanhamento e avaliação do Fator Acidentário de Prevenção - FAP. Diário Oficial da União, Brasília, 10 set 2009 [citado em 11 dez 2016]. $\quad$ Disponível em: http://www010.dataprev.gov.br/sislex/paginas/23/2009/6957.htm.

Brasil. Lei n. 8213 de 24 de julho de 1991. Dispõe sobre os planos de benefícios da previdência social e dá outras providências. Diário Oficial da União, Brasília (DF), 1991 jul. 24; Sec.1: 14809.

Brasil. Ministério da Educação. Instituto Nacional de Estudos e Pesquisas Educacionais Anísio Teixeira. Censo da Educação Superior 2016: principais resultados. INEP: MEC. [citado 2017 set. 26]. Disponível em:http://download.inep.gov.br/educacao_superior/censo_superior/documentos/201 6/censo_superior_tabelas.pdf.

Brasil. Ministério da Saúde. Conselho Nacional da Saúde. Resolução no 466, de 12 de dezembro de 2012. Resolve aprovar as seguintes diretrizes e normas regulamentadoras de pesquisas envolvendo seres humanos. Diário Oficial da União, Brasília, 13 jun. 2013. [citado 2017 set. 26]. Disponível em: http://conselho.saude.gov.br/resolucoes/2012/Reso466.pdf.

Brasil. Ministério do Planejamento, Orçamento e Gestão. IBGE-cidade@ [base de dados na internet]. Brasília: Ministério do Planejamento, Orçamento e Gestão. [citado em 12 fev. 2014]. Disponível em: http://cidades.ibge.gov.br/xtras/home.php.

Brasil ${ }^{\mathrm{a}}$. Câmara dos Deputados. Projeto de Lei n.2.295, de 11 de janeiro de 2000. Dispõe sobre a jornada de trabalho dos Enfermeiros, Técnicos e Auxiliares de Enfermagem. [citado 2017 set. 27]. Disponível em: http://www.camara.gov.br/proposicoesWeb/fichadetramitacao?idProposicao=17915.

Brasil $^{a}$. Ministério da Saúde. Portal da Saúde. Departamento de Atenção BásicaDAB. Histórico de Cobertura da Saúde da Família. Brasilia: Ministério da Saúde [citado em 05 jan 2016]. Disponível em: http://dab.saude.gov.br/portaldab/historico_cobertura_sf.php.

Brasil $^{\mathrm{b}}$. Câmara dos Deputados. Projeto de Lei n.459, de 25 de fevereiro de 2015. Altera a Lei no 7.498, de 1986. Dispõe sobre o Piso Salarial do Enfermeiro, do Técnico de Enfermagem, do Auxiliar de Enfermagem e da Parteira. [citado 2017 set. 28]. http://www.camara.gov.br/proposicoesWeb/fichadetramitacao?idProposicao=949035.

Brasil $^{b}$. Ministério da Saúde. Secretaria de Atenção à Saúde: Cadastro Nacional de Estabelecimentos de Saúde- CNES-Net. Brasília: Ministério da Saúde. [citado em 05 dez. 2016]. Disponível em: http://cnes2.datasus.gov.br. 
Brunetto Y, Shriberg A, Farr-Wharton R, Shacklock K, Newman S, Dienger J. The importance of supervisor-nurse relationships, teamwork, wellbeing, affective commitment and retention of North American nurses. J Nurs Manag. 2013;21(6):82737.

Carlotto M, Câmara S. Propriedades psicométricas do Questionário de Satisfação no Trabalho (S20/23). Psico-USF. 2008; 13(2):203-10.

Carlotto MS, Queirós C, Dias S, Kaiseler M. Hardiness and Burnout Syndrome: A cross-cultural study among Portuguese and Brazilian nurses. Temas em Psicologia. $2014 ; 22(1): 121-32$.

Carvalho LSF, Matos RCS, Souza NVDO, Ferreira REDS. Motivos de afastamento por licença de saúde dos trabalhadores de enfermagem. Cienc Cuid Saude. 2010; $9(1): 60-6$.

Cimmioti JP, Aiken LH. Burnout. In: Harada MJCS (org). Gestão em Enfermagem: ferramenta para a prática segura. São Paulo: Yendis, 2011.

COFEN. Conselho Federal de Enfermagem (Brasil) [Internet]. Enfermagem em números. Brasília: COFEN. [citado 2017 ago. 5]. Disponível em: http://www.cofen.gov.br/enfermagem-em-numeros.

COREN-SP. Conselho Regional de enfermagem de São Paulo. Número de profissionais [homepage na internet]. São Paulo, Brasil; 2015 [citado em 02 dez. 2016]. Disponível em: http://portal.coren-sp.gov.br/node/40194.

Cruvinel E. Relação entre Clima Organizacional e Atividades de Prevenção ao Uso de Risco de Álcool, Tabaco e Outras Drogas entre Profissionais da Atenção Primária à Saúde [dissertação]. Juiz de Fora: Faculdade de Medicina, Universidade Federal de Juiz de Fora; 2011.

Dehaghani AR, Akhormeh KA, Mehrabi T. Assessing the effectiveness of interpersonal communication skills training on job satisfaction among nurses in $\mathrm{Al}-$ Zahra Hospital of Isfahan, Iran. Iran J Nurs Midwifery Res. 2012; 17(4): 290-5.

Dejours C. A banalização da injustiça social. Rio de Janeiro: FGV; 2000.

Elias MA, Navarro VL. A relação entre o trabalho, a saúde e as condições de vida: negatividade e positividade no trabalho das profissionais de enfermagem de um hospital escola. Rev Latino-am Enfermagem.2006; 14(4):517-25.

Ewers P, Bradshaw T, McGovern J, Ewers B. Does training in psychosocial interventions reduce burnout rates in forensic nurses? Journal of Advanced Nursing. 2002; 37: 470-6. 
Fernandez Larraguibel B, Paravic Klinjn T. Nível de satisfação laboral em enfermeras de hospitales publicos y privados de la provincia de Concepcion, Chile. Cienc. Enferm. 2003;9(2):57-66.

FIOCRUZ/COFEN. Pesquisa Perfil da Enfermagem no Brasil- 2013. Fundação Oswaldo Cruz/ Conselho Federal de enfermagem [citado em 02 dez 2015]. Disponível em: rs.gov.br/docs/Perfil_Enfermagem_DadosRS.pdf http://www.portalcoren-

Fonseca FAC, Pecorari MJR, Cury THC, Miotto LB, Magagnini MAM. A Saúde de quem cuida da Saúde: Trabalho de Enfermagem e Qualidade de Vida. Cuidarte enf.2008; 2(1):30-8.

França FM, Ferrari R, Ferrari DC, Alves ED. Burnout and labor aspects in the nursing teams at two medium-sized hospitals. Rev Latino Am Enfermagem. 2012;20(5):96170.

Freire MTC, Rodrigues MP, Silva GSN, Melo RHV, Vilar RLA. A voz dos trabalhadores sobre a gestão participativa em um hospital de grande porte. Revista Brasileira de Inovação Tecnológica em Saúde. 2014; 4(4): 34-53.

Freudenberger HJ. Staff burn-out. Journal of Social Issues. 1974;30(1): 159-65.

Galindo RH, Feliciano KVO, Lima RAS, Souza Al. Síndrome de burnout entre enfermeiros de um hospital geral da cidade do Recife. Rev Esc Enferm USP. 2012; $46(2): 420-7$.

Gallo CMC. Desvelando fatores que afetam a satisfação e a insatisfação no trabalho de uma equipe de enfermagem [dissertação]. Rio Grande: Universidade Federal do Rio Grande; 2005.

Gasparino RC. Síndrome de burnout na equipe de enfermagem de um hospital universitário. Cogitare Enferm. 2014; 19(2):232-8.

Gershon RR, Karkashian CD, Groch JW, Murphy LR, Escamilla-Cejudo A, Flanagan PA, et al. Hospital safety climate and its relationship with safe work practices and workplace exposure incidents. Am J Infect Control. 2000;28(3):211- 21.

Geuens N, Van Bogaert P, Franck E. Vulnerability to burnout within the nursing workforce: The role of personality and interpersonal behaviour. J Clin Nurs. 2017;112.

Gil-Monte PR. El síndrome de Quemarse por el Trabajo: una enfermedad laboral en la sociedad del bienestar.Madrid: Ediciones Pirámide; 2005.

Gil-Monte PR. Influencia del género sobre el proceso de desarrollo del síndrome de quemarse por el trabajo (Burnout) en profesionales de enfermería. Psicol Est. 
2002;7(1):3-10.

Gokcen C, Zengin S, Oktay MM, Alpak G, Al B, Yildirim C. Burnout, job satisfaction and depression in the healthcare personnel whowork in the emergency department. Anatolian Journal of Psychiatry. 2013;14:122-8.

González IB, Melo NAP, Limón MLS. El clima organizacional y su relación con la calidad de los servicios públicos de salud: diseño de un modelo teórico.Estudios Gerenciales. 2015;31:8-19.

Goodman MJ, Schorling JB. A mindfulness course decreases burnout and improves well-being among healthcare providers. Int J Psychiatry Med. 2012; 43(2): 119-28.

Grazziano ES, Bianchi ERF. Impacto do stress ocupacional e burnout para enfermeiros. Enfermería Global. 2010; 18:1-20.

Guirardello EB. Impact of critical care environment on burnout, perceived quality of care and safety attitude of the nursing team. Rev. Latino-Am. Enfermagem. 2017;25:e2884.

Guo J, Chen J, Fu J, Ge X, Chen M, Liu Y. Structural empowerment, job stress and burnout of nurses in China. Applied Nursing Research. 2016; 31: 41-45.

Hanzelman RS, Pasos JP. Nursing images and representations concerning stress and influence on work activity. Rev Esc Enferm USP. 2010;44(3):687-93.

Henne D, Locke EA. Job dissatisfaction: what are the consequences? International Journal of Psychology.1985;20: 221-40.

Hernandez JAE, Melo FM. O clima organizacional e a satisfação dos funcionários de um Centro Médico Integrado. Revista Psicologia: Organização e Trabalho. 2003;3 (1):11-26.

Hoe VCW, Kelsall HL, Urquhart DM, Sim MR. Risk factors for musculoskeletal symptoms of the neck or shoulder alone or neck and shoulder among hospital nurses. Occup Environ Med. 2012;69(3):198-204.

Hofstede G,Neuijen B, Ohayv DD, Sanders G. Measuring organizational cultures: a qualitative and quantitative study across twenty cases. Administrative Science Quarterly. 1990;35 (2):286-316.

Hyeda A, Handar Z. Avaliação da produtividade na síndrome de Burnout. Rev Bras Med Trab. 2011;9(2):78-84.

Kessler Al, Krug SBF. Do prazer ao sofrimento no trabalho da enfermagem: o discurso dos trabalhadores. Rev Gaúcha Enferm. 2012; 33(1):49-55. 
Kravits K, McAllister-Black R, Grant M, Kirk C. Self-care strategies for nurses: A psycho-educational intervention for stress reduction and the prevention of burnout. Applied Nursing Research. 2010; 23 (3):130-8.

Kuo $\mathrm{H}-\mathrm{T}$, Lin $\mathrm{K}-\mathrm{C}$, Li I-C. The mediating effects of job satisfaction on turnover intention for long-term care nurses in Taiwan. Journal of Nursing Management. 2014;22:225-33.

Kutney-Lee A, McHugh MD, Sloane DM, Cimiotti JP, Fynn L, et al. Nursing: A key to patient satisfaction. Health Affair. 2009;28:w667-9.

Kvist $\mathrm{T}$, Voutilainen A, Mantynen $\mathrm{R}$, Vehvilainen-Julkunen $\mathrm{K}$. The relationship between patients perceptions of care quality and three factors: nursing staff job satisfaction, organizational characteristics and patient age. BMC Health Serv Res. $2014 ; 14: 466$.

Lautert. L. O desgaste do Profissional enfermeiro. Tese. Salamanca. Universid Pontificia Salamanca, 1995.

Lee S-J, Lee JH, Gillen M, Krause N. Job stress and work-related musculoskeletal symptoms among intensive care unit nurses: a comparison between job demandcontrol and effort-reward imbalance models. Am. J. Ind. Med. 2014; 57: 214-221.

Leite PC, Silva A, Merighi MAB. A mulher trabalhadora de enfermagem e os distúrbios osteomusculares relacionados ao trabalho. Rev Esc Enferm USP. 2007; 41(2):287-91.

Leiter MP, Harvie P, Frizzle C. The correspondence of patient satisfaction and nurse burnout. Soc Sci Med. 1998;47(10):1611-7.

Leiter MP, Maslach C. The impacto of interpersonal environment on Burnout and organizational commitment. Journal of Organizational Behavior. 1988; 9:297-308.

Locke EA. Job satisfaction. In: Gruneberg M, Wall T (edit). Social psychology and organizational behaviour. New York: John Wiley \& Sons; 1984. p.93-117.

Locke EA. The nature and causes of job satisfaction. In: Dunnette MD (ed). Handbook of industrial and organizational psychology. Chicago: Rand McNally College Publishing Company, 1976. p1297-349.

Locke EA. What is job satisfaction? Organizational Behavior and Human Performance. 1969; 4 (4):309-36.

Machado MH, Wermelinger M, Vieira M, Oliveira E, Lemos W, Aguiar Filho W et al. Aspectos gerais da formação da enfermagem: o perfil da formação dos enfermeiros, técnicos e auxiliares. Enferm. Foco. 2016; 6 (2/4): 15-34. 
Machado $^{\mathrm{a}} \mathrm{MH}$, Aguiar Filho W, Lacerda WF, Oliveira E, Lemos W, Wermelinger M et. al. Características gerais da enfermagem: o perfil sócio demográfico. Enferm Foco. 2015; 6 (1/4): 11-17.

Machado $^{\mathrm{b}} \mathrm{MH}$, Oliveira E, Lemos W, Lacerda WF, Aguiar Filho W, Wermelinger M et al. Mercado de trabalho da enfermagem: aspectos gerais. Enferm Foco. 2015; 6 (1/4): 43-78.

Martinato MCNB, Severo DF, Marchand EAA, Siqueira HCH. Absenteísmo na enfermagem: uma revisão integrativa. Rev Gaúcha Enferm. 2010;31(1):160-6.

Martinez MC, Paraguay AIBB. Satisfação e saúde no trabalho- aspectos conceituais e metodológicos.Cad.Psicol. Soc.Trabalho.2003; 6:59-78.

Martins MCF, Oliveira B, Silva CF, Pereira KC, Sousa MR. Construção e validação de uma escala de medida de clima organizacional. Revista Psicologia Organizações e Trabalho. 2004; 4(1): 37-60.

Martins MCF. Clima organizacional. In: Siqueira MMM(Org.), Medidas do comportamento organizacional: Ferramentas de diagnóstico e de gestão. Porto Alegre: Artmed, 2008.p.29-40.

Maslach C, Schaufel WB, Leiter MP. Job burnout. Annual Review of Psychology. 2001; 52: 397-422.

Maslach C, Jackson SE, Leiter MP. Maslach Burnout inventory. 3rd ed. Palo Alto (CA): Consulting Psychologists; 1996.

Maslach C, Jackson SE. The measurement of experienced burnout. J Occup Behav. $1981 ; 2(2): 99-113$

Maslach C, Jackson SE. The role of sex and family variables in Burnout. Sex Roles. 1985;12:837-51.

Maslach C, Leiter MP. The truth about burnout: how organization cause, personal stress and what to do about it. San Francisco: Jossey-Bass, 1997.

Maslach C, Schaufelli WB. Historical and conceptual development of burnout. In: Schaufelli WB, Maslach C, Marek T. (Orgs.). Professional burnout: Recent developments in theory and research. Washington, DC: Taylor \& Francis, 1993.p.118.

Maslach C. Entendendo o Burnout. In: Rossi AM, Perrewé PL, Sauter SL. Stress e Qualidade de Vida no trabalho: perspectivas atuais da saúde ocupacional. São Paulo: Atlas. 2005. p.41-55. 
Massano DT. O clima organizacional em unidades hospitalares públicas e privadas: A perspectiva dos Técnicos de Radiologia [dissertação]. Lisboa: Universidade de Évora; 2012.

McHugh MD, Kutney-Lee A, Cimiotti JP, Sloane DM, Aiken LH. Nurses Widespread job dissatisfaction, burnout and frustation with health benefits signal problems for patient care. Health Aff. 2011; 30(2):202-10.

Medeiros-Costa ME, Maciel RH, Rêgo DP, Lima LL, Silva MEP, Freitas JG. Occupational Burnout Syndrome in the nursing context: an integrative literature review. Rev Esc Enferm USP. 2017;51:e03235.

Meliá JL, Peiró JM. La medida de la satisfacción laboral en contextos organizacionales: el cuestionario de satisfacción S20/23. Psicologemas.1989; 3:5974.

Melo MB, Barbosa MA, Souza PR. Job satisfaction of nursing staff: integrative review Rev. Latino- Am. Enfermagem. 2011;19(4):1047-55.

Mendes R, Dias EC. Saúde dos trabalhadores. In: Rouquayrol MZ, Almeida Filho N. Epidemiologia e saúde. 5 ed. Rio de Janeiro: Medsi, 1999; 43 -456.

Meneghini F, Paz AA, Lautert L. Fatores ocupacionais associados aos componentes da síndrome de burnout em trabalhadores de enfermagem. Texto Contexto Enferm. $2011 ; 20(2): 225-33$.

Menezes IG, Gomes ACP. Clima organizacional: uma revisão histórica do construto. Psicologia em Revista. 2010;16(1):158-79.

Menezes IG, Sampaio LR, Gomes ACP, Teixeira FS, Santos PS. Escala de clima organizacional para organizações de saúde: desenvolvimento e estrutura fatorial. Estudos de Psicologia.2009; 26(3):305-16.

Menezes L. Qualidade de vida no trabalho e sua influência no clima organizacional: estudo de caso em uma empresa do setor de alimentos [dissertação]. Fortaleza; Fundação Edson Queiroz, Universidade de Fortaleza-Unifor; 2008.

Molina JM, Avalos F, Giménez I. Burnout en enfermería de atención hospitalaria. Enferm Clin. 2005;15(5):275-82.

Morais MP, Martins JT, Robazzi MLCC, Cardelli AAM. Insatisfação no trabalho de enfermeiros de um hospital universitário. Cogitare enferm. 2014;19( 2 ): 316-22.

Moran ET, Volkwein JF. The cultural approach to the formation of organizational climate. Human Relations. 1992; 45 (1):19-47. 
Muñoz-Seco E, Coll-Benejam JM, Torrent-Quetglas M, Linares-Pou L. Influencia del clima laboral en la satisfacción de los profesionales sanitarios. Aten Primaria. 2006;37(4):209-14.

Murofuse NT, Abranches SS, Napoleão AA. Reflexões sobre estresse e Burnout e a relação com a enfermagem. Rev Latino-am Enfermagem. 2005; 13(2):255-61.

Neto JMB, Anjos EA, Silva SEV, Tavares CM, Pedro ANC. A formação do profissional enfermeiro e o mercado de trabalho na atualidade. Revista Eletrônica Gestão \& Saúde. 2014; 5(1):176-93.

Nogueira MLF. Afastamentos por adoecimento de trabalhadores de enfermagem em oncologia [dissertação]. Rio de Janeiro: Universidade Federal do Estado do Rio de Janeiro-UNIRIO; 2007.

Nowrouzi B, Lightfoot N, Larivière M, Carter L, Rukholm E, Schinke R et al. Occupational Stress Management and Burnout Interventions in Nursing and Their Implications for Healthy Work Environments: A Literature Review. Workplace Health \& Safety. 2015; 63 (7): 308-15.

Ntantana A, Matamis D, Savvidou S, Giannakou M, Gouva M, Nakos G et al. Burnout and job satisfaction of intensive care personnel and the relationship with personality and religious traits: An observational, multicenter, cross-sectional study. Intensive and Critical Care Nursing. 2017; 41:11-17.

Nunes CM, Tronchin DMR, Melleiro MM, Kurcgant P. Satisfação e insatisfação no trabalho na percepção de enfermeiros de um hospital universitário. Rev. Eletr. Enf. 2010;12(2):252-7.

O'Brien-Pallas L, Griffin P, Shamian J, Buchan J, Duffield C, Hughes F, et al. The impact of nurse turnover on patient, nurse and system outcomes: a pilot study and focus for a multicenter international study. Policy Polit Nurs Pract. 2006;7:169-79.

Oviedo CS, Calderón JL. La satisfacción laboral y su papel en la evaluación de La calidad de la atención médica. Salud Pública (México). 1994;36 (1):22-29.

Paschoalin HC, Griep RH, Lisboa MTL. A produção científica sobre o presenteísmo na enfermagem e suas repercussões no cuidado. Rev APS. 2012; 15(3): 306-11.

Peduzzi M. Trabalho em equipe de saúde da perspectiva de gerentes de serviços de saúde: possibilidades da prática comunicativa orientada pelas necessidades de saúde dos usuários e da população [tese livre-docência]. São Paulo: Escola de Enfermagem, Universidade de São Paulo; 2007.

Pereira AM, Queirós C, Gonçalves SP, Carlotto M, Borges E. Burnout e interação trabalho-família em enfermeiros:estudo exploratório com o survey work--home interaction nijmegen (swing). Revista Port. Enferm Saúde Mental. 2014;11:24-30. 
Pereira LL, Galvão CR, Chanes M . Administração hospitalar: instrumento para gestão profissional. São Paulo: Centro Universitário São Camilo: Edições Loyola, 2005.

Perry L, Lamont S, Brunero S, Gallagher R, Duffield C. The mental health of nurses in acute teaching hospital settings: a cross-sectional survey. BMC Nursing. 2015; $14: 15$.

Poghosyan L, Clarke S, Finlayson M, Aiken LH. Nurse burnout and quality of care: Cross-national investigation in six countries. Research in Nursing \& Health. 2010;33:288-98.

Portero de la Cruz S, Vaquero Abellan M. Professional burnout, stress and job satisfaction of nursing staff at a university hospital. Rev. Latino-Am. Enfermagem. $2015 ; 23(3): 543-552$.

Porto JS, Marziale MHP. Motivos e consequências da baixa adesão às precauções padrão pela equipe de enfermagem. Rev Gaúcha Enferm. 2016 ;37(2):e57395.

Prefeitura Municipal de Caraguatatuba. Caragua Governo Municipal. Portal da Transparência [homepage na internet]. Caraguatatuba, São Paulo, Brasil; 2013 [citado em 12 fev. 2015]. Disponível em: http://www.caraguatatuba.sp.gov.br/?pg=dadosgerais.

Prestes FC, Beck CLC, Silva RM, Tavares JP, Camponogara S, Burg G. Prazersofrimento dos trabalhadores de enfermagem de um serviço de hemodiálise. Rev Gaúcha Enferm. $2010 ; 31(4): 738-45$.

Queirós C, Carlotto MS, Kaiseler M, Dias S, Pereira AM. Predictors of burnout among nurses: An interactionist approach. Psicothema. 2013; 25(3): 330-5.

Ribeiro OP. Marketing e comunicação: inovação conceptual na gestão de serviços de saúde. Millenium- Journal of Education, Tecnologies, and Health. 2004;30(9): 223-33.

Rickard G, Lenthall S, Dollard M, Opie T, Knight S, Dunn S et al. Organisational intervention to reduce occupational stress and turnover in hospital nurses in the Northern Territory, Australia. Collegian. 2012; 19(4): 211-21.

Ríos-Risquez MI, García-Izquierdo M. Patient satisfaction, stress and burnout in nursing personnel in emergency departments: A cross-sectional study. International Journal of Nursing Studies. 2016; 59: 60-7.

Rocha SSL, Felli VEA. Qualidade de vida no trabalho docente em enfermagem. Rev Lat Am Enfermagem. 2004;12(1):28-35. 
Rodrigues CCFM. Ambiente hospitalar: clima organizacional x estresse na equipe de enfermagem [tese]. Natal: Centro de Ciências da Saúde, Universidade Federal do Rio Grande do Norte; 2016.

Rosa C, Carlotto MS. Síndrome de Burnout e satisfação no trabalho em profissionais de uma instituição hospitalar Rev Bras Psicologia Hospitalar.2005; 8(2):1-15.

Rueda FJM, Santos AAA. Escala de Avaliação do Clima Organizacional (CLIMOR). São Paulo: Vetor Editora Psicopedagógica Ltda, 2011.

Sá AMS, Martins-Silva PO, Funchal B. Burnout: o impacto da satisfação no trabalho em profissionais de enfermagem. Psicologia \& Sociedade. 2014; 26(3), 664-74.

Sanchez FFS, Oliveira R. Aspectos mediadores e desencadeadores da síndrome de burnout nos enfermeiros. Cuid Enferm. 2016; 10(1): 61-7.

Sancinetti TR, Gaidzinski RR, Felli VEA, Fugulin FMT, Baptista PCP, Ciampone MHT et al. Absenteísmo - doença na equipe de enfermagem: relação com a taxa de ocupação. Rev Esc Enferm USP. 2009; 43(Esp 2):1277-83.

Santos LJ, Paranhos MS. Family Health Teams workers in Rio de Janeiro: leadership aspects in a study on organizational climate. Ciência \& Saúde Coletiva. 2017; 22(3):759-769.

Santos SMP, Sousa V, Rueda FJM. Burnout e sua relação com o clima organizacional em funcionários de um hospital. ABCS Health Sci. 2015; 40(1):11-5.

Sartoreto IS. Satisfação e Insatisfação no Trabalho dos Enfermeiros: revisão integrativa da literatura [dissertação]. São Paulo: Escola de Enfermagem, Universidade de São Paulo; 2013.

Schaufeli WB, Buunk BP. Burnout: An overview of 25 years of research in theorizing. In M.J. Schabracq, J.A.M. Winnubst \& C.L. Cooper (Eds.), The handbook of work and health psychology (p. 383-425). Chichester: John Wiley \& Sons, 2003.

Schneider B, Ehrhart MG, Macey WH. Organizational Climate and Culture. Annu Rev Psychol. 2013.64:361-88.

Schneider B, Salvaggio AN, Subirats M. Climate strength: a new direction for climate research. Journal of Applied Psychology. 2002; 87 (2): 220-9.

Silva DSD, Tavares NVS, Alexandre ARG, Freitas DA, Brêda MZ, Albuquerque MCS et al. Depression and risk of suicide in professional Nursing: integrative review. Rev Esc Enferm USP. 2015; 49(6):1027-36. 
Silva FJ. Capacidade para o trabalho e presenteísmo em trabalhadores de enfermagem: propostas de intervenções gerenciais [tese]. São Paulo: Escola de Enfermagem, Universidade de São Paulo, 2016.

Silva TD, Carlotto MS. Síndrome de Burnout em trabalhadores da enfermagem de um hospital geral. Rev. SBPH, 2008;11(1):113-30.

Siqueira VTA, Kurcgant P. Satisfacao no trabalho: indicador de qualidade no gerenciamento de recursos humanos em enfermagem. Rev Esc Enferm USP.2012; 46(1):151-7.

Smith GS, Huang YH, Ho M, Chen PY. The relationship between safety climate and injury rates across industries: the need to adjust for injury hazards. Accid Anal Prev. 2006;38(3):556-62.

Souza NR, Bernardes EH, Fonseca RP, Gonçalves HO, Lopes TFS. Identificando o nível de estresse e suas causas nos profissionais de enfermagem em um hospital geral de Passos (MG). Ciência et Praxis. 2009;2(4):27-32.

Spence Laschinger HK, Leiter MP. The impact of nurse work environments on patient safety outcomes. Journal of Nursing Administration.2006; 36 (5):259-67.

Tarcan M, Hikmet N, Schooley B, Top M, Tarcan GY. An analysis of the relationship between burnout, socio-demographic and workplace factors and job satisfaction among emergency department health professionals. Appl Nurs Res. 2017;34:40-7.

Teixeira E, Fernandes JD, Andrade AC, Silva KL, Rocha M MO, Lima RJO. Panorama dos cursos de Graduação em Enfermagem no Brasil na década das Diretrizes Curriculares Nacionais. Rev. bras. enferm. 2013; 66(esp):102-10.

Tinubu BMS, Mbada CE, Oyeyemi AD, Fabunmi AA. Work-related musculosketal disorders among nurses in Ibadan, South-west Nigeria: a cross-sectional survey. BMC Musculosketal Disordes. 2010;11(12):1-8.

Tomás CC. Riscos Psicossociais e Clima Organizacional: Burnout nos Enfermeiros que cuidam de Toxicodependentes. Rev. Toxicodependencias. 2011; 17 (2):23-30.

Trigo TR, Teng CT, Hallar JEC. Síndrome de burnout ou estafa profissional e os transtornos psiquiátricos. Rev Psiq Clin. 2007;34(5):223-33.

Umann J, Guido LA, Grazziano ES. Presenteísmo em enfermeiros hospitalares. Rev. Latino-Am. Enfermagem [Internet]. 2012 [acesso em: 05 març 2014];20(1):[08 telas]. Disponível em: http://www.scielo.br/pdf/rlae/v20n1/pt_21.pdf.

Vahey DC, Aiken LH, Sloane DM, Clarke SP, Vargas D. Nurse burnout and patient satisfaction. Med Care. 2004;42:57-66. 
Varella, TC. Mercado de Trabalho do Enfermeiro no Brasil: configuração do Emprego e Tendências no Campo de Trabalho [tese]. Rio de Janeiro: Instituto de Medicina social, Universidade do Estado do Rio de Janeiro; 2006.

Vieira GLC, Santos EO, Mesquita TQO. Satisfação no trabalho entre técnicos de enfermagem em hospitais psiquiátricos de Minas Gerais - Brasil. REME rev. min. enferm. 2015; 19(1): 167-73.

Warshawsky NE, Havens DS. Nurse manager job satisfaction and intent to leave. Nurs Econ. 2014; 32(1): 32-9.

Westermann C, Kozak A, Harling M, Nienhaus A. Burnout intervention studies for inpatient elderly care nursing staff: Systematic literature review. International Journal of Nursing Studies. 2014; 51:63-71.

WHO. World Health Organization, Global Health Workforce Alliance. A universal truth: No health without a workforce. WHO: Genebra; 2013.

Zavareze TE, Cruz RM. Measure instruments of safety climate at work: A literature review. Arq Bras Psicol. 2010;62(2):65-77.

Zhang LF, You LM, Liu K, Zheng J, Fang JB, Lu MM et al. The association of Chinese hospital work environment with nurse burnout, job satisfaction, and intention to leave. Nurs Outlook. 2014;62(2):128-37. 
Apêndices 


\section{APÊNDICE A- Caracterização dos Sujeitos da Pesquisa}

Data

1. Idade:

2. Sexo: [ ] feminino [ ] masculino

3. Estado Civil:

[ ]solteiro [ ]casado ou amasiado [ ]divorciado, separado ou viúvo

4. Idade dos Filhos:

5. Números de pessoas com quem reside:

[ ]nenhum [ ]um [ ]dois [ ]três [ ]quatro [ ]cinco [ ]

6. Renda Pessoal (em R $\$$ ):

7. Renda Familiar (em $R \$$ ):

8. Participação na Vida Econômica da Família:

[ ] É responsável pelo sustento da família

[ ] Não contribui

[ ] Contribui parcialmente

[ ] Contribui esporadicamente

9. Escolaridade:

10. Formação Profissional (se tiver mais de uma formação profissional, informar quais)

11. Tempo de formação na área em que atua: anos e meses.

12. Local de Trabalho (Hospital (Especificar o setor), Unidade Básica de Saúde, Outros):

13. Cargo:

14. Tempo de atuação profissional neste local de trabalho:

anos e meses.

15. Tipo de contrato de trabalho (CLT, Estatutário, contrato por tempo determinado, outro):

16. Número médio de horas semanais trabalhadas

17. Turnos de Trabalho: [ ]fixo [ ]rotativo Horário:

18. Possui outro vínculo empregatício além deste?

[ ]Sim.Quantos e quais [ ]Não

19. Considera o seu trabalho estressante? [ ]Sim [ ]Não

20. Realiza alguma atividade física/lazer?

[ ]Sim. Qual(is)? [ ]Não.

21. Você possui alguma pessoa dependente na sua casa na qual você presta cuidados? [ ]Sim [ ]Não 


\section{APÊNDICE B- Escala de Clima Organizacional para Organizações de Saúde (ECOOS)}

Essa é uma Pesquisa de Clima Organizacional. Por gentileza, responda às perguntas abaixo de acordo com a seguinte escala:

Clima

Refere-se as influências do ambiente de trabalho sobre o comportamento humano, estando relacionado às percepções e interpretações comuns das dimensões das atividades, do ambiente e das políticas que caracterizam a organização.

Por favor assinale com um $X$ a sua opinião acerca das afirmações abaixo, tendo em conta a escala: "Concordo totalmente, Concordo, Indeciso(a), Discordo e Discordo totalmente".

\section{Fator 1- LIDERANÇA}

Diz respeito à competência de influenciar as atitudes, crenças, comportamentos e sentimentos de outras pessoas, assim como, o grau de feedback e orientação fornecido ao subordinado sobre seu desempenho e assuntos de seu interesse.

\begin{tabular}{|c|c|c|c|c|c|}
\hline & $\begin{array}{l}\text { Concordo } \\
\text { Totalmente }\end{array}$ & $\begin{array}{l}\text { Concordo } \\
\text { levemente }\end{array}$ & $\begin{array}{l}\text { Não } \\
\text { concordo } \\
\text { nem discordo }\end{array}$ & $\begin{array}{l}\text { Discordo } \\
\text { levemente }\end{array}$ & $\begin{array}{l}\text { Discordo } \\
\text { Totalmente }\end{array}$ \\
\hline $\begin{array}{l}\text { 1. Meu chefe trata de forma justa e adequada } \\
\text { seus servidores }\end{array}$ & & & & & \\
\hline 2. Confio nas decisões tomadas pelo meu chefe & & & & & \\
\hline $\begin{array}{ll}\text { 3. } & \text { Meu chefe tem capacidade de motivar a } \\
\text { equipe }\end{array}$ & & & & & \\
\hline $\begin{array}{ll}4 . & \text { Meu chefe aceita sugestões para melhoria do } \\
\text { trabalho }\end{array}$ & & & & & \\
\hline $\begin{array}{l}\text { 5. Meu chefe encara os erros não propositais } \\
\text { como oportunidade de crescimento }\end{array}$ & & & & & \\
\hline $\begin{array}{l}\text { 6. Meu chefe conhece bem os aspectos } \\
\text { técnicos do seu trabalho }\end{array}$ & & & & & \\
\hline $\begin{array}{ll}\text { 7. } & \text { Meu chefe me mantém informado sobre as } \\
\text { metas da unidade }\end{array}$ & & & & & \\
\hline $\begin{array}{l}\text { 8. } \begin{array}{l}\text { Meu chefe me mantém informado sobre as } \\
\text { metas da unidade }\end{array} \\
\end{array}$ & & & & & \\
\hline $\begin{array}{ll}\text { 9. } & \begin{array}{l}\text { Meu chefe tem uma visão clara sobre para } \\
\text { onde estamos indo e como fazer para chegar } \\
\text { lá }\end{array} \\
\end{array}$ & & & & & \\
\hline $\begin{array}{l}\text { 10. Participo das decisões que atingem o meu } \\
\text { trabalho }\end{array}$ & & & & & \\
\hline $\begin{array}{l}\text { 11. A comunicação com meu chefe é fácil e } \\
\text { aberta }\end{array}$ & & & & & \\
\hline $\begin{array}{l}\text { 12. Sou informado sobre a contribuição do meu } \\
\text { trabalho para os resultados da minha } \\
\text { unidade }\end{array}$ & & & & & \\
\hline $\begin{array}{l}\text { 13. Existe igualdade de tratamento entre chefia e } \\
\text { subordinados }\end{array}$ & & & & & \\
\hline $\begin{array}{l}\text { 14. Sou avaliado de acordo com os resultados do } \\
\text { meu trabalho }\end{array}$ & & & & & \\
\hline $\begin{array}{l}\text { 15. Sou informado pelo meu chefe sobre os } \\
\text { assuntos relativos à unidade na qual trabalho }\end{array}$ & & & & & \\
\hline $\begin{array}{l}\text { 16. A chefia envolve as pessoas em decisões } \\
\text { que afetam os diferentes aspectos do } \\
\text { trabalho (ambiente de trabalho, segurança, } \\
\text { remuneração, estratégias etc.) }\end{array}$ & & & & & \\
\hline $\begin{array}{l}\text { 17. Considero que os servidores se sentem livres } \\
\text { para expressar abertamente suas opiniões }\end{array}$ & & & & & \\
\hline \multicolumn{6}{|c|}{$\begin{array}{l}\text { Fator } 2 \text { - DESENVOLVIMENTO PROFISSIONAL } \\
\text { Consiste no conjunto de estratégias organizacionais voltadas para o desenvolvimento das competências dos seus } \\
\text { trabalhadores em áreas e funções específicas. }\end{array}$} \\
\hline $\begin{array}{l}\text { 18. O que tenho aprendido nos treinamentos } \\
\text { oferecidos na unidade melhora minhas } \\
\text { condições de trabalho }\end{array}$ & & & & & \\
\hline $\begin{array}{l}\text { 19. O que tenho aprendido nos treinamentos } \\
\text { oferecidos pela Secretaria melhora minha } \\
\text { produtividade }\end{array}$ & & & & & \\
\hline
\end{tabular}




\begin{tabular}{|c|c|c|c|c|c|}
\hline & $\begin{array}{l}\text { Concordo } \\
\text { Totalmente }\end{array}$ & $\begin{array}{l}\text { Concordo } \\
\text { levemente }\end{array}$ & $\begin{array}{l}\text { Não } \\
\text { concordo } \\
\text { nem discordo }\end{array}$ & $\begin{array}{l}\text { Discordo } \\
\text { levemente }\end{array}$ & $\begin{array}{l}\text { Discordo } \\
\text { Totalmente }\end{array}$ \\
\hline $\begin{array}{l}\text { 20. Os programas de treinamento e } \\
\text { desenvolvimento têm procurado desenvolver } \\
\text { o potencial técnico dos servidores }\end{array}$ & & & & & \\
\hline $\begin{array}{l}\text { 21. Os programas de treinamento e } \\
\text { desenvolvimento têm procurado desenvolver } \\
\text { o potencial humano dos servidores }\end{array}$ & & & & & \\
\hline $\begin{array}{l}\text { 22. Os últimos treinamentos que recebi pela } \\
\text { instituição atenderam às minhas expectativas }\end{array}$ & & & & & \\
\hline $\begin{array}{l}\text { 23. Os conhecimentos que adquiro em } \\
\text { programas de treinamento e } \\
\text { desenvolvimento são aplicados no meu } \\
\text { trabalho }\end{array}$ & & & & & \\
\hline $\begin{array}{l}\text { 24. Participo do levantamento de minhas } \\
\text { necessidades de treinamento e } \\
\text { desenvolvimento }\end{array}$ & & & & & \\
\hline $\begin{array}{l}\text { 25. Os programas de treinamento e } \\
\text { desenvolvimento preparam realmente o } \\
\text { profissional para desempenhar as atividades } \\
\text { do cargo que ocupa }\end{array}$ & & & & & \\
\hline $\begin{array}{l}\text { 26. Os treinamentos preparam o indivíduo para } \\
\text { adaptar-se à sua unidade }\end{array}$ & & & & & \\
\hline $\begin{array}{l}\text { 27. Na minha unidade existe plano de } \\
\text { treinamento e desenvolvimento para todos os } \\
\text { servidores }\end{array}$ & & & & & \\
\hline $\begin{array}{l}\text { 28. Realizo o meu plano de treinamento e } \\
\text { desenvolvimento de forma negociada }\end{array}$ & & & & & \\
\hline
\end{tabular}

29. O trabalho da minha equipe é bem distribuído entre os servidores

30. Sou acolhido como um importante membro da minha equipe de trabalho

31. Na minha equipe existe cooperação para o alcance das metas

32. Eu confio nas pessoas da equipe em que trabalho

33. No meu grupo de trabalho, as pessoas possuem um bom relacionamento

34. Sou respeitado pela minha equipe de trabalho

35. Na minha equipe tenho condições de ensinar o que sei aos meus colegas e aprender com eles

36. No meu grupo de trabalho existe liberdade de falar, criticar, sugerir e trocar ideias

37. Existe um forte sentido de trabalho em equipe dentro da minha unidade

\section{Fator 4- RELAÇÃO COM A COMUNIDADE}

É caracterizada pela qualidade do relacionamento estabelecido entre os servidores e a comunidade a qual utiliza os serviços.

38. O hospital tem uma boa imagem dentro da comunidade

39. A UBS/ESF tem uma boa imagem dentro da comunidade

40. Na instituição existe um sistema eficaz para resolver as reclamações da comunidade

41. A instituição comunica adequadamente à comunidade os seus projetos, investimentos e realizações

42. Existe um bom relacionamento entre os servidores e as pessoas que fazem uso dos serviços oferecidos pela instituição

\begin{tabular}{|l|l|l|l|l|l|}
\hline & & & & \\
\hline & & & & & \\
\hline & & & & & \\
\hline & & & & & \\
\hline
\end{tabular}




\begin{tabular}{|l|l|l|l|l|l|}
\hline & $\begin{array}{l}\text { Concordo } \\
\text { Totalmente }\end{array}$ & $\begin{array}{l}\text { Concordo } \\
\text { levemente }\end{array}$ & $\begin{array}{l}\text { Não } \\
\text { concordo } \\
\text { nem discordo }\end{array}$ & $\begin{array}{l}\text { Discordo } \\
\text { levemente }\end{array}$ & $\begin{array}{l}\text { Discordo } \\
\text { Totalmente }\end{array}$ \\
\hline $\begin{array}{l}\text { 43. Acredito que a comunidade esteja satisfeita } \\
\text { com a qualidade dos serviços oferecidos pela } \\
\text { instituição }\end{array}$ & & & & & \\
\hline $\begin{array}{l}\text { 44. Os servidores desta instituição atendem à } \\
\text { comunidade adequadamente }\end{array}$ & & & & & \\
\hline $\begin{array}{l}\text { 45. Os usuários dos serviços de saúde } \\
\text { reconhecem o trabalho dos servidores desta } \\
\text { instituição }\end{array}$ & & & & & \\
\hline Fator 5- SEGURANÇA NO TRABALHO & & & & \\
\hline
\end{tabular}

\section{Fator 5- SEGURANÇA NO TRABALHO}

Diz respeito às condições do ambiente de trabalho e equipamentos que asseguram a integridade física dos trabalhadores.

46. As condições do meu local de trabalho são satisfatórias

47. Na minha unidade existem recursos de trabalho adequados para a realização do meu trabalho

48. A instituição se preocupa com a minha segurança no trabalho

49. Existem medidas de segurança adequadas para a execução do meu trabalho

50. Os equipamentos de trabalho são adequados para garantir a segurança do servidor

51. A instituição se preocupa com meu bemestar no trabalho

52. Tenho as condições necessárias para a realização do meu trabalho

\section{Fator 6- ESTRATÉGIA}

Corresponde aos componentes do planejamento estratégico que caracterizam a atuação de uma determinada organização.

53. Conheço o planejamento estratégico da instituição

54. Conheço os indicadores e as metas traçadas pela instituição

55. Conheço a estrutura organizacional da instituição

56. Participei, de alguma forma, do processo de elaboração do planejamento estratégico

57. Consigo aplicar nas minhas atividades diárias as diretrizes do planejamento estratégico

58. A instituição tem realizado as mudanças necessárias visando ao seu crescimento e desenvolvimento

59. Na instituição, os servidores são estimulados a participar das contínuas mudanças

\section{Fator 7- REMUNERAÇÃO}

Aborda a compatibilidade entre a remuneração recebida na empresa e as exigências e responsabilidades inerentes ao trabalho realizado nesta, além da consistência entre a remuneração na organização e a remuneração praticada no mercado para trabalhos similares.

60. Minha remuneração é compatível com as responsabilidades do trabalho que realizo

61. Minha remuneração está de acordo com a praticada pelo mercado

62. De um modo geral, estou satisfeito com a minha remuneração

63. Considero as políticas de remuneração da instituição justas e motivadoras

64. A minha remuneração é melhor do que a da maior parte dos meus colegas de trabalho

\begin{tabular}{|l|l|l|l|l|l|}
\hline & & & & & \\
\hline & & & & & \\
\hline & & & & & \\
\hline
\end{tabular}

Referência: Menezes IG, Sampaio LR, Gomes ACP, Teixeira FS, Santos PS. Escala de clima organizacional para organizações de saúde: desenvolvimento e estrutura fatorial. Estudos de Psicologia.2009; 26(3):305-16. 


\section{APÊNDICE C - Questionário de Satisfação no Trabalho- S20/S23}

O presente questionário avalia em que medida se considera satisfeito com o seu trabalho.

Por favor responda a cada um dos itens de acordo com a escala de respostas que se segue, mas apenas relacionado à atividade que exerce.

\begin{tabular}{|c|c|c|c|c|c|}
\hline & $\begin{array}{l}\text { Totalmente } \\
\text { Insatisfeito }\end{array}$ & $\begin{array}{c}\text { Parcialmente } \\
\text { insatisfeito }\end{array}$ & Indiferente & $\begin{array}{c}\text { Parcialmente } \\
\text { satisfeito }\end{array}$ & $\begin{array}{c}\text { Totalmente } \\
\text { satisfeito }\end{array}$ \\
\hline $\begin{array}{l}1.0 \text { trabalho enquanto propiciador de } \\
\text { realização. }\end{array}$ & & & & & \\
\hline $\begin{array}{l}\text { 2.As oportunidades que o seu trabalho } \\
\text { oferece de fazer coisas nas quais se destaca. }\end{array}$ & & & & & \\
\hline $\begin{array}{l}\text { 3. As oportunidades que o seu trabalho } \\
\text { oferece de fazer coisas de que gosta }\end{array}$ & & & & & \\
\hline 5. Os objetivos e metas que deve alcançar. & & & & & \\
\hline $\begin{array}{l}\text { 6. Higiene e salubridade do local de } \\
\text { trabalho. }\end{array}$ & & & & & \\
\hline $\begin{array}{l}\text { 7. Ambiente e espaço físico do local de } \\
\text { trabalho }\end{array}$ & & & & & \\
\hline 8. A iluminação do local de trabalho. & & & & & \\
\hline 9. A ventilação do local de trabalho. & & & & & \\
\hline 10. A climatização do local de trabalho. & & & & & \\
\hline $\begin{array}{l}\text { 13. As relações pessoais com as instâncias } \\
\text { de poder (seus superiores / chefes). }\end{array}$ & & & & & \\
\hline $\begin{array}{l}\text { 14. A supervisão sobre o trabalho que } \\
\text { realiza. }\end{array}$ & & & & & \\
\hline 15. Periodicidade da Supervisão. & & & & & \\
\hline $\begin{array}{l}\text { 16. Forma com que avaliam e julgam o seu } \\
\text { trabalho. }\end{array}$ & & & & & \\
\hline $\begin{array}{l}\text { 17. Igualdade de tratamento e sentido de } \\
\text { justiça. }\end{array}$ & & & & & \\
\hline $\begin{array}{l}18 . \quad \text { O apoio recebido das instâncias } \\
\text { superiores. }\end{array}$ & & & & & \\
\hline $\begin{array}{l}\text { 19.A possibilidade de decidir } \text { com } \\
\text { autonomia sobre o próprio trabalho }\end{array}$ & & & & & \\
\hline $\begin{array}{lcc}\text { 20.Participação nas decisões } & \text { na } \\
\text { organização ou na sua área de trabalho. } & \end{array}$ & & & & & \\
\hline $\begin{array}{l}\text { 21. Possibilidade que lhe dão em participar } \\
\text { nas decisões da área de trabalho }\end{array}$ & & & & & \\
\hline $\begin{array}{l}22 \text { Modo como são cumpridos as normas } \\
\text { legais e os acordos coletivos }\end{array}$ & & & & & \\
\hline $\begin{array}{lllll}23 . \quad \text { Forma } & \text { como } & \text { se } & \text { processam } & \text { as } \\
\text { negociações } & \text { sobre } & \text { a } & \text { contratação } & \text { de } \\
\text { benefícios } & & & & \end{array}$ & & & & & \\
\hline
\end{tabular}

Referência: Carlotto M, Câmara S. Propriedades psicométricas do Questionário de Satisfação no Trabalho (S20/23). Psico-USF. 2008; 13 (2): 203-210. 


\section{APÊNDICE D- Maslach Burnout Inventory (MBI)}

As afirmações seguintes referem-se a sentimentos relacionados com a sua atividade profissional, e a forma como encara o seu trabalho e as pessoas com quem trabalha.

\begin{tabular}{|c|c|c|c|c|c|}
\hline & Nunca & $\begin{array}{l}\text { Algumas } \\
\text { vezes por } \\
\text { ano }\end{array}$ & $\begin{array}{l}\text { Algumas } \\
\text { vezes por } \\
\text { mês }\end{array}$ & $\begin{array}{l}\text { Algumas } \\
\text { vezes por } \\
\text { semana }\end{array}$ & Diariamente \\
\hline \multicolumn{6}{|l|}{$\begin{array}{l}\text { 1. Sinto-me emocionalmente decepcionado com } \\
\text { meu trabalho. Com que frequência sente isso? }\end{array}$} \\
\hline \multicolumn{6}{|l|}{$\begin{array}{l}\text { 2. Quando termino minha jornada de trabalho sinto- } \\
\text { me esgotado. Com que frequência sente isso? }\end{array}$} \\
\hline \multicolumn{6}{|l|}{$\begin{array}{l}\text { 3. Quando me levanto pela manhã e enfrento outra } \\
\text { jornada de trabalho, sinto-me fatigado. Com que } \\
\text { frequência sente isso? }\end{array}$} \\
\hline \multicolumn{6}{|l|}{$\begin{array}{l}\text { 4. Sinto que posso entender facilmente como as } \\
\text { pessoas que tenho que atender se sentem a } \\
\text { respeito das coisas. Com que frequência sente isso? }\end{array}$} \\
\hline \multicolumn{6}{|l|}{$\begin{array}{l}\text { 5. Sinto que estou tratando alguns receptores do } \\
\text { meu trabalho como se fossem objetos impessoais. } \\
\text { Com que frequência sente isso? }\end{array}$} \\
\hline \multicolumn{6}{|l|}{$\begin{array}{l}\text { 6. Sinto que trabalhar todo o dia com gente me } \\
\text { cansa. Com que frequência sente isso? }\end{array}$} \\
\hline \multicolumn{6}{|l|}{$\begin{array}{l}\text { 7. Sinto que trato com muita efetividade os } \\
\text { problemas das pessoas que tenho que atender. } \\
\text { Com que frequência sente isso? }\end{array}$} \\
\hline \multicolumn{6}{|l|}{$\begin{array}{l}\text { 8. Sinto que meu trabaho está me desgastando. } \\
\text { Com que frequência sente isso? }\end{array}$} \\
\hline \multicolumn{6}{|l|}{$\begin{array}{l}\text { 9. Sinto que estou influenciando positivamente na } \\
\text { vida das pessoas, através do meu trabalho. Com } \\
\text { que frequência sente isso? }\end{array}$} \\
\hline \multicolumn{6}{|l|}{$\begin{array}{l}\text { 10. Sinto que tornei-me mais duro com as pessoas, } \\
\text { desde que eu começei este trabalho. Com que } \\
\text { frequência sente isso? }\end{array}$} \\
\hline \multicolumn{6}{|l|}{$\begin{array}{l}\text { 11. Preocupo-me com este trabalho que está } \\
\text { endurecendo-me emocionalmente. Com que } \\
\text { frequência sente isso? }\end{array}$} \\
\hline \multicolumn{6}{|l|}{$\begin{array}{l}\text { 12. Sinto-me muito vigoroso em meu trabalho. Com } \\
\text { que frequência sente isso? }\end{array}$} \\
\hline \multicolumn{6}{|l|}{$\begin{array}{l}\text { 13. Sinto-me frustrado por meu trabalho. Com que } \\
\text { frequência sente isso? }\end{array}$} \\
\hline \multicolumn{6}{|l|}{$\begin{array}{l}\text { 14. Sinto que estou trabalhando demais no meu } \\
\text { trabalho. Com que frequência sente isso? }\end{array}$} \\
\hline \multicolumn{6}{|l|}{$\begin{array}{l}\text { 15. Sinto que realmente não me importo o que } \\
\text { ocorre com as pessoas as quais tenho que atender } \\
\text { profissionalmente. Com que frequência sente isso? }\end{array}$} \\
\hline \multicolumn{6}{|l|}{$\begin{array}{l}\text { 16. Sinto que trabalhar em contato direto com as } \\
\text { pessoas me estressa. Com que frequência sente } \\
\text { isso? }\end{array}$} \\
\hline \multicolumn{6}{|l|}{$\begin{array}{l}\text { 17. Sinto que posso criar, com facilidade um clima } \\
\text { agradável com os receptores do meu trabalho. Com } \\
\text { que frequência sente isso? }\end{array}$} \\
\hline \multicolumn{6}{|l|}{$\begin{array}{l}\text { 18. Sinto-me estimulado depois de haver trabalhado } \\
\text { diretamente com quem tenho que atender. Com que } \\
\text { frequência sente isso? }\end{array}$} \\
\hline \multicolumn{6}{|l|}{$\begin{array}{l}\text { 19. Creio que consigo muitas coisas valiosas neste } \\
\text { trabalho. Com que frequência sente isso? }\end{array}$} \\
\hline \multicolumn{6}{|l|}{$\begin{array}{l}\text { 20. Sinto-me como se estivesse no limite de minhas } \\
\text { possibilidades. Com que frequência sente isso? }\end{array}$} \\
\hline \multicolumn{6}{|l|}{$\begin{array}{l}\text { 21. No meu trabalho eu manejo com os problemas } \\
\text { emocionais com muita calma. Com que frequência } \\
\text { sente isso? }\end{array}$} \\
\hline $\begin{array}{l}\text { 22. Parece-me que os receptores do meu trabalho } \\
\text { culpam-me por alguns dos seus problemas. Com } \\
\text { que frequência sente isso? }\end{array}$ & & & & & \\
\hline
\end{tabular}

Referência: Lautert. L. O desgaste do Profissional enfermeiro. Tese. Salamanca. Universid Pontificia Salamanca, 1995. 


\section{APÊNDICE E- Estratégias para Promoção de Clima Organizacional Favorável e Satisfação no Trabalho}

1- Segundo a sua vivência, que estratégias você recomenda para a promoção de um clima organizacional favorável e da satisfação no trabalho? 


\section{ANEXO 1- Parecer do Comitê de Ética e Pesquisa da Escola de Enfermagem da USP}

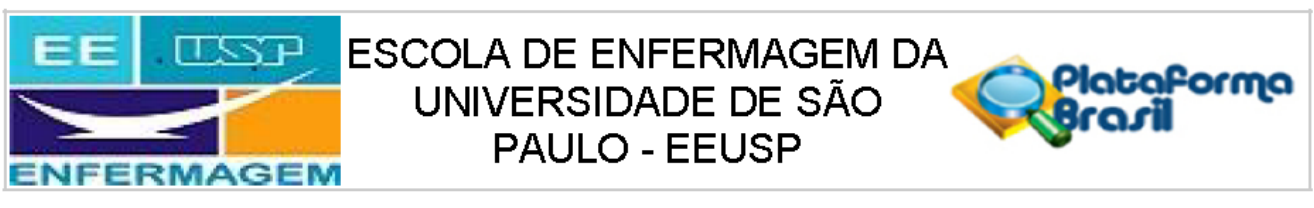

\section{PARECER CONSUBSTANCIADO DO CEP}

\section{DADOS DO PROJETO DE PESQUISA}

Título da Pesquisa: DOS CONTEXTOS DE TRABALHO À SAÚDE DOS TRABALHADORES DE ENFERMAGEM, UM ESTUDO COMPARATIVO ENTRE PORTUGAL, BRASIL E ESPANHA

Pesquisador: Patricia Campos Pavan Baptista

Área Temática:

Versão: 2

CAAE: 37104214.8 .0000 .5392

Instituição Proponente: Escola de Enfermagem da Universidade de São Paulo - EEUSP

Patrocinador Principal: Financiamento Próprio

\section{DADOS DO PARECER}

Número do Parecer: 912.483

Data da Relatoria: $17 / 11 / 2014$

Apresentação do Projeto:

Trata-se de um projeto transversal, do tipo quantitativo. Embora seja multicêntrico, são apresentados apenas objetivos e métodos referentes à etapa a ser conduzida no Brasil. O objetivo é mensurar a síndrome de Burnout, a satisfação com o trabalho, o clima organizacional, o presenteísmo e a resiliência, e a respectiva relação entre estas variáveis, em trabalhadores de enfermagem de instituições hospitalares e de atenção primária da cidade de São Paulo (Hospital Universitário da Universidade de São Paulo) e das cidades de Ubatuba, Caraguatatuba, São Sebastião e Ilhabela, todas no litoral norte do Estado de São Paulo. A amostra prevista é de 500 trabalhadores de enfermagem. A coleta de dados será realizada pelos próprios pesquisadores, por meio dos respectivos instrumentos: Maslach Burnout Inventory, Cuestionario de Satisfacción Laboral, Escala de Clima Organizacional para Organizações de Saúde (ECOOS), Stanford Presenteeism, e Resillience Scale. Os dados quantitativos serão codificados em planilha eletrônica Microsoft Excel e submetidos à análise estatística descritiva e analítica.

Objetivo da Pesquisa:

Caracterizar sociodemograficamente os trabalhadores de enfermagem.

Avaliar e comparar o Burnout, a satisfação no trabalho, o clima organizacional, o presenteísmo e a

Endereço: Av. Dr Enéas de Carvalho Aguiar, 419

Bairro: Cerqueira Cesar

UF: SP Município: SAOPAULO

Telefone: (11)3061-7548 Fax: (11)3061-7548

CEP: $\quad 05.403-000$

Fax: (11)3061-7548 E-mail: edipesq@usp.br 


\section{EE $\begin{gathered}\text { ESCOLA DE ENFERMAGEM DA } \\ \text { UNIVERSIDADE DE SÃO } \\ \text { PAULO - EEUSP }\end{gathered}$
Plotoforma
Prasil}

Continuaçẫo do Parecer: 912.483

resiliência em trabalhadores de enfermagem.

Avaliação dos Riscos e Benefícios:

Os sujeitos de pesquisa não serão expostos a procedimentos invasivos, portanto considera-se risco mínimo. Caso seja identificado algum dado relevante no que se refere ao desconforto, os trabalhadores serão encaminhados ao Serviço de Medicina do trabalho dos hospitais e, no caso das unidades básicas de saúde, serão encaminhados ao CAPS.

Benefícios:

O estudo servirá de subsídios para intervenções à saúde do trabalhador nos diferentes contextos de atenção à saúde.

\section{Comentários e Considerações sobre a Pesquisa:}

A pesquisa toma como objeto tema relevante sobre a saúde dos trabalhadores de enfermagem, contemplando aqueles que atuam tanto em instituição hospitalar quanto na atenção básica. O projeto está bem fundamentado e apresenta coerência entre as partes.

Considerações sobre os Termos de apresentação obrigatória:

TCLE é apresentado e contempla todos as partes adequadamente.

Recomendações:

Conclusões ou Pendências e Lista de Inadequações:

Nenhuma pendência. A pesquisadora responsável adequou a metodologia e o TCLE conforme recomendações deste CEP.

Situação do Parecer:

Aprovado

Necessita Apreciação da CONEP:

Não

Considerações Finais a critério do CEP:

A aprovação do Comitê de Ética em Pesquisa da EEUSP não substitui a autorização da instituição coparticipante para o início da pesquisa.

O CEP EEUSP informa que há necessidade de registro dos relatórios: parcial e final da pesquisa, na Plataforma Brasil.

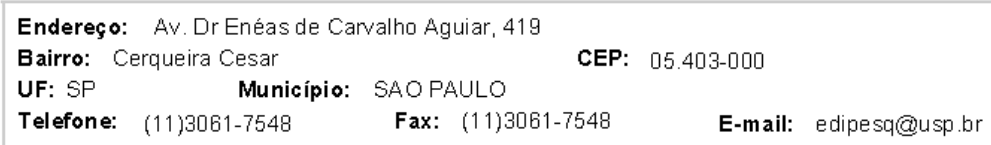




\section{$\equiv \equiv$. USP ESCOLA DE ENFERMAGEM DA UNIVERSIDADE DE SÃO
PAULO - EEUSP \\ Continuaçẫo do Parecer: 912.483}

SAO PAULO, 12 de Dezembro de 2014

Assinado por:

Ruth Natalia Teresa Turrini

(Coordenador) 